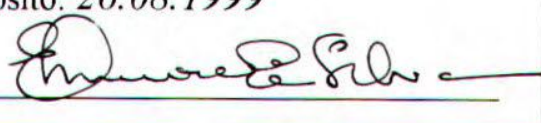

\title{
Utilizando o IPv6 em uma Aplicação de Transmissão Segura de Dados
}

\author{
Daniel Ferreira Nunes de Oliveira
}

Orientador: Prof. Dr. Fredy João Valente

Dissertação apresentada ao Instituto de Ciências Matemáticas e de Computação - ICMC-USP, como parte dos requisitos para obtenção do título de Mestre em Ciências - Área: Ciências de Computação e Matemática Computacional.

São Carlos

Agosto/1999 
para meus, pais Ana e Irapuan, que me mostraram o caminho. 


\section{Agradecimentos}

Muitas pessoas, de uma forma ou de outra, foram essenciais para esse projeto e sinto muito em não poder agradecer a todas elas.

Mas gostaria de agradecer ao meu orientador, Dr. Fredy João Valente, que tornou esse trabalho possível, em teoria e pratica.

À minha namorada, Ana Luísa Figueira Sales, que com carinho e compreensão me incentivou a nunca desistir e soube, nos momentos certos, me apoiar, criticar e contribuir com este trabalho.

Aos meus amigos, Renato da Silva Pereira e Rainer Finocchiaro da S\&V Consultoria e Tecnologia, pela prestativa ajuda na configuração do Servidor Linux IPv6 utilizado neste Projeto.

Ao meu amigo, Sean Michael Wykes, que em muito contribuiu com meu crescimento profissional e com a evolução deste trabalho.

A todos os amigos da S\&V Consultoria e Tecnologia, que entenderam minha ausência e me apoiaram incondicionalmente. Fernando Celso Figueira, Penido Stahlberg Filho, Edna Ruth Tejada, Carlos Alberto Becerra Soto, Alexandre José Tiberti , Daniela Sbizerra, Mário Prado, Júlio César Pires, Alfredo Colenci Neto e Lígia Carla Botelho.

A minha amiga, Andressa Simone Pinatti, pela paciência inesgotável e pelo cuidado com toda a burocracia.

A Elderclei Regis Reami, pela ajuda durante a primeira fase de implementação do SDT.

A Keith Schaab e Richard Draves, da Microsoft Research, pelas valiosas discussōes sobre Winsock2 e programação multi-thread no Windows NT.

A Chad Hower, do time de desenvolvimento Winshoes, pelas valiosas discussões sobre programação com sockets no Windows NT e por me convidar a participar do desenvolvimento de um dos melhores componentes de sockets para Delphi que existem na Internet.

A Elizabeth Silva, Laura Turi e Marília Finazzi de Andrade Marino, da Secretaria da Pós-graduação do ICMC, que com paciência e dedicação me ajudaram e orientaram, inúmeras vezes, desde a matricula.

A meu amigo Laércio Augusto Baldochi Júnior, pelos conselhos, criticas e sugestões desde o inicio deste trabalho.

A meus amigos Luiz Augusto Cassimiro de Araújo e Luciano José Senger, pelas valiosas discussōes sobre TCP/IP no inicio do curso.

À Professora Dra. Renata Pontin Fortes do ICMC, pelos conselhos e orientações, principalmente na primeira fase deste trabalho.

A meus pais, Ana Maria Ferreira Nunes de Oliveira e José Irapuan Nunes de Oliveira e a minha irmã Tatiana Ferreira Nunes de Oliveira, que local ou remotamente nunca deixaram de me apoiar.

Ao CNPq, Conselho Nacional de Desenvolvimento Científico e Tecnologico, pela bolsa de estudos que me foi concedida.

A Universidade de São Paulo, particularmente ao Departamento de Computą̧ão do ICMC e à S\&V Consultoria e Tecnologia, que tornaram esse trabalho factível. 


\section{RESUMO}

O Protocolo Internet (IP), base de toda arquitetura da Internet, está envelhecendo. Projetado numa época onde comércio eletrônico, computadores pessoais, mobilidade e segurança eram ficção científica, o IP está se tomando incapaz de suportar os próximos passos da Revolução da Informação. Em resposta a esse espantoso crescimento da Internet e à necessidade das aplicações que vão ser executadas na rede no próximo milênio, desenvolveu-se uma nova versão do protocolo IP. O IPv6, a versão 6 do Protocolo Internet, oferece um enorme espaço de endereçamento, melhorias de segurança, suporte à mobilidade e diversas outras características que, juntas, vão possibilitar a verdadeira interconexão global. Este trabalho descreve a implementação de uma Aplicação de Transmissão Segura de Dados que utiliza tecnologia de smart cards para armazenar chaves criptográficas, e a integração desta tecnologia com o IPSec, um protocolo de segurança embutido no IPv6. 


\begin{abstract}
Internet Protocol (IP), the basis of the underlying architecture of Internet, is showing its age. Designed at a time when e-commerce, personal computing, mobility and network security were all science-fiction, the current version of IP has been shown to be unable to support the next steps involved in the continuing Information Revolution. In response to the explosive growth and the needs of the next generation of network applications which will arrive with the new millennium, a new version of Internet Protocol has been developed. IP version 6 (IPv6) offers a vastly expanded addressing scheme, security enhancements, mobility support and many other features that will enable truly global interconnection. This work describes the implementation of a Secure Data Transfer Application, using smart-card technology to store cryptographic keys, and the integration of this technology into IPSec - a built-in security protocol of IPv6.
\end{abstract}




\section{Índice}

INTRODUÇÃO .1

1. A INTERNET E O PROTOCOLO INTERNET .............................................................................2

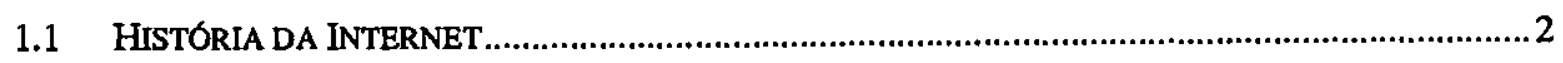

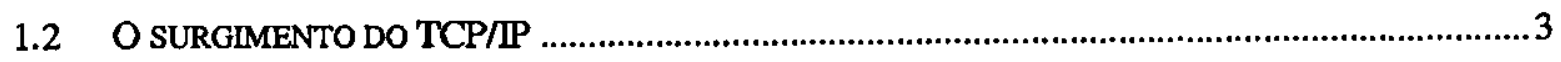

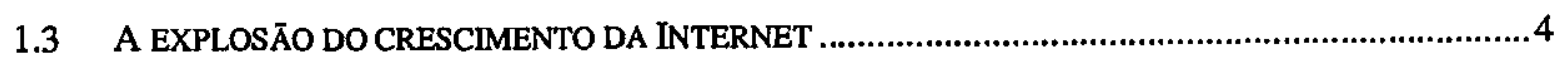

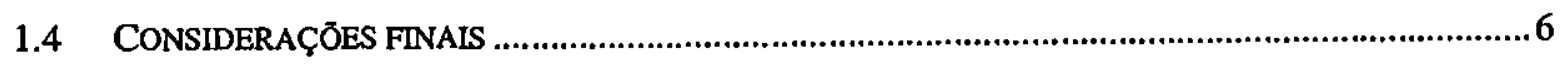

2. $\mathrm{O}$ TCP/IP

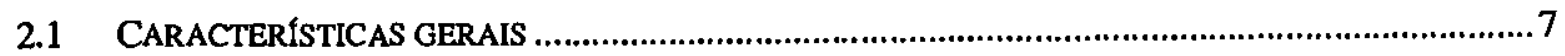

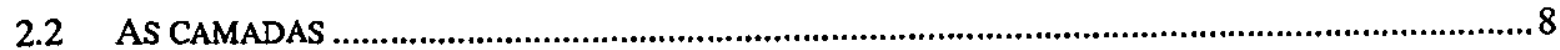

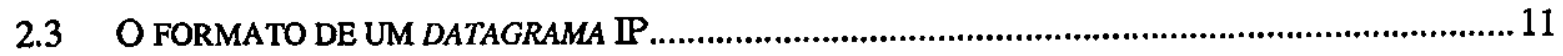

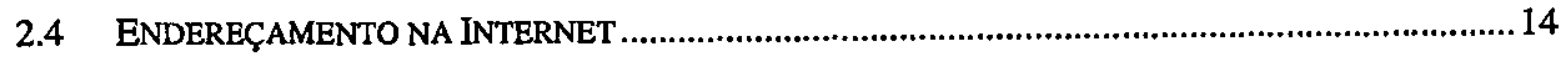

2.5 O DESENVOLVIMENTO DE APLICAÇÕES TCP/IP ………................................................ 17

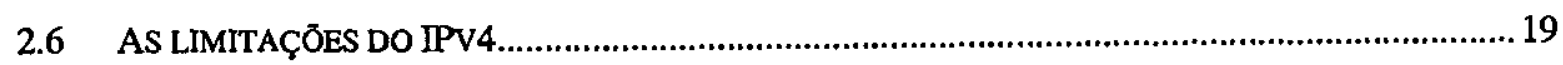

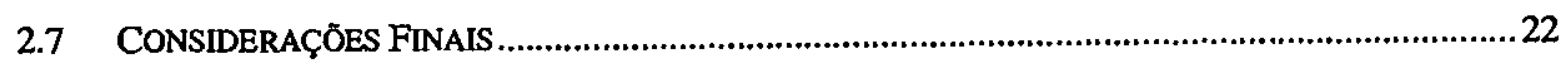

3. IPV6: A NOVA VERSÃO DO PROTOCOLO INTERNET ..........................................................23

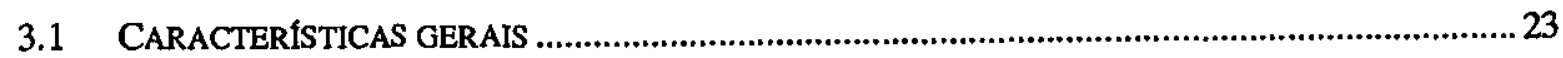

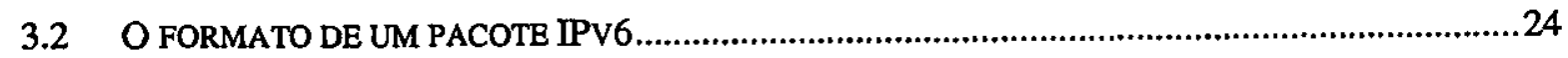

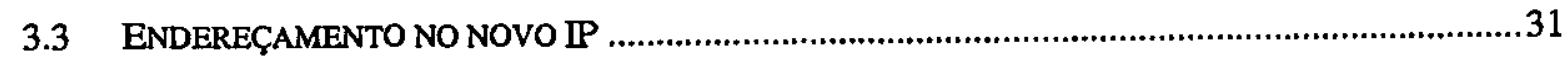

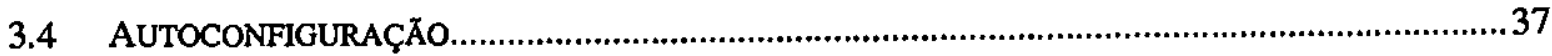

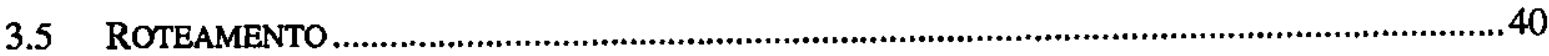

3.6 DESENVOLVIMENTO DE APLICAÇÕES PARA O IPV6...........................................................

3.7 CONSIDERAÇÕES FINAIS .................................................................................................4

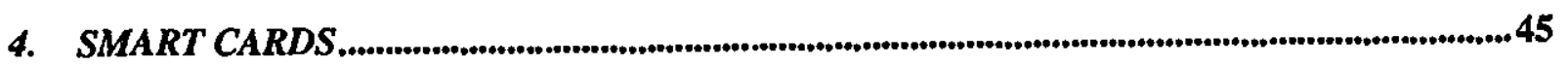

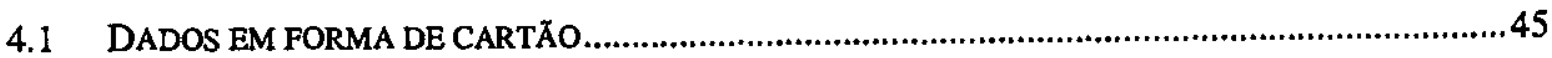

4.2 ARQUITETURAS DIFERENTES PARA APLICAÇ̄̃ES DIFERENTES ............................................... 46

4.3 SISTEMAS OPERACIONAIS DE CARTÕES.......................................................................4

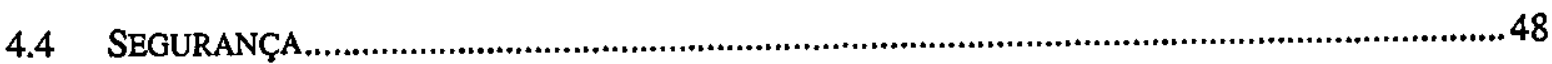

4.5 CONSIDERAÇÖES FINAIS ......................................................................................... 49

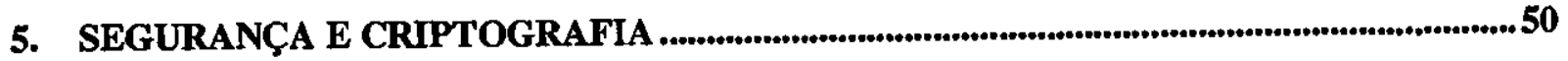

5.1 CRIPTOGRAFIA SIMÉTRICA ..................................................................................... 


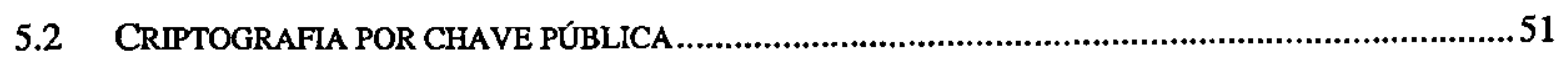

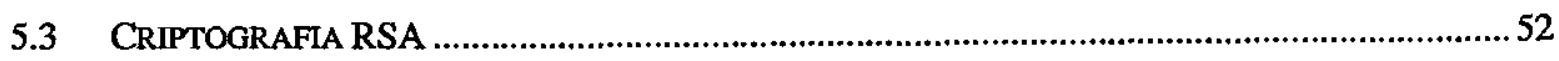

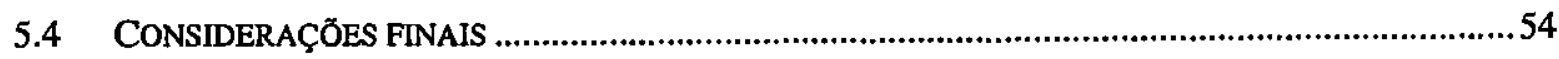

6. IPSEC, SEGURANÇA NO PROTOCOLO INTERNET ....................................................55

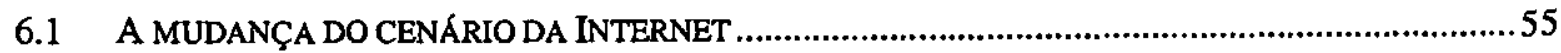

6.2 PROTOCOLOS PARA GARANTIR SEGURANÇA DO TRAFEGO INTERNET ....................................55

6.3 A DIFERENÇA ENTRE O IPSEC E OS DEMAIS PROTOCOLOS DE SEGURANÇA ...........................56

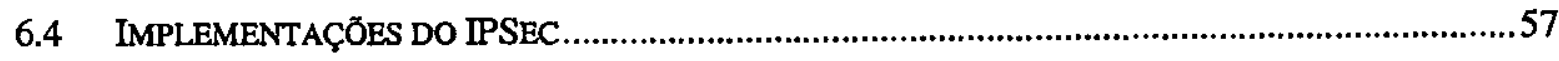

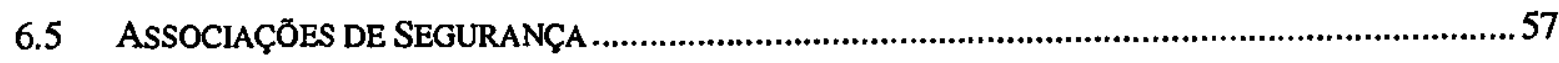

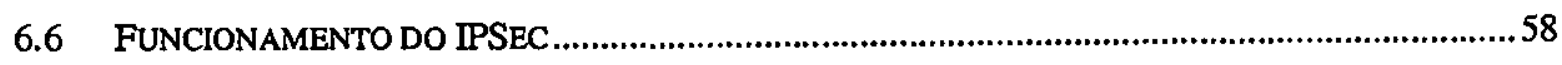

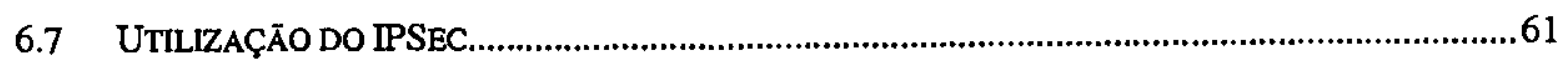

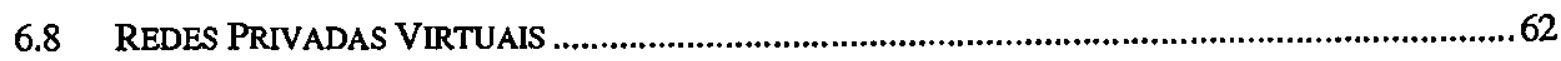

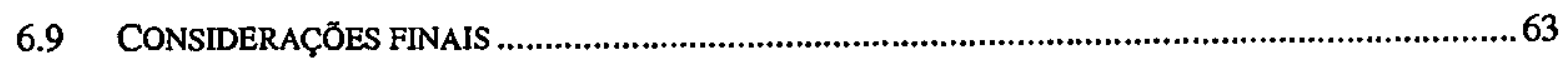

7. MODIFICANDO UMA APLICAÇÃO PARA UTILIZAR O IPV6........................................64

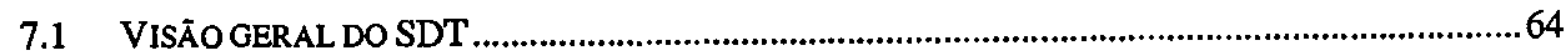

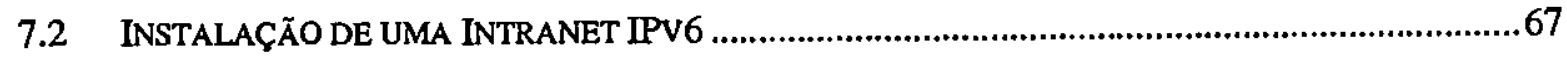

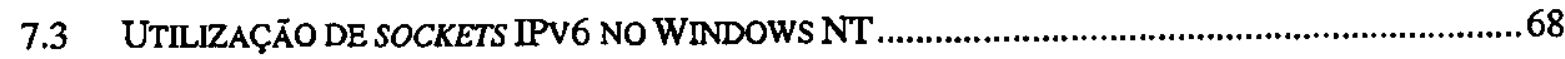

7.4 CONFIGURANDO O IPSEC PARA AUTENTICAR O TRÁFEGO IPV6..........................................73

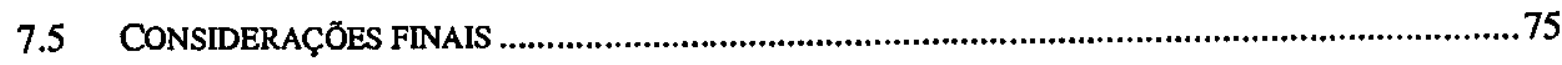

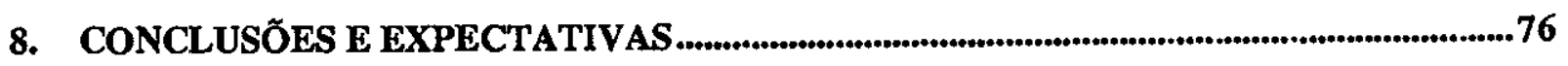

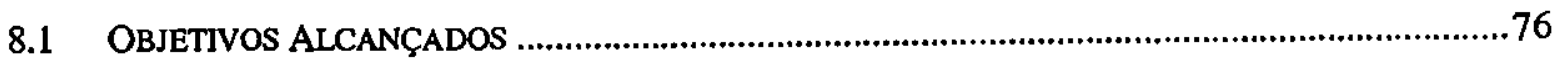

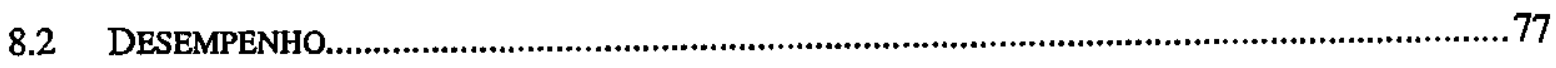

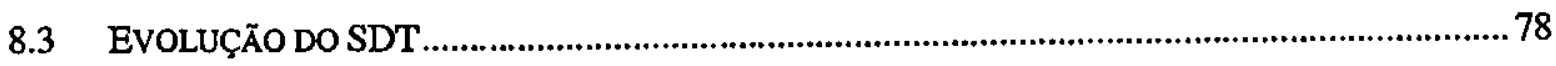

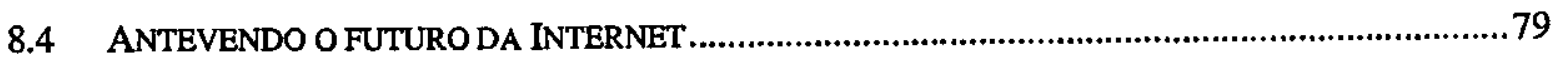

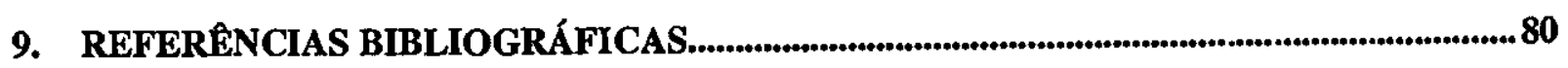




\section{Índice de figuras e tabelas}

Figura 1-1: Cronologia da História da Internet.

Figura 1-2: O Crescimento do número de redes ligadas à Internet.........................................................5

Figura 1-3: Crescimento do número de hosts conectados à Internet de acordo com o tempo................5

Figura 2-1: A Internet como uma abstração da interligação de várias outras redes. ............................... 8

Figura 2-2: Uma comparação entre as camadas do TCP/IP e do modelo OSI .................................... 8

Figura 2-3: exemplo de várias aplicações rodando sobre a arquitetura TCP/IP ...................................11

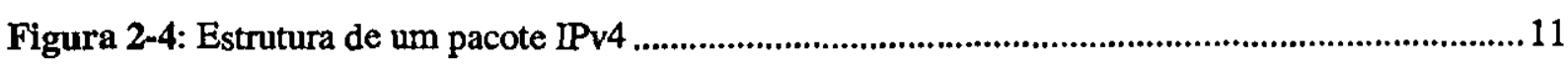

Tabela 2-1: Descrição dos campos do cabeçalho de um pacote IPv4 ............................................... 12

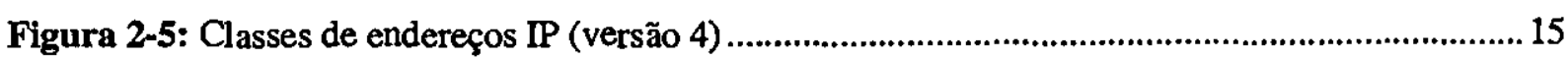

Figura 2-6: Um exemplo de utilização de diversos endereços IP por máquina. ....................................16

Figura 2-7: A ilustração da utilização de sockets na comunicação através de um canal virtual .......... 18

Figura 3.1 - Formato de um pacote IPv6 ...........................................................................................24

Tabela 3-1: campos do cabeçalho de um pacote IPv6 ....................................................................25

Figura 3.2 - estrutura de um frame Ethernet abrigando um pacote IPv6 .............................................26

Figura 3.3 - Encadeamento de cabeçalhos de extensão no IPv6............................................................29

Figura 3.4 - O formato de um endereço IPv6 unicast baseado em Provedor de acesso........................ 34

Figura 3.5 - $\mathrm{O}$ formato de um endereço IPv6 unicast de uso local baseado em um Site......................35

Figura 3.6 - $\mathrm{O}$ formato de um endereço IPv6 unicast de uso local baseado em um link........................35

Figura 3.7 - $O$ formato de um endereço multicast no IPv6................................................................35

Figura 3.8 - $O$ formato de um endereço anycast no IPv6.....................................................................36

Figura 3.9 - A distribuição de endereços IPv6.................................................................................37

Figura 3. 8 - Exemplo de uma seqüência de autoconfiguração no IPv6 ............................................38

Figura 3.10 - trecho de código em Delphi que manipula sockets através de eventos ...........................42

Figura 3.11 - trecho de código em Delphi que exemplifica a programação com sockets

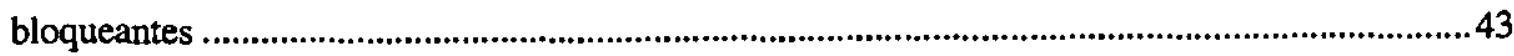

Figura 4.1 - Estrutura de um smartcard com contato........................................................................46

Figura 4.2 - Estrutura de um smartcard contactless ..........................................................................47

Figura 4.3 - estrutura de um cartão híbrido e de um cartão combi.......................................................4 48

Figura 5.1 - Diferença entre esquemas de criptografia simétrica e com chave pública........................51

Figura 6.1 formato de um cabeçalho de autenticação $(\mathrm{AH})$ de um pacote IPv6.................................59

Figura 6.2 formato de um cabeçalho de encriptação (ESP) de um pacote IPv6 ..................................60

Figura 6.3 exemplo da utilização do IPSec para conexão segura entre dois hosts ............................... 61

Figura 6.4 - exemplo da utilização do IPSec para conectar dois um host à um gateway.......................61

Figura 6.5 -exemplo da utilização do IPSec para conectar dois gateways de forma segura..................62 
Figura 7.1 Esquema de uma comunicação utilizando o SDT

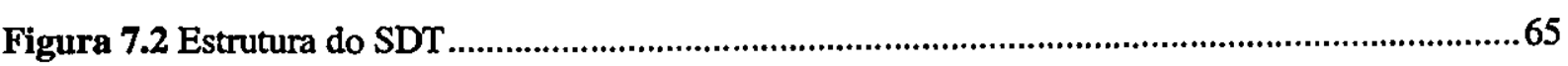

Figura 7.3 - Esquema em camadas da aplicação SDT rodando sore uma rede IPv6 segurac ..............66

Figura 7.4 - Esquema da Intranet IPv6 instalada na S\&V ..........................................................67

Figura 7.5 -A arquitetura Winsock no Windows NT .....................................................................68

Figura 7.6 - trecho de código da unit Winsock2 . pas exibindo as novas estruturas de

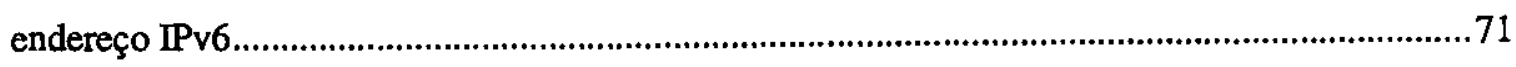

Figura 7.7 -A hierarquia das principais classes no Winshoes ..........................................................72

Figura 7.8 - Exemplo do editor de propriedades de objeto (Object Inspector) no Ambiente de Desenvolvimento Integrado (IDE) do Delphi. .............................................................................72

Figura 7.9 - exemplo da utilização da aplicação IPSecGUI para configurar o IPSec............................74

Tabela 8-1 -Comparação entre os valores de throughput obtidos com a utilização de sockets IPv6 pela aplicação SDT e pela a aplicação ttcp ${ }^{51}$ no Windows NT...............................................77

Figura 8.1 - Esquema da utilização do IPSec e do SDT para criar uma Rede Privada Virtual.............78 


\section{Introdução}

A Internet evoluiu de um sistema de uso acadêmico e científico para uma rede mundial de computadores, responsável por parte do tráfego de dados no planeta. Para suportar os novos usuários e as aplicações que devem ser desenvolvidas nos próximos anos, criou-se uma nova versão do Protocolo Internet. O novo protocolo possibilitará a utilização de um número muito maior de endereços e solucionará antigos problemas como suporte à segurança, mobilidade $e$ autoconfiguração.

Este trabalho descreve a utilização do IPv6, o novo protocolo da Internet, no aprimoramento de uma aplicação de transmissão segura de dados que vem sendo desenvolvida na S\&V Consultoria e Tecnologia. Essa aplicação, que utiliza algoritmos de criptografia e chaves criptográficas armazenadas em cartões inteligentes para transmitir dados confidenciais, demandava maior flexibilidade e mecanismos adicionais de segurança. A utilização do IPv6 está nos permitindo, ao mesmo tempo, alcançar esse objetivo e nos preparar para a Internet 2.

Este documento está dividido em nove capítulos. O primeiro capítulo trata da história da Internet e discute como um design de mais de vinte anos pôde suportar tantas evoluções e um crescimento tão grande. O segundo capítulo descreve a versão atual do Protocolo Internet $\mathrm{e}$ como suas limitações estão impedindo um desenvolvimento ainda maior da rede. $O$ terceiro capítulo discute as características da nova versão do Protocolo Internet e como deve ser a sua utilização em massa, num futuro próximo. $O$ capítulo quatro faz uma breve introdução aos smart cards, e explica porque esta tecnologia está sendo utilizada neste Projeto para armazenar chaves criptográficas. O quinto capítulo trata de alguns aspectos de segurança e criptografia, principalmente em relação aos mecanismos de autenticação e encriptação de dados por chave pública que estão sendo utilizados nesse projeto. O sexto capítulo trata do IPSec, um padrão que permite adicionar segurança à todo o tráfego de dados IPv6. O sétimo capítulo descreve como utilizamos o IPSec para adicionar segurança à nossa aplicação de transmissão segura de dados e os pormenores desta implementação. Por fim, o oitavo capítulo apresenta algumas conclusões e expectativas em relação à evolução deste projeto. 
“Antes mundo era pequeno, porque Terra era grande,

Hoje mundo é muito grande, porque Terra é pequena"

(Gilberto Gil)

\section{A Internet e o Protocolo Internet}

\subsection{História da Internet}

Em 1957, a União Soviética lançava o Sputnik, o primeiro satélite artificial a orbitar a Terra e, em resposta, o Departamento de Defesa dos Estados Unidos criava a ARPA ${ }^{1}$, ou Agência de Projetos Avançados de Pesquisa, para tentar recolocar os EUA na liderança das pesquisas militares.

Em 1962, a Força Aérea americana começava a estudar uma maneira de armazenar o conhecimento de uma forma distribuída e resistente a ataques de instalações militares. A idéia era desenvolver uma rede de computadores que garantisse que, mesmo que linhas de comunicação, computadores e cidades inteiras fossem destruídos, os dados pudessem encontrar um novo caminho entre o que restasse e continuar trafegando. Assim surgiu o conceito de rede de comutação de pacotes, onde a informação seria quebrada em blocos, ou pacotes, de dados e estes transmitidos ao longo de um caminho, mais tarde denominado rota [Fei93].

A ARPA começou então a desenvolver uma rede de comutação de pacotes chamada de ARPANET que, em 1969, interligava quatro computadores de quatro Universidades americanas através de conexões de $50 \mathrm{Kbps}$ e um protocolo rudimentar de comunicação conhecido como $\mathrm{NPC}^{2}$.

\footnotetext{
${ }^{1}$ (Advanced Research Projects Agency)

${ }^{2}$ Network Control Protocol - Protocolo de Controle de Rede
} 


\subsection{0 surgimento do TCP/IP}

Até 1974, apesar do reconhecimento do governo americano e de diversas entidades de pesquisa em relação à importância das redes, só havia cerca de vinte e três computadores interligados através da tecnologia ARPANET. O NCP, principal protocolo da ARPANET, era ineficiente em uma série de aspectos e instável - o que ocasionava frequientes problemas de comunicação e interrupções no funcionamento da rede.

Em meados de 1974, pesquisadores da Universidade de Stanford e da ARPA publicaram um artigo sobre um protocolo de interligação de redes com enfoque em heterogeneidade e portabilidade [Kah74]. Desde então as pesquisas no desenvolvimento desse protocolo se fortificaram. Mais três anos foram necessários para adaptar os computadores que existiam na ARPANET, PRNET ${ }^{3}$ e NSFNET ${ }^{4}$ ao novo protocolo, mas por volta de 1977 , depois de três sucessivos refinamentos (versões), surgia o que se conhece hoje como o IP ou Protocolo Internet ${ }^{5}$.

O TCP/P, isto é, o IP mais uma camada de transporte conhecida como Protocolo de Controle de Transporte (TCP - Transport Control Protocol), foi utilizado de maneira pioneira na interligação de três redes com infra-estruturas e velocidades bem diferentes: a ARPANET, baseada em cabos terrestres de $50 \mathrm{~Kb} / \mathrm{s}$; a PRNET, baseada em conexões de rádio de 100 a $400 \mathrm{~Kb} / \mathrm{s}$ e a SATNET ${ }^{6}$ baseada em conexões de satélite de $64 \mathrm{~Kb} / \mathrm{s}$.

A versatilidade do TCP/IP, um protocolo que deveria possibilitar a interconexão de redes heterogêneas baseadas nas mais diversas tecnologias, foi demonstrada em 1978 quando um terminal instalado dentro de um furgão que percorria uma rodovia nos Estados Unidos permitia que se operasse remotamente ${ }^{7}$ um computador na Inglaterra. $O$ terminal instalado dentro do

${ }^{3}$ PRNET - Packet Radio Net - Rede de comutação de Pacotes por Rádio;

${ }^{4}$ NSFNET - Nation Science Foundation Net - Rede (de comutação de pacotes) da NSF;

${ }^{5} \mathrm{IP}$ - Internet Protocol, Protocolo Internet, versão 4

${ }^{6}$ SATNET - Satellite Network - Rede (de comutação de pacotes) via satélite.

${ }^{7}$ Através de um remote login ('login' remoto): uma aplicação que permite a um usuário conectar-se (logar) à um computador remoto e utilizá-lo como se estivesse numa máquina local. 
furgão transmitia dados por rádio para a PRNET, que eram por sua vez transmitidos através dos cabos da ARPANET até uma antena de satélite da SATNET e então enviados a Londres [Fei93].

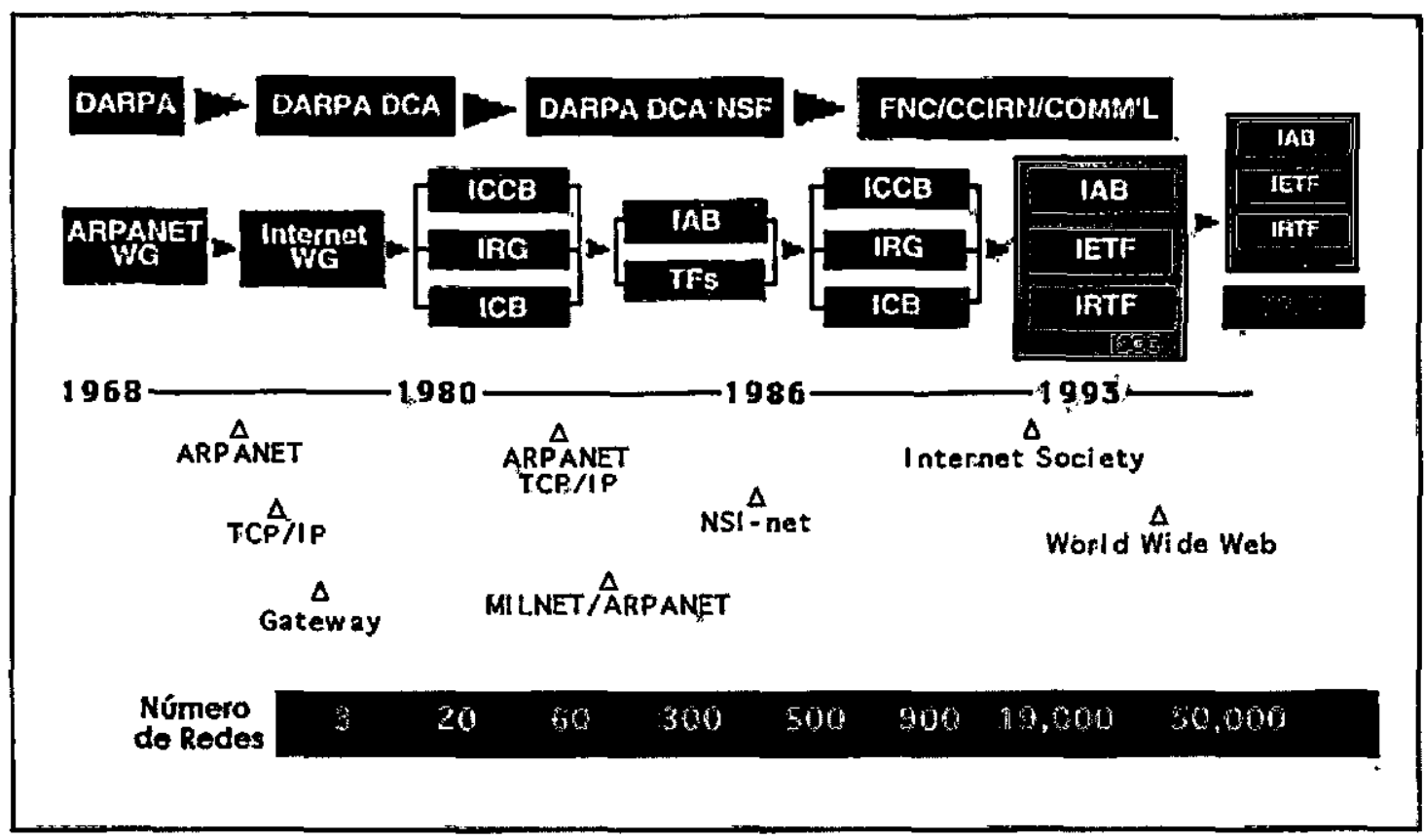

Figura 1-1: Cronologia da História da Internet

Depois do sucesso dessa experiência, diversas estações terrestres foram adicionadas na Noruega, Alemanha, Itália e mais nós da PRNET foram conectados nos Estados Unidos. Em 1983, a rede já interligava mais de sessenta sub-redes ao redor do mundo (Figura 1-1).

\subsection{A explosão do crescimento da Internet}

Em 1984, preocupado com questões de segurança, o governo americano dividiu a ARPANET em duas redes (ver Figura 1-1): a MILNET, uma rede de uso militar e outra, que continuou sendo chamada de ARPANET, para aplicações acadêmicas e científicas. Também nesta época, percebendo a importância do TCP/IP no sucesso das redes, o Departamento de Defesa começou a incentivar sua implementação no UNIX, que estava sendo desenvolvido em Berkeley.

A integração com o UNIX permitia que o TCP/IP ganhasse mercado e fosse utilizado em diferentes plataformas. Em pouco tempo, ele se tornava o protocolo mais disponível e utilizado em todo o mundo. Com ele, a Internet começava a crescer até se transformar no imenso universo de computadores interligados atualmente [Com95]. 


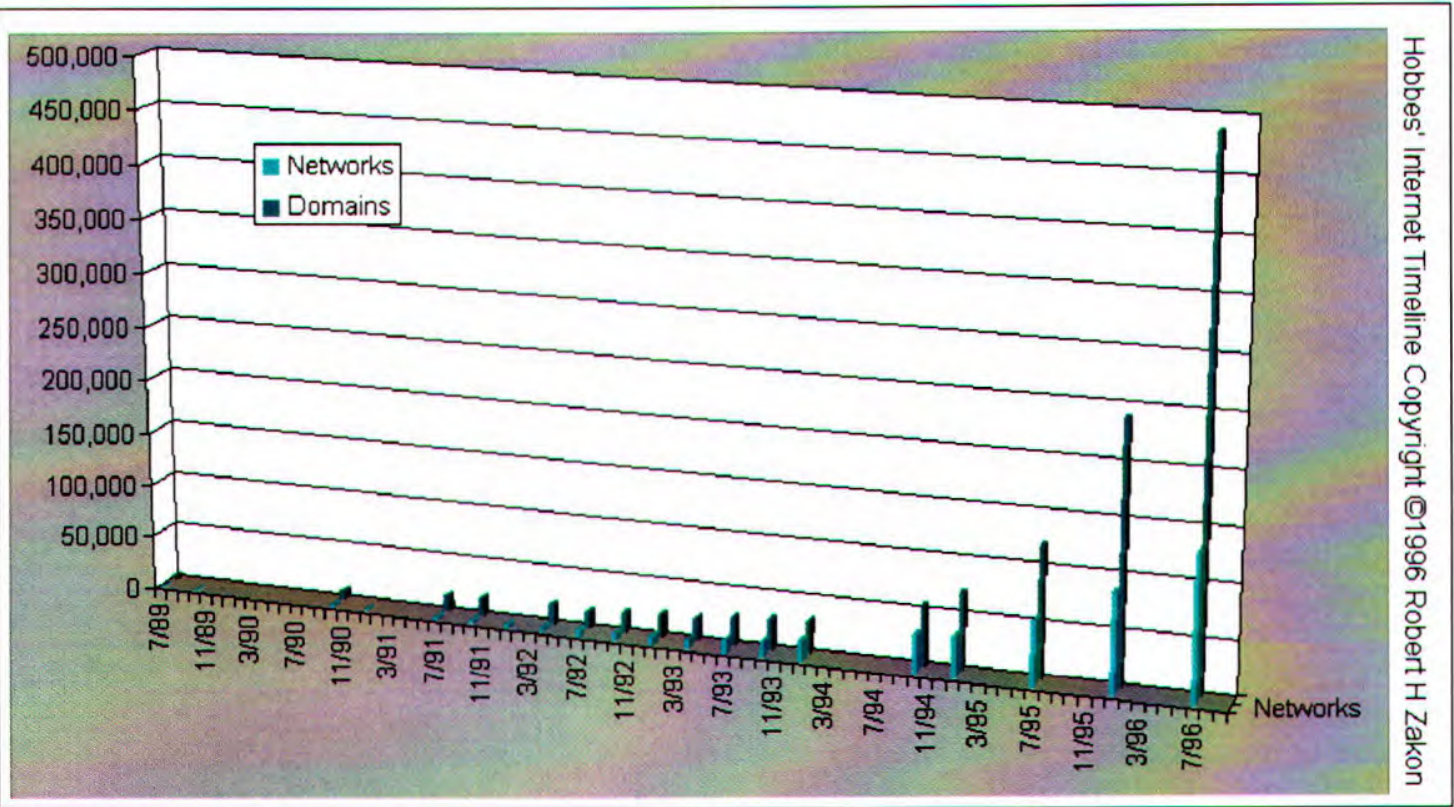

Figura 1-2: O Crescimento do número de redes ligadas à Internet

A Figura 1-2 mostra o crescimento do número de redes interligadas à Internet. As três primeiras redes se transformaram em mais de 100.000 em 1996 e o número de domínios cresceu de 3 para mais de 450.000 .

\section{Número de hosts}

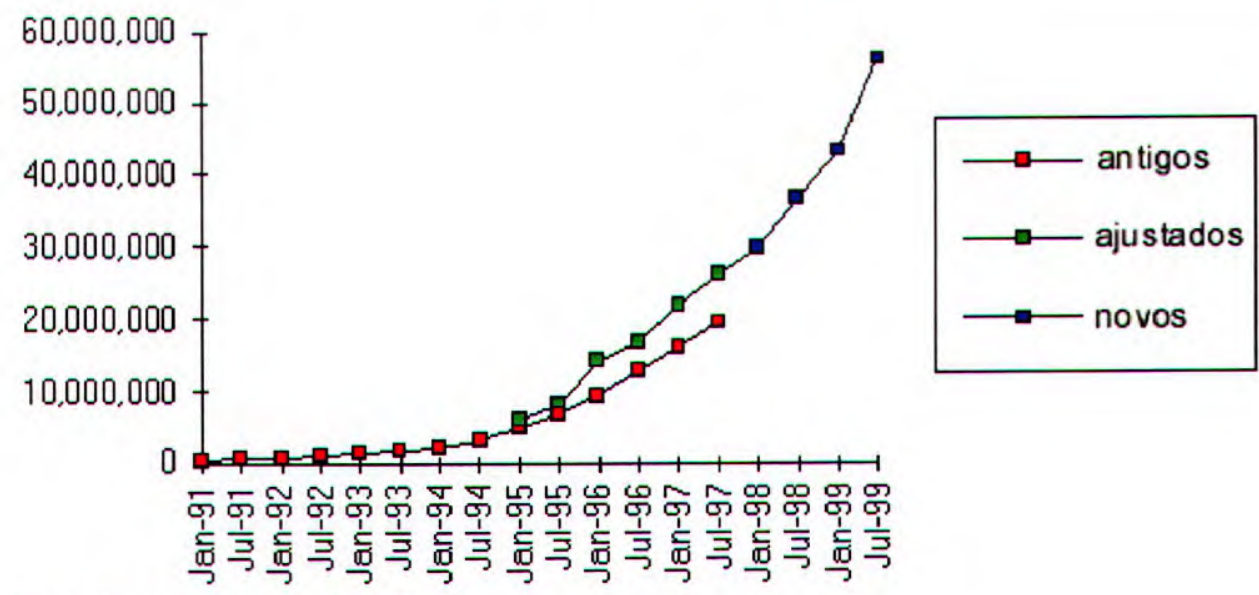

Fonte: Internet Software Consortium

Figura 1-3: Crescimento do número de hosts conectados à Internet de acordo com o tempo. 
O gráfico na Figura 1-3 exibe as medições efetuadas por uma aplicação $\left(\mathrm{ZONE}^{8}\right)$, desenvolvida pelo pesquisador Mark Lottor [Lot99]. A aplicação periodicamente interroga servidores de domínio $\left(\right.$ DNS $^{9}$ ) em busca de novos equipamentos cadastrados e avalia quais deles respondem ao sinal de ping ${ }^{10}$, montando assim uma estimativa do número de hosts conectados à Internet.

\subsection{Considerações finais}

Este capítulo discutiu brevemente a história da Internet e os fatores que possibilitaram que, em poucos anos, uma rede que conectava uma dezena de computadores passasse a interligar milhões de computadores e pessoas no Planeta. Conhecendo o passado e presente da Internet, poderemos compreender melhor para onde se direciona o seu futuro, principalmente em relação às características da nova versão do Protocolo Internet, base desse projeto de pesquisa.

${ }^{8}$ ZONE - Zealot Of NamE notification - crente na notificação de nomes, numa tradução literal;

${ }^{9}$ DNS - Domain Name Server - Servidor que armazena nomes de domínio. É utilizado na Internet para converter um nome em um endereço IP numérico.

${ }^{10}$ ping - ICMP echo request/reply: Aplicação clássica que utiliza o protocolo ICMP e permite avaliar se uma máquina conectada à Internet está ativa. 
"Não existe razão de um indivtduo ter um computador em casa" (Ken Olsen, presidente da Digital em 1977)

\section{2. $0 \mathrm{TCP} / \mathrm{IP}$}

\subsection{Características gerais}

Para interligar diferentes redes através de diferentes tecnologias, o TCP/IP deveria ser independente de hardware e de Sistema Operacional; para manter a informação trafegando mesmo em condições desfavoráveis, deveria suportar grandes taxas de erro; para continuar interligando computadores mesmo no caso de destruição de canais de comunicação ou de subredes inteiras, deveria ser capaz de encontrar um novo caminho, quando algum trecho deixasse de funcionar. Esses requisitos obrigaram que o TCP/IP surgisse como um protocolo ao mesmo tempo, robusto, flexível e independente de plataforma [Ss198] [Bla99].

Para o usuário ou para programas que se comunicam através da Internet, não existem conversões de formato entre diferentes arquiteturas, mudanças de hardware e software, algoritmos de roteamento e nem mesmo a necessidade de conhecer a topologia de interligação das redes. $O$ que existe é um canal virtual entre o usuário e a rede que permite enviar mensagens pelo correio eletrônico, transferir arquivos ou participar de uma videoconferência; não importando se o usuário ou computador que se deseja contatar esteja localizado na mesa ao lado ou a milhares de quilômetros, esteja utilizando ou não um hardware diferente, um Sistema Operacional diferente ou conectado à rede de uma maneira diferente [Com95] [Sta96]. 


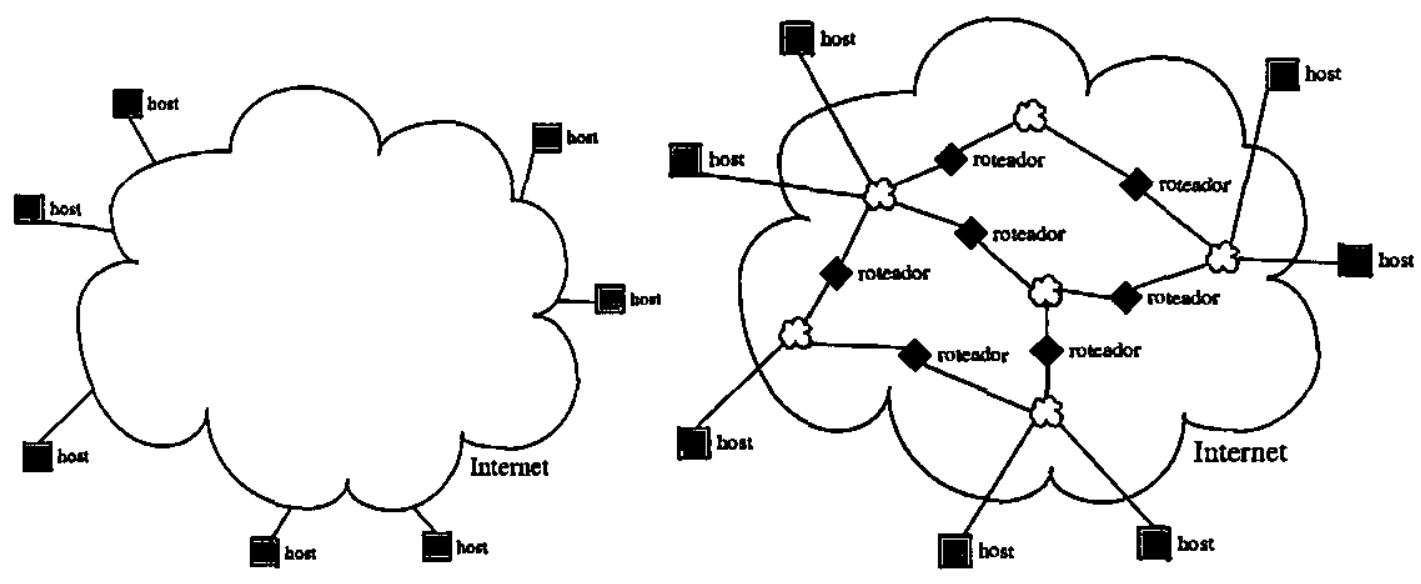

Figura 2-1: A Internet como uma abstração da interligação de várias outras redes.

A Figura 2-1 ilustra esse conceito da abstração de uma rede universal: a Internet interligando várias redes e fazendo com que os usuários conectados a ela acreditem estar utilizando uma rede única [Sho78].

\subsection{As camadas}

T CP/P

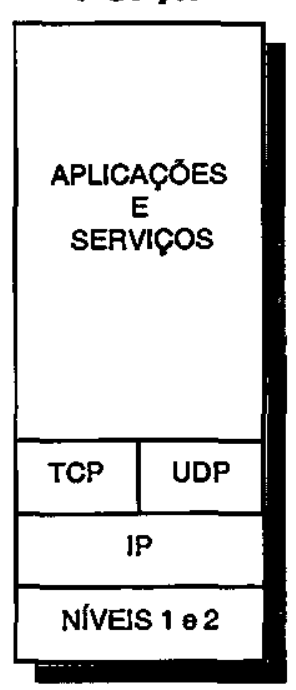

Figura 2-2: Uma comparação entre as camadas do TCP/IP e do modelo OSI

OS 1

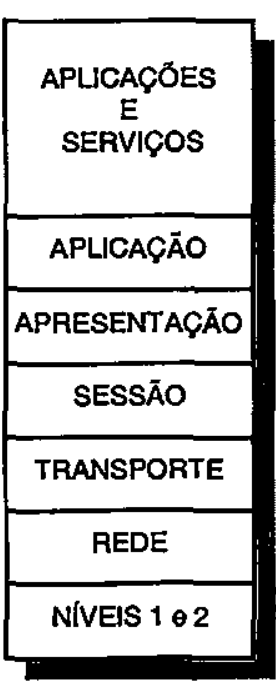

A necessidade de portabilidade para as mais diversas plataformas e, consequentemente, de independência em relação às tecnologias de conexão, fez com que o TCP/IP fosse desenvolvido em uma estrutura de camadas bem dividida.

Dividir as funcionalidades em camadas é interessante porque garante que uma alteração realizada em um nível não implique, necessariamente, em alterações em outros níveis - assegurando robustez e portabilidade ao protocolo. 
Por exemplo quando uma nova tecnologia de rede surge, basta desenvolver para a camada de acesso ao meio o software necessário para manipular esta nova tecnologia e possibilitar que ela transmita pacotes IP. Com isso, preserva-se tudo o que já está desenvolvido para as camadas superiores.

Posteriormente, o TCP/IP se tomou um exemplo para divisão em camadas mesmo em modelos de referência como o ISO OSI ${ }^{11}$ (ver Figura 2-2) [Com95].

\subsubsection{Os níveis inferiores (1 e 2)}

No TCP/IP, os primeiros níveis são responsáveis pela comunicação direta com os meios físicos, isto é, manipulam a tecnologia de comunicação de redes Ethernet, Token Ring, etc. É tarefa desses níveis gerenciar os dispositivos (através de device drivers) e controlar o acesso aos meios físicos, muitas vezes em nível eletrônico.

Os níveis inferiores dividem os dados em pedaços denominados frames e os enviam de uma interface $^{12}$ local para uma outra interface destino dentro de uma mesma rede física. Normalmente, as funções desses níveis estão presentes nos drivers dos adaptadores de rede .

\subsubsection{IP, o nível de rede (3)}

A camada de rede do protocolo TCP/IP é dedicada ao roteamento dos pacotes, isto é, à tarefa de determinar um caminho, ou rota, entre um remetente e um destinatário. O conceito de roteamento vem da diferença entre entregar um determinado pacote na mesma rede em que ele está trafegando ou fazer com que um pacote alcance uma determinada rede através de um

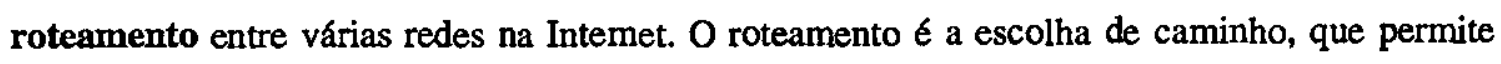
que um pacote saia de seu host de origem e alcance seu host de destino [Cla82].

A camada IP é connectionless, isto é, não orientada à conexão, porque os datagramas são roteados independentemente e sem nenhuma garantia de ordenamento ou confiabilidade. O nível

\footnotetext{
${ }^{11}$ ISO OSI - International Standards Organisation Open Systems Interconnection - modelo de Interconexão para Sistemas Abertos (OSI) da Organização de Padrões Intemacionais (ISO)

${ }^{12}$ Exemplos de interfaces incluem placas Ethernet, Token Ring, FDDI e linhas seriais;
} 
IP corresponde ao nível de rede do modelo OSI, que prevê um roteamento não orientado à conexão bastante semelhante ao implementado pelo IP.

\subsubsection{Nível de transporte orientado à conexão - TCP (4)}

O TCP - Transmission Control Protocol (ou Protocolo de Controle de Transmissão) provê um serviço confiável de transmissão de dados para as aplicações e estabelece um canal virtual entre um remetente e um destinatário, garantindo que os dados alcancem seu destino, livres de erro, completos e em sequência.

\subsubsection{Nível de transporte não orientado à conexão - UDP (4)}

Aplicações utilizam o UDP - User Datagram Protocol (ou Protocolo de Datagrama de Usuário) para enviar mensagens sem controle de sessão e erro. O UDP divide os dados em datagramas e os envia para o nível de rede (IP) para que sejam roteados até o seu destino. Por não estabelecer uma conexão virtual entre o remetente e o destinatário, nem possuir mecanismos de verificação de erros, o UDP não garante ao remetente que um pacote alcançará seu destino, mas garante às aplicações um maior desempenho na transmissão de dados. Por exemplo, aplicações como Real Audio, que recebem pacotes em tempo real e se preocupam mais com desempenho e com a qualidade da média dos pacotes recebidos do que com a integridade individual de cada pacote, utilizam o UPD em vez do TCP [Com95].

\subsubsection{Níveis de Aplicação (5)}

Como mostra a Figura 2-3, a família de protocolos do TCP/IP provê uma série de serviços para serem utilizados pelas aplicações. Dentre eles, podemos destacar: comunicação ponto-a-ponto, correspondência eletrônica, protocolos de transferência de arquivos $\left(\right.$ FTP $\left.^{13}\right)$ e de hiperdocumentos $\left(\mathrm{HTTP}^{14}\right)$.

\footnotetext{
${ }^{13}$ FTP - File Transfer Protocol, ou protocolo de transferência de arquivos;

${ }^{14}$ HTTP - Hyper Text Transfer Protocol, ou protocolo de transferência de hipertexto;
} 


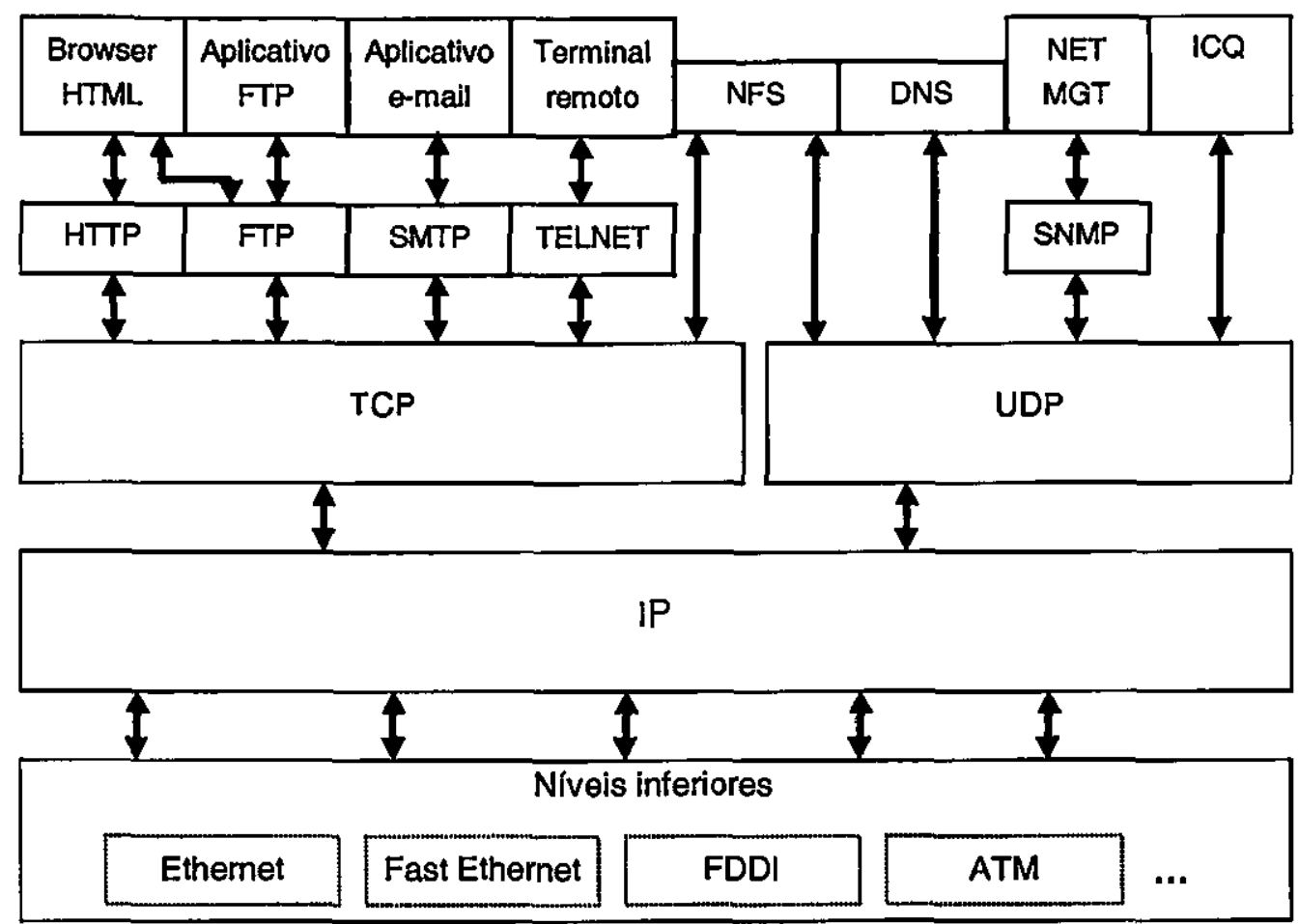

Figura 2-3: exemplo de várias aplicações rodando sobre a arquitetura TCP/IP

\subsection{0 formato de um datagrama IP}

A unidade básica de todo o tráfego IP é o que se chama de um datagrama IP. Um datagrama IP, como mostra a Figura 2-4, é um pacote de dados que contém um cabeçalho com algumas opções que permitem determinar como os dados trafegarão até o destino e uma área de dados.

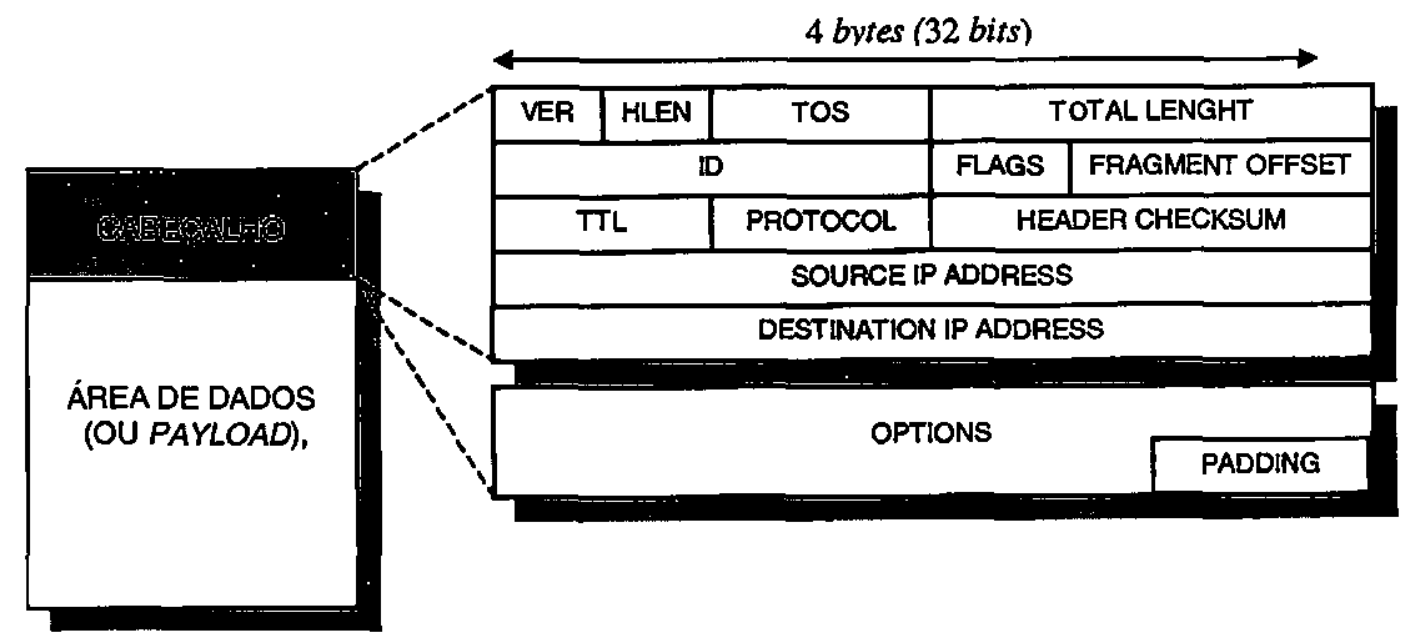

Figura 2-4: Estrutura de um pacote IPv4 


\begin{tabular}{|c|c|c|}
\hline (ampo & Bits & Descrição \\
\hline VERSION & 4 & Versão do protocolo \\
\hline $\begin{array}{l}\text { HEADER } \\
\text { LENGHT }\end{array}$ & 4 & $\begin{array}{l}\text { Tamanho do cabeçalho do pacote } \\
\text { em octetos }\end{array}$ \\
\hline $\begin{array}{l}\text { TYPE QF } \\
\text { SERVICE }\end{array}$ & 8 & Tipo do serviço \\
\hline $\begin{array}{r}\text { TOTAL } \\
\text { LENGHT }\end{array}$ & 16 & Tamanho total em bytes \\
\hline ID & 16 & controle de fragmentação \\
\hline FLAGS & 4 & controle de fragmentação \\
\hline $\begin{array}{r}\text { FRAGMENT } \\
\text { OFFSET }\end{array}$ & 12 & controle de fragmentaçāo \\
\hline TIME TO LIVE & 8 & Tempo de vida do pacote \\
\hline PROTOCOL & 8 & $\begin{array}{l}\text { Identificaça do protocolo da } \\
\text { camada superior: TCP, UDP, ... }\end{array}$ \\
\hline $\begin{array}{r}\text { HEADER } \\
\text { CHECKSUM }\end{array}$ & $1 \overline{6}$ & Checksum do cabeçalho \\
\hline $\begin{array}{r}\text { SOURCE } \\
\text { ADDRESS }\end{array}$ & 32 & Endereço IP do remetente \\
\hline $\begin{array}{r}\text { DESTINATION } \\
\text { ADDRESS }\end{array}$ & 32 & Endereço IP do destinatário \\
\hline PADDING & - & $\begin{array}{l}\text { Complemento para garantir que o } \\
\text { tamanho seja múltiplo de } 4 \text { bytes }\end{array}$ \\
\hline
\end{tabular}

Tabela 2-1: Descrição dos campos do cabeçalho de um pacote IPv4
A Tabela 2-1 exibe os campos que compõem o cabeçalho um pacote IPv4.

O campo Version (VER), ou versão, contém o valor 4 e é o primeiro campo analisado pelos roteadores durante 0 processamento do pacote. Quando um roteador IPv4 encontra um pacote com um valor diferente de 4 neste campo, o pacote é ignorado.

O campo Header Length (HLEN), de quatro bits, contém o tamanho do cabeçalho em octetos (múltiplos de 4 bytes) e portanto permite que 0 cabeçalho contenha até $2^{4} * 4=64$ bytes, sempre em múltiplos de 4 bytes.

O campo Type of Service (TOS), ou Tipo de Serviço, especifica como um datagrama deveria ser tratado pelos roteadores. Ele é composto de um subcampo (precedence) que determina a prioridade do datagrama e de três bits (D, T e R) que permitem informar se o datagrama deveria ser enviado com o menor atraso possível (low Delay), alto throughput ${ }^{15}$ (high Throughput) ou com alta confiabilidade (high Reliability).

Com o campo TOS um roteador poderia escolher um determinado caminho também baseado nas informações do datagrama. Por exemplo, se um roteador pudesse escolher entre um canal de satélite, de alto bandwidth e alta latência, e uma linha discada, de menor bandwidth mas com uma latência menor, ele poderia enviar datagramas de um tráfego $F T P^{16}$ para o canal de satélite

\footnotetext{
${ }^{15}$ vazão, numa tradução literal

${ }^{16}$ FTP - File Transfer Protocol, Protocolo de Transferência de Arquivos
} 
e os datagramas que transmitem as teclas pressionadas por um usuário num "login remoto" pela linha discada. É interessante notar, entretanto, que os roteadores têm autonomia para utilizar ou não essas informações adicionais e que a simples presença dessas opções não garante um roteamento perfeito.

O campo Total Length, ou tamanho total, de 16 bits, indica quantos bytes de dados o datagrama possui. Por ser de 16 bits, ele permite que um datagrama IP transporte até $2^{16}$ (65.536) bytes, ou seja, 64Kb. Pode parecer pouco, mas na época em que o IP foi projetado, esse era um tamanho razoável e ainda continua sendo, se comparado com o tamanho dos frames da maioria das tecnologias de rede encontradas no mercado. A Ethernet, por exemplo, transporta frames de 1514 bytes $(1,5 \mathrm{~Kb})$ e a FDDI frames de cerca de $34 \mathrm{~Kb}$. Se o tamanho máximo do datagrama IP fosse muito superior a isso, com certeza haveria muita fragmentação, isto 6 , frequentemente o datagrama teria que ser dividido antes de ser transmitido dentro dos frames das redes utilizada [Com95].

Os campos Identification (identificação), flags e fragment offget (deslocamento da fragmentação) controlam a fragmentação dos datagramas. Como dito anteriormente, fragmentação é uma técnica utilizada quando o tamanho do pacote é maior do que o suportado pelos frames da rede onde se estão transmitindo os dados. Quando isso acontece, o pacote é dividido em fragmentos e depois eles são transmitidos, um a um. Durante a fragmentação, o roteador copia para os fragmentos a identificação do datagrama original e ajusta o offset (deslocamento) de cada fragmento de acordo com sua posição em relação ao datagrama

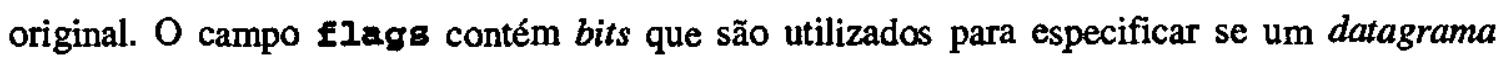
pode ou não ser fragmentado (em alguns casos é melhor descartar o pacote do que fragmentá-lo) e se o fragmento é ou não o último fragmento. $O$ bit que especifica se o fragmento é ou não o último é utilizado durante a remontagem para determinar o tamanho total do datagrama. $\mathrm{O}$ tamanho total é o tamanho do fragmento mais o of fset do último fragmento.

O campo Time To Live (TTL), ou tempo de vida, especifica o tempo máximo (teoricamente em segundos, na prática em número de hops) que um datagrama pode permanecer na Internet, prevenindo a existência de datagramas em loop, mesmo que tabelas de roteamento estejam corrompidas ou não exista mais um caminho entre um host origem e um destino. 
Quando um datagrama é enviado, o campo Time To Itve é preenchido pela aplicação e decrementado por cada host ou roteador que processa o datagrama. Se ele chegar a zero, o datagrama é descartado e uma mensagem de erro é enviada para o remetente. A especificação (da versão 4) do IP sugere que os roteadores decrementem o número de segundos que gastaram no processamento do datagrama. Entretanto, como essas estimativas de tempo são imprecisas e

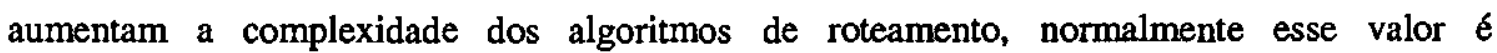
decrementado de um a cada equipamento que processa o pacote (hop).

O campo Protocol identifica o protocolo de alto nível transportado no datagrama e é utilizado pelas aplicações destino durante a interpretação do datagrama. Valores possíveis seriam TCP, UDP, ICMP, etc.

O campo Header Checksum é preenchido pela aplicação com um valor de checksum (Complemento de 1 do cabeçalho), um algoritmo que realiza uma soma dos valores de cada byte do cabeçalho e gera um número de 16 bits que permite que o destinatário avalie se o cabeçalho foi ou não corrompido durante o trajeto. Basta que o receptor execute mais uma vez o algoritmo de checksum e compare o valor obtido com o valor armazenado no campo. É importante enfatizar que este campo é utilizado para checar a integridade do cabeçalho apenas, e não do pacote inteiro (cabeçalho+dados).

Os campos Source Adaress (endereço de origem) e Destination Adaress (endereço destino) são campos de 32 bits que identificam o remetente e o destinatário do pacote.

\subsection{Endereçamento na Internet}

\subsubsection{Endereçamento Universal}

Um sistema de comunicação é dito universal quando possibilita que um indivíduo qualquer se comunique com qualquer outro através de um método global de acesso. Na Internet, esse acesso universal é um endereço IP único [Com95]. 
Em geral, pessoas preferem utilizar nomes para identificar objetos, enquanto que computadores conseguem um desempenho muito maior quando trabalham diretamente com uma representação mais compacta dos dados. Essa dualidade levou à padronização de uma representação ao mesmo tempo numérica e literal de um endereço IP. A representação numérica permite cálculos mais eficientes e, portanto, um roteamento mais eficiente ao mesmo tempo que um esquema de conversão entre os endereços numéricos e um formato alfanumérico permite endereços mais legíveis por seres humanos. A conversão é feita por computadores espalhados pela rede conhecidos como servidores de domínio ou DNS ${ }^{17}$. Juntos, os servidores DNS disponibilizam uma base de dados distribuída que consegue converter um domínio em um endereço numérico [Fei96].

\subsubsection{Classes de endereços IP}

Pensando em uma arquitetura que possibilitasse roteamento eficiente, os projetistas do IP dividiram os endereços de 32 bits em cinco classes de endereços que atenderiam diferentes tamanhos de sub-redes e permitiriam que, facilmente, se extraísse de um endereço qualquer, seu identificador de rede (netid) e de máquina (hostid).

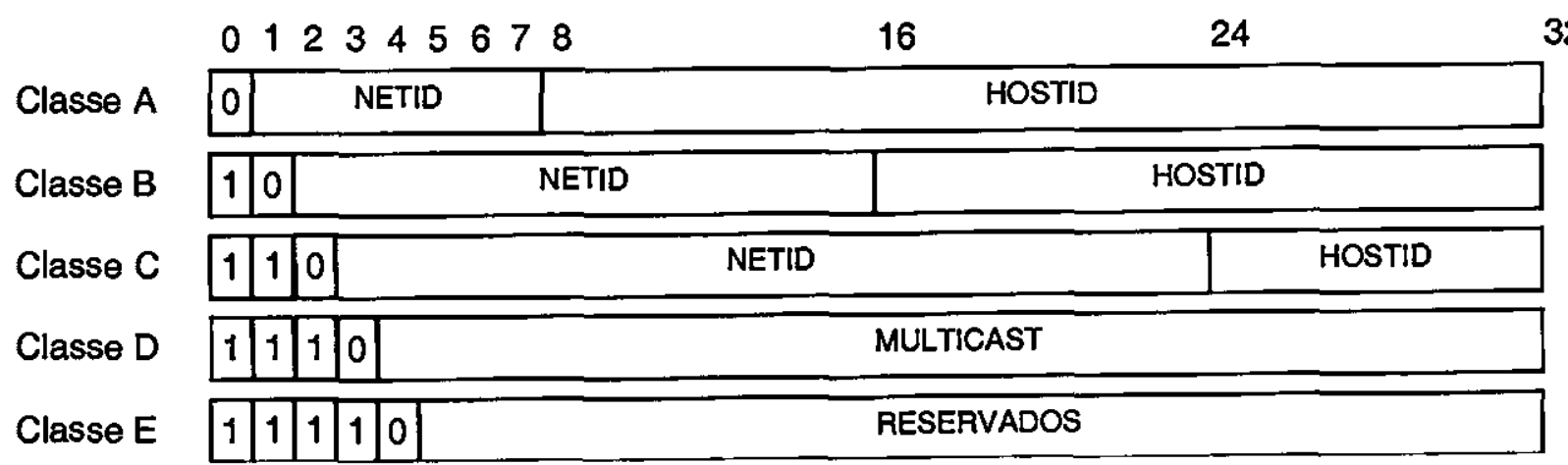

Figura 2-5: Classes de endereços IP (versão 4)

A classe de um determinado endereço IP pode ser determinada examinando os quatro bits superiores do endereço.

${ }^{17}$ DNS - Domain Name Server, Servidores de Domínio de Nome, numa tradução literal. 
- Endereços classe A deveriam ser utilizados por redes com entre $2^{16}(65.536)$ e $2^{24}$ (16.777.216) hosts, e, de acordo com os 7 bits do netid (endereço de rede) comportariam até $2^{7}(128)$ redes dessa categoria;

- Endereços classe B deveriam ser utilizados por até $2^{14}(16.384)$ redes contendo entre $2^{8}(256)$ e $2^{16}(65.536)$ hosts, cada.

- Endereços classe C deveriam ser utilizados por até $2^{21}$ (2.097.152) redes com até 255 hosts, cada;

- Endereços classe D não identificam uma interface de um host ou de um roteador, mas sim um grupo de roteadores e deveriam ser utilizados para multicast, isto é, o endereçamento de um grupo de vários hosts em vez de um único. Entretanto, devido à dificuldade em especificar as interfaces conectadas, eles nunca foram largamente utilizados na Internet [Sta96].

- Endereços classe E (Estendidos) foram reservados para uso futuro;

\subsubsection{Endereços identificando interfaces}

Apesar de cada endereço IP possuir uma componente que identifica a rede (netid) e uma componente que identifica um host (hostid), em alguns casos é necessário que um mesmo equipamento possua mais de um endereço. Por isso, endereços IP devem ser interpretados não como endereços de uma máquina, mas como endereços de uma interface. Baseado nestas definições, um host fica melhor definido como um equipamento (ou parte dele) que possua uma interface de rede [Car97].

\section{REDE 1}

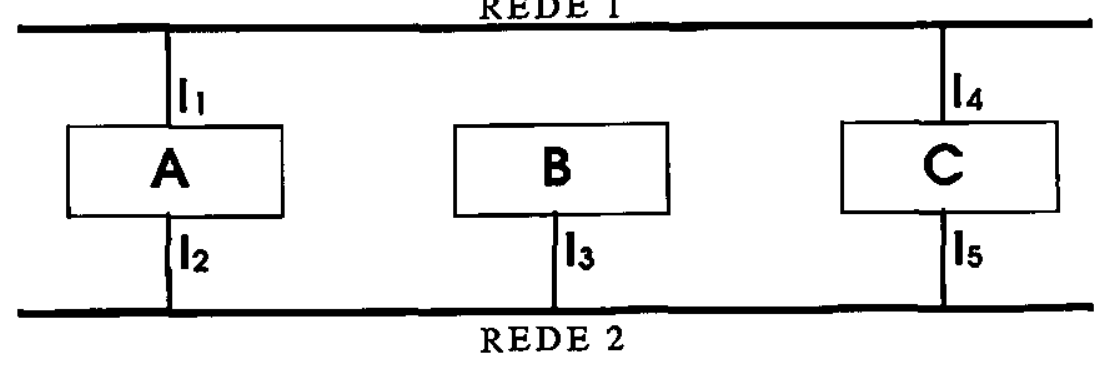

Figura 2-6: Um exemplo de utilização de diversos endereços IP por máquina. 
Na Figura 2-6, os equipamentos A e C são roteadores, e cada um deles possui dois endereços IP: um para cada interface de rede. Isto é necessário porque se, por exemplo, a interface $\mathbf{I}_{2}$ estiver com problemas, o equipamento $\mathbf{B}$ poderá acessar o equipamento $\mathbf{A}$ através da interface $\mathrm{I}_{1}$ [Com95].

\subsubsection{Endereços de rede e broadcast}

No TCP/IP, convencionou-se que 0 valor 0 em hostid nunca seria associado a nenhum equipamento e designaria uma rede especificada por netid; convencionou-se também que um hostid com todos os bits em 1 identificaria um endereço broadcast, ou seja, todos os equipamentos conectados a rede especificada no netid.

Em muitas tecnologias de rede, por exemplo nas redes Ethernet, a idéia de endereçar ao mesmo tempo todos os hosts pode ser tão eficiente quanto uma transmissão normal; em outras, broadcast pode ter que ser feito por software ou simplesmente não existir. Por isso, apesar do IP possuir um esquema de endereçamento broadcast, ele não assegura que a transmissão seja efetuada em broadcast pela camada de enlace [Car97].

\subsection{0 desenvolvimento de aplicações TCP/IP}

Em geral, Sistemas Operacionais que suportam o TCP/IP possuem bibliotecas de funções, ou APIs ${ }^{18}$ que permitem que as aplicações enviem e recebam dados através da camada de transporte do protocolo sem, que precisemmanipular estruturas de baixo nível como pacotes e tabelas de roteamento.

Uma das bibliotecas mais famosas para auxiliar o desenvolvimento de aplicações TCP/IP é a Interface de programação com sockets ${ }^{19}$ que surgiu no UNIX de Berkeley (BSD UNIX 4.2) e depois foi portada para os mais diversos sistemas operacionais, incluindo Windows 95 , Windows 98, Windows NT, Linux, MacOS, Solaris e Irix.

\footnotetext{
${ }^{18}$ API - Application programming interface (Interface de Programação de Aplicações)

${ }^{19}$ sockets programming interface, ou Interface de Programação com Sockets
} 


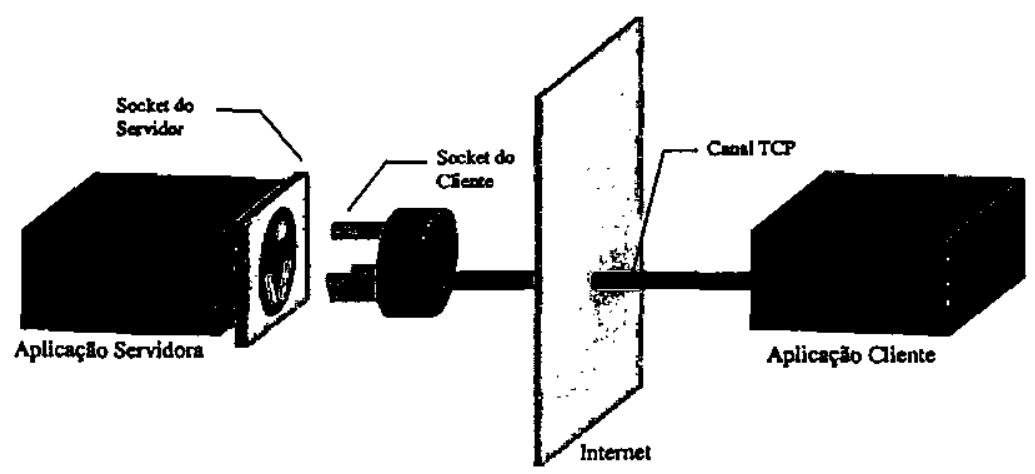

Figura 2-7: A ilustraçāo da utilização de sockets na comunicação através de um canal virtual

Essa entidade, conhecida como um $\operatorname{socket~}^{20}$ (ver Figura 2-7), permite que aplicações recebam ou enviem dados através de um canal de comunicação TCP ou UDP. Como visto anteriormente nas seções 2.2.3 e 2.2.4, canais TCP provêem comunicação confiável orientada à conexão enquanto que UDP provêem comunicação não orientada à conexão e não confiável [Com94].

Sumariamente, a comunicação por sockets envolve os seguintes passos:

1. O Servidor informa ao sistema que está aceitando conexões e em que porto ${ }^{21}$ isto está sendo feito;

2. O Cliente cria um socket dispondo de seu endereço IP, o endereço IP servidor, o tipo de protocolo que deseja utilizar e em que porto ele deverá se conectar ao servidor;

3. Enquanto a conexão permanecer aberta, ambas as partes podem enviar e receber dados do canal através de primitivas de leitura e escrita;

4. Qualquer uma das partes pode encerrar a conexão através de uma primitiva de fechamento;

${ }^{20}$ sockets - soquetes numa tradução literal. A denominação se refere à idéia de conectores que possibilitam o tráfego de dados de um equipamento para outro através de um canal virtual

${ }^{21}$ port - porto: quando uma requisição chega a uma máquina, o sistema procura em uma tabela que relaciona números de porto e aplicações, para saber que aplicação receberá a requisição. 


\subsection{As limitações do IPv4}

\subsubsection{A dificuldade de prever o futuro}

O IP e os demais protocolos que compõem a chamada "família de protocolos TCP/IP" constituem verdadeiros padrões de facto, com memoráveis qualidades que não podem, nem devem, ser esquecidas. Entretanto, não se pode ignorar ue o IPv4 é um protocolo de mais de vinte anos [Oli97].

Seria muito difícil prever em 1978 que a rede atingisse suas proporções atuais. Portanto não se pode culpar os idealizadores do IP por sua ineficiencia no suporte à nova e enorme gama de aplicações que têm sido desenvolvidas para a Internet e da quantidade de novos usuários que devem ser conectados à rede no futuro. Pelo contrário, deles e o crédito de prever mais de vinte anos de evolução nas tecnologias de telecomunicações, software e serviços, e de desenvolver um protocolo tão robusto e flexível a ponto de suportar um crescimento de quase $100 \%$ ao ano durante vinte anos [Bra95].

\subsubsection{Ausência de características de segurança, mobilidade e tempo- real}

No IPv4, o controle de segurança deve ser feito pela aplicação. Nada impede um roteador de capturar um pacote IP, alterar o seu conteúdo e devolvê-lo à rede sem que seja possível identificar a diferença. $O$ problema é que a camada de rede da Internet (IP) não implementa nenhum controle de segurança. Para a Internet das décadas de setenta e oitenta, isso não apresentava maiores consequuências, já que apenas algumas aplicações necessitavam de controle de segurança e o controle podia ser implementada na camada de transporte ou de aplicação. Atualmente, entretanto, características de segurança essenciais para o sucesso da maioria das aplicaç̃es Internet não são bem exploradas com o IPv4.

Mobilidade na Internet também $́$, ainda, uma tarefa complicada. $O$ usuário que está viajando ou se movendo de um lugar para o outro precisa conectar-se ao seu $\operatorname{ISP}^{22}$ usual ou conseguir

${ }^{22}$ ISP - Internet Service Provider, Provedor de Serviços Internet (ou provedor de acesso) 
acessos locais emprestados todas as vezes que desejar estabelecer uma conexão Intemet. No futuro, espera-se que ao desembarcar em um outro país, ele possa utilizar um endereço IP móvel que automaticamente informe aos ISPs locais que ele está "em trânsito" e que estará, temporariamente, utilizando seus serviços.

Transportar dados em tempo-real no IPv4 também não é muito eficiente. Os pacotes são limitados a 64Kbytes de dados, chegam sem ordenamento, ficam retidos em congestionamentos e o protocolo não realiza nenhum tipo de controle de fluxo nem permite às aplicações multimídia aproveitar todas as características das redes que utilizam [Tan96].

A Internet tem evoluído de uma rede de troca de mensagens e arquivos em formato texto para uma rede global que transmite cada vez mais dados multimf́dia como áudio e vídeo além de hipertextos e mensagens eletrônicas. O IPv4, entretanto, não consegue suportar, de uma maneira satisfatória, esse tipo de tráfego e por isso espera-se que, num futuro próximo, algo seja feito para que a Internet possa transmitir dados de tempo real com mais eficiência [Sta96] [Sym94].

\subsubsection{Esgotamento do número de endereços}

Como visto no capítulo anterior, endereços IP são números de 32 bits que referenciam, de forma única, um equipamento na rede; teoricamente $2^{32}$ (4.294.967.296) hosts.

O problema é que devido ao espantoso crescimento da Internet, os endereços IP estão se esgotando e, obviamente, algum dia devem atingir o limite teórico dos quatro bilhões de endereços. Se a curva prevista por Mark Lottor, exibida no capítulo anterior (Figura 1.2) for prolongada, poder-se-ia estimar que o esgotamento total se daria em alguma data entre o ano 2000 e 2015 [Lot97] [Lot99].

A afirmação de que os endereços IP devem se esgotar entre os anos 2000 e 2015 parece ser inverídica quando se questiona se quatro bilhões de endereços não seriam realmente suficientes para uma rede mundial de computadores num planeta onde, provavelmente, nem todas as 6 bilhões de pessoas estarão conectadas à Intemet até o ano 2000. Entretanto, o problema não é só que existem poucos bits - na verdade, poucos quando se vislumbra a possibilidade de centenas de computadores para cada pessoa no planeta e endereços IP para todos eles - mas também a 
forma com que eles são utilizados. O esquema hierárquico de escolha de endereços no IPv4 faz com que muitos endereços sejam desperdiçados [Sta96] [Sag98].

Por exemplo, se uma rede classe $\mathrm{C}$ com suporte a ate 255 hosts possui 20 computadores conectados, 235 endereços IP (92\%) são desperdiçados e não podem ser atribuídos a nenhum outro usuário fora da rede. Há algum tempo atrás seria comum fornecer um endereço classe $\mathrm{B}$ para uma Instituição que desejasse conectar à Intemet cerca de 1000 hosts - um desperdício de 98\% dos endereços de uma classe que comporta de 256 a 65536 hosts [Com95].

Na verdade, há alguns anos, percebeu-se que se a atribuição de endereços continuasse seguindo a risca o esquema de classes $\mathrm{A}, \mathrm{B}, \mathrm{C}$, em pouco tempo não haveria mais endereços disponíveis. $\mathrm{O}$ INTERNIC $^{23}$ passou a ser mais rigoroso nas atribuições, fornecendo classes $C$ ao invés de classes B para as situações onde o desperdício fosse tão elevado, revogar endereços já atribuídos e mesmo assim não foi suficiente. Se não fosse a introdução do $\mathrm{CIDR}^{24}$ (Protocolo de Roteamento Interdomínio sem classes), provavelmente hoje os endereços IP já teriam se esgotado [Hiu96] [Fiu98].

O CIDR permite alocar dentro de classes A e B, diversas redes classe C. O CIDR possibilita ainda que sub-redes diferentes possam compartilhar mesmas classes $C$ [Ful93].

Entretanto, essa é uma solução paliativa que aumenta as tabelas de roteamento e diminui a performance dos roteadores [Rek93].

Hiutema [Hiu94] propôs uma maneira de avaliar o desperdício de enderȩ̧os em termos de uma taxa $(\mathrm{H})$ que medisse o número de endereços alocados pelo número de bits disponíveis; na verdade o logaritmo na base 10 do número de endereços alocados pelo número de bits utilizados.

\footnotetext{
${ }^{23}$ INTERNET NIC-Network Information Centre (Centro de Informações sobre a Internet) ${ }^{24}$ CIDR - Classless Inter-Domain Routing (Protocol)
} 


$$
\mathrm{H}=\frac{\log _{10} \text { (número de endereços) }}{\text { número de bits }} \quad \begin{aligned}
& \text { número de } \\
& \text { endereços }
\end{aligned}=10^{\text {(número de bits * } \mathrm{H})}
$$

Se a alocação fosse perfeita ( 2 endereços para 1 bit, 8 endereços para 3 bits, 1024 endereços para 10 bits, etc.) a taxa $\mathrm{H}$ seria de $0,301029995664\left(\log _{10} 2 / 1=\log _{10} 8 / 3=\log _{10} 1024 / 10\right)$. Hiutema estirnou essa taxa de alocação em várias redes e constatou que, mesmo após o CIDR, a taxa $\mathrm{H}$ ainda continuava bastante insatisfatória. Ela varia aproximadamente entre 0.22 e 0.26 , o que permite, corn os 32 bits atuais, uma alocação de entre 11.000 .000 e 209.000.000 hosts, um número rnuito abaixo dos 4 bilhões teóricos que acabariam depois do ano 2000 [Lot97][Hiu94].

A solução mais intuitiva é, antes que o esgotamento total ocorra e se torne impossível conectar mais equipamentos à Internet, rnudar a versão do protocolo e atribuir mais bits de endereço nos campos do cabeçalho [Hiu96].

\subsection{Considerações Finais}

Este capitulo abordou as principais vantagens e desvantagens de um dos principais motivos do sucesso da Internet - o Protocolo Internet. O IP sempre esteve à frente do seu tempo, e é atualmente, a base da cornunicação de dados no mundo. Entretanto, já começa a exibir os sinais de desgaste de um design de quase vinte anos e se mostra ineficiente para suportar o futuro da Internet. O próximo capítulo irá tratar sobre o IPv6, a nova versão do IP 
"Existem os que pensam que o número de gräos de areia (no mundo) é infinito. Existem os que, sem pensar no infinito, imaginam que näo existe como nomear um número tão grande. Mas tentarei mostrar-lhes números que excedem năo só o número de grãos de areia equivalentes à massa da terra mas também, em magnitude, à massa do Universo.

(Aquimedes.)

"A melhor maneira de prever o futuro é construt-lo"

(Alan Kay)

\section{IPv6: A nova versão do Protocolo Internet}

\subsection{Características gerais}

O IPv6, ou a versão 6 do Protocolo Internet ${ }^{25}$, é baseado em uma filosofia: a de que a Internet não teria sido tão bem sucedida se a versão 4 não fosse realmente muito boa; portanto, qualquer coisa que a sucedesse deveria herdar o máximo possível das suas características. Na verdade, chegou-se até a cogitar uma mudança apenas no espaço de endereçamento; alterar-se-ia a versão, far-se-iam pequenas modificações nos softwares de roteamento e em pouco tempo tudo poderia voltar ao normal [Hiu96].

Entretanto, vinte anos de experiência com o TCP/IP trouxeram lições. O IPv6 foi desenhado com base neste conhecimento adquirido por centenas de especialistas ao longo de anos de tentativas, erros e acertos desenvolvendo aplicações TCP/IP. Essa é a razão para se afirmar que - IPv6 é muito mais que apenas uma extensão do espaço de endereçamento do IPv4 - é uma evolução da arquitetura consagrada do IPv4, conduzida, acima de tudo, pela luz da experiência [Hin96] [Los98] [Kas94].

Um dos objetivos primordiais que norteou o desenvolvimento do IPv6 que ele pudesse substituir o IPv4 gradativamente e não de uma maneira radical. É impossível imaginar que milhões de

${ }^{25}$ O IPv6 não se chama IPv5 porque a versão 5 já havia sido alocada para um protocolo experimental de suporte a tráfego tempo-real conhecido como Stream Protocol (ST) 
computadores $^{26}$, e um número ainda incalculável de usuários, tenham todas as suas bibliotecas atualizadas e migrem para o IPv6 em um curto espaço de tempo. O IPv6 foi projetado para coexistir indefinidamente com o IPv4 e para permitir que a Intemet aproveite suas características sem nunca ter que passar por um período de caos [Bra95b] [Hin96] [Car94].

As mudanças não são revolucionárias, mas solucionarão o problema do esgotamento de endereços, permitirão um roteamento mais eficiente e adicionarão novas características de segurança e controle de congestionamento. Além disso, farão com que se aproveitem melhor as tecnologias de rede que têm surgido desde o estabelecimento do IP, como por exemplo, FDDI e ATM [Bra95a] [Hin96] .

\subsection{0 formato de um pacote ${ }^{27}$ IPv6}

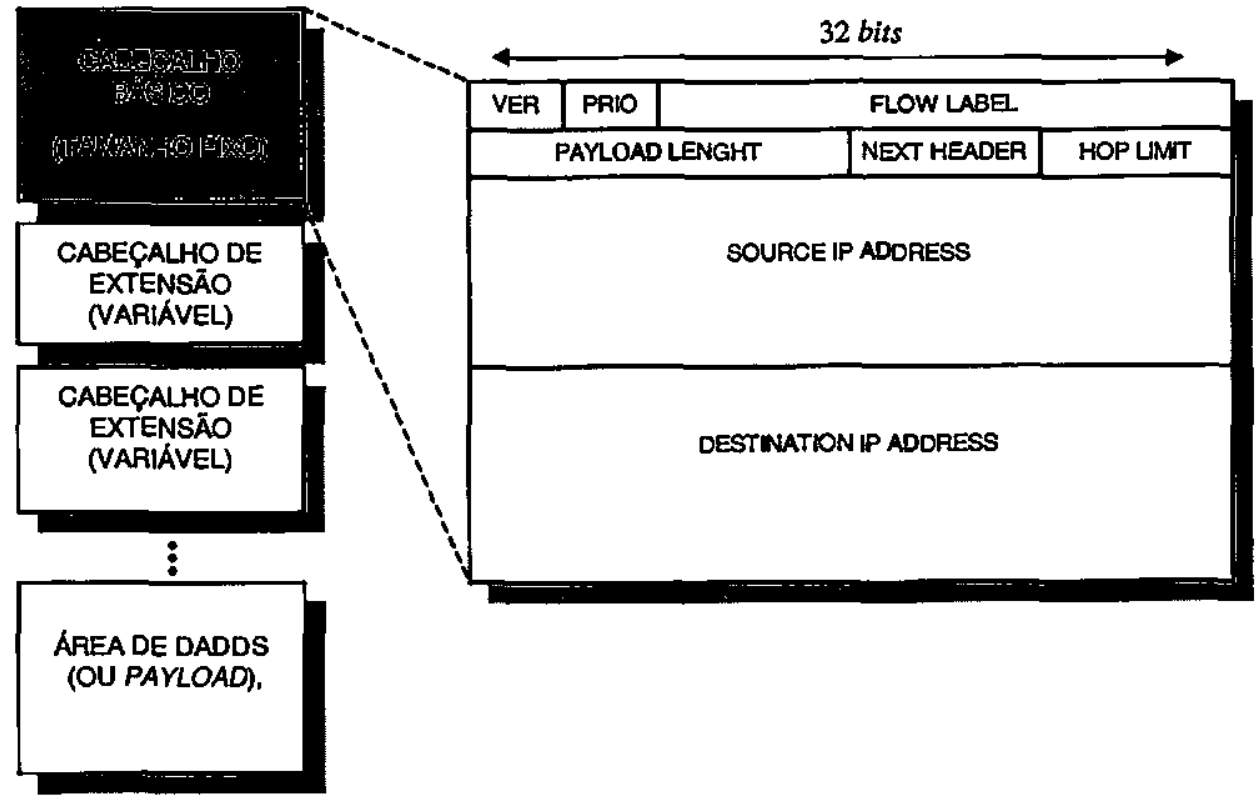

Figura 3.1 • Formato de um pacote IPv6

${ }^{26}$ pela última medição de Lottor [Lot99] em janeiro de 1999. Teoricamente esse número deve continuar aumentando mesmo durante o período de transição entre o IPv4 e o IPv6;

${ }^{27}$ A especificação do IPv6 recomenda o uso do termo pacote ao invés de datagrama. Essa nomenclatura ajuda a reforçar a diferença e a idéia de que pacotes IPv6 possam ser maiores que os datagramas IPv4. 


\begin{tabular}{|r|c|l|}
\hline VERSION & 4 & Versāo do protocolo -6 \\
\hline PRIORTYY & 4 & Prioridade de envio do pacote \\
\hline FLOW LABEL & 24 & Fluxo de dados \\
\hline PAYLOAD LENGHT & 16 & Tamanho dos dados em bytes (sem contar o cabeçalho) \\
\hline NEXT HEADER & 8 & Identificador do próximo cabeçalho de extensão ou de transporte \\
\hline HOP LIMTT & 8 & Número máximo de hops para o pacote não ser desprezado \\
\hline SOURCE ADDRESS & 128 & Endereço IP do remetente \\
\hline DESTINATION ADDRESS & 128 & Endereço IP do destinatário \\
\hline
\end{tabular}

Tabela 3-1: campos do cabeçalho de um pacote IPv6

\subsubsection{Simplicidade e funcionalidade}

Comparando-se a Figura 2-4, do capítulo anterior, e a Figura 3.1, pode-se perceber que o cabeçalho do Ipv6 é bem mais simples que o do IPv4 e que, apesar de o número de bits de endereçamento ter sido quadruplicado, o novo cabeçalho não ultrapasse o dobro do tamanho mínimo do antigo.

Campos foram modificados, alterados e adicionados e, na verdade, o único campo que não sofreu nenhuma alteração, seja no tamanho, seja no significado, foi o campo VষR, que especifica a versão do protocolo. Originalmente até cogitou-se a possibilidade utilizar os mesmos drivers e permitir que o IPv4 e o IPv6 rodassem simultaneamente na mesma rede, alterando-se apenas o software de processamento do pacote no nível de rede. Essa idéia foi praticamente abandonada porque percebeuu-se que se o IPv4 e o IPv6 pudessem ser transmitidos de forma diferente pelo nível físico, as tecnologias de rede poderiam obter maiores vantagens do novo protocolo [Hin96b].

De fato, diversas padronizações têm sido estabelecidas permitindo que as tecnologias de rede sejam utilizadas de maneira mais eficiente pelo novo protocolo. Dentre elas, podemos citar IPv6 sobre Ethemet [Cra98], FDDI [Cra96b], PPP [Ham99] e ainda esforços de padronização de suporte a IPv6 em redes ARCNet [Sou97] e Token Ring [Cra98b]. 


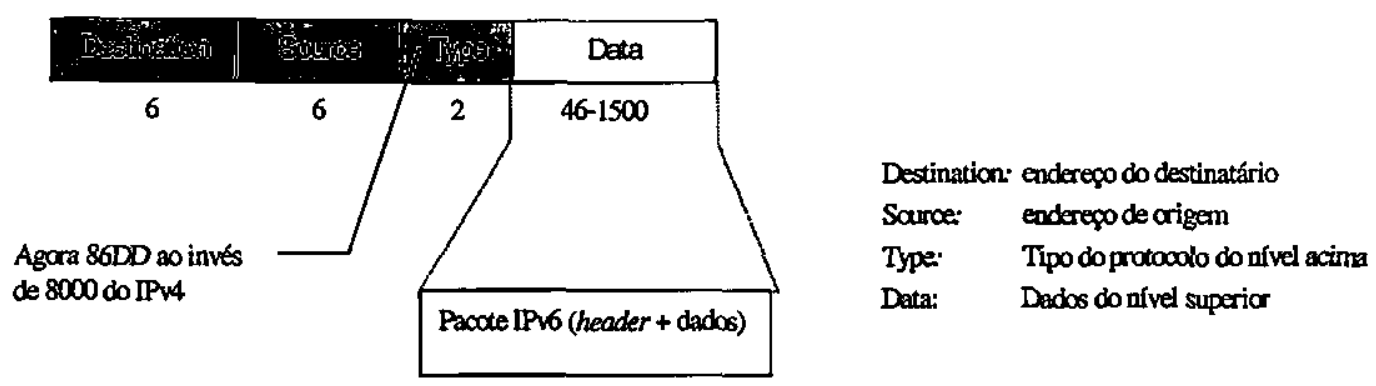

Figura 3.2 - estrutura de um frame Ethernet abrigando um pacote IPv6

A Figura 3.2 exibe a estrutura de um frame Ethernet e como um pacote IPv6 seria transmitido. Note-se a definição do valor $86 \mathrm{DD}$ para o campo type que possibilitará a transmissão de pacotes maiores $\left(\mathrm{MTU}^{28}\right)$ [Mil98] .

\subsubsection{Remoção de campos}

O IPv4 foi projetado com base no estado da arte da tecnologia da época em que ele foi desenvolvido. Entretanto, vinte anos mais tarde, as tecnologias que compõem os equipamentos e os meios de comunicação diferem radicalmente das linhas telefônicas e mainframes utilizados na década de setenta. Muitas opções tornaram-se inúteis, outras muito pouco utilizadas e a experiência mostrou que muitas poderiam ser melhoradas se modificassem a maneira de abordar o problema.

Em relação às mudanças estruturais, três delas exemplificam bastante essa evolução da abordagem com base no conhecimento empírico adquirido ao longo dos anos:

- Padronização do tamanho do cabeçalho (fixo em 40 bytes);

- Exclusão da verificação de integridade (ckecksum) do cabeçalhor,

- Exclusão das técnicas tradicionais de fragmentação;

${ }^{28}$ MTU - Maximum Transfer Unit, Unidade Máxima de Transferência, referência à quantidade de octetos que podem trafegar dentro de um frame. 
A padronização do tamanho do cabeçalho e, conseqüentemente, a exclusão do campo \#LEN ocorreram porque no IPv6, em vez de fazerem parte do cabeçalho básico, as opções são transportadas por um cabeçalho de extensão, independente do cabeçalho principal A maioria das aplicações não utilizavam com frequência campos opcionais, ao passo que os roteadores sempre tinham que controlar a variação do tamanho do cabeçalho através do campo HLFN. Gastava-se ainda tempo preenchendo o pacote até completar um octeto de dados, visto que o campo ILEHN representava o tamanho do cabeçalho em múltiplos de 8 bytes (padding).

A idéia de criar um cabeçalho de op̧̧ões separado do principal não só aumenta a performance do roteamento mas permite que novas opções sejam mais facilmente inseridas no pacote. Além disso, cabeçalhos de extensão do IPv6 podem ser de tamanho arbitrário e não ficam limitados ao tamanho máximo de 40 bytes imposto pelo IPv4 [Par95].

A exclusão da checagem de integridade do cabeçalho (header checksum) pode parecer uma decisão arriscada; uma mudança que possibilitará um ganho de velocidade (o software de roteamento não precisará mais computar o checksum de cada pacote que processar) mas que, ao mesmo tempo, poderia causar problemas muito graves (se o cabeçalho de um pacote for corrompido o endereço do remetente pode mudar, ou a versão do protocolo, ou o tamanho do cabeçalho, etc.). Na verdade, muitos projetistas ainda consideram este um risco muito grande "É o mesmo que remover os freios de um automóvel para deixá-lo mais veloz" — alguns diziam. Entretanto, o risco não é tão iminente se considerarmos que a maioria das tecnologias de rede atuais já é bastante confíavel e provê seus próprios métodos de controle de integridade no nível de enlace.

A remoção do campo Tos (Type of Service) ocorreu porque estatísticas comprovaram que a grande maioria dos algoritmos de roteamento não utilizava essa característica do IPv4. Como visto no capítulo anterior, esse campo deveria ser preenchido pelas aplicações com informações sobre o pacote e permitir que os roteadores pudessem realizar um roteamento adequado ao conteúdo. O IPv6 provê um mecanismo denominado "controle de fluxo" que consegue abordar esse problema de uma forma muito mais abrangente, permitindo que os roteadores interpretem fluxos de dados como um conjunto ou uma seqüência e não como dados individuais. 
A remoção da técnica de fragmentação também é uma característica interessante do IPv6. Como anteriormente na seção 2.3, a fragmentação permitia que as aplicações IPv4 enviassem dados utilizando TCP ou UDP sem se preocupar com a capacidade do meio físico. Se necessário, isto é, se um pacote fosse maior que o tamanho máximo permitido para um frame de uma determinada tecnologia de rede, o pacote seria fragmentado e os fragmentos seriam transmitidos separadamente. Cada receptor deveria montar os fragmentos, gerar um novo pacote e reenviá-lo. O problema é que, além do esforço computacional despendido para desmontar e remontar os pacotes em cada roteador, quando um único segmento era perdido, todo o pacote tinha que ser retransmitido, resultando numa utilização ineficiente da rede. Mais uma vez, os anos de experiência trouxeram lições: a experiência com o $\mathrm{MTU}^{29} \mathrm{em}$ alguns sistemas Unix, como o Linux, mostrou que a unidade de controle deveria ser a mesma unidade de transmissão. No IPv6, antes de enviar um pacote, os hosts devem determinar a capacidade da rede executando um procedimento chamado de path MTU discovery. O MTU garante que os pacotes enviados sejam de um tamanho compatível com os frames da camada inferior, eliminando a necessidade de um controle automático de fragmentação [Hiu96][Mcc96].

\subsubsection{Reformulação de campos}

O campo WLEN ou total lenght, que determinava o tamanho total do pacote (cabeçalho+dados), foi renomeado para payload length ${ }^{30}$ (tamanho da área de dados) já que agora o tamanho do cabeçalho é fixo. No IPv4, os pacotes só podiam ter $64 \mathrm{~Kb}$ de tamanho já que o tamanho do TLEN era de 16 bits, mas no IPv6 os pacotes podem ter tamanhos extremamente superiores a isso. O campo payload length continua limitado a 16 bits, mas se ele for preenchido com ' 0 ' e um cabeçalho "jumbograma" ${ }^{31}$ for adicionado, os pacotes podem ter valores praticamente ilimitados [Hiu96].

Esta decisão de limitar o tamanho do pacote a $64 \mathrm{~Kb}$, um dos pontos de maior controvérsia no Projeto do IPv6, foi baseada na idéia de que o overhead criado por um cabeçalho de 40 bytes

\footnotetext{
${ }^{29}$ MTU - Maximum Transfer Unit - Unidade Máxima de Transferência;

${ }^{30}$ payload length - tamanho da carga; numa tradução literal;

${ }^{31}$ jumbograma - uma alusão a um grande datagrama
} 
num pacote de $64 \mathrm{~Kb}$ é de apenas $0,06 \%$; pacotes de tamanho muito maior (que poderiam causar um overhead significativo) devem ser enviados através da opção "jumbograma" [Pos96].

O campo Protocol Type (tipo do protocolo), que na verdade determinava o tipo do dado que estava sendo carregado, foi renomeado para next headex type, já que no IPv6, antes dos dados ainda existem cabeçalhos de extensão, cada um com um campo next headex type que define o que virá depois, por exemplo outro cabeçalho de opção, ou um bloco TCP. A Figura 3.3 exibe um pacote IPv6 que carrega um cabeçalho de roteamento e um cabeçalho TCP. Em cada cabeçalho o campo next headex type é preenchido com o tipo do próximo.

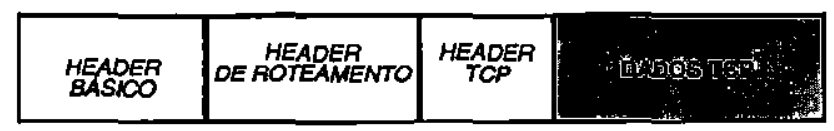

Figura 3.3 - Encadeamento de cabeçalhos de extensāo no IPv6

O campo TrTL - Time to Live (tempo de vida) foi renomeado para hop limit (limite de hops), já que se provou ser extremamente difícil seguir, à risca, a recomendação do IPv4 e desenvolver softwares de roteamento que conseguissem decrementar exatamente o número de segundos despendidos no processamento do pacote. Na verdade, o que se fazia, na maioria dos casos, era decrementar de 1 o campo, cada vez que o pacote era processado. A mudança do nome veio também para oficializar essa solução. Protocolos de transporte que desejem um controle mais preciso do tempo de vida do pacote do que o provido pelo campo hop limit podem utilizar cabeçalhos de extensão e prover, por exemplo, um controle temporal com precisão de milissegundos.

\subsubsection{Adição de características de controle de fluxo}

O campo Tos (que continha os subcampos $D, T, R$, e precedence) foi renomeado para prioxity (prioridade) também para refletir sua verdadeira utilização. No IPv4, as aplicações já utilizavam o subcampo precedence para determinar (em 16 possíveis valores) que alguns pacotes deveriam ter prioridade em relação a outros, mas quase nunca utilizavam os três bits $\mathbf{D}, \mathbf{T}, \mathbf{R}$. 
No IPv6, em vez dos três bits, o controle de tráfego e congestionamento é feito por um campo denominado flow label ${ }^{32}$ (fluxo), que adiciona ao protocolo características de $\mathrm{QOS}^{33}$ e controle de congestionamento.

Segundo a especificação do IPv6, esse tráfego de pacotes com características de QoS e controle de congestionamento é denominado fluxo, e é definido formalmente como "uma sequiência de pacotes que viaja de um remetente qualquer para um destinatário qualquer com necessidade de um tratamento especial por parte dos roteadores".

Do ponto de vista do usuário, um fluxo é uma sequiência de pacotes com requisitos de transferência semelhantes e que, portanto, devem ser tratados como um conjunto e não como itens isolados. Um exemplo clássico da utilização de fluxo é o transporte de dados em uma videoconferência. Neste exemplo, as seqüências de vídeo poderiam ser transportadas através de um fluxo (fluxo de vídeo) diferente do fluxo que abrigaria as sequiências de áudio (fluxo de áudio), refletindo assim as diferenças em termos de taxas de transmissão requeridas, atrasos mínimos e máximos, etc.

Para um roteador, entretanto, o conceito de fluxo de dados pode permitir um roteamento mais justo ao possibilitar que o processamento dos pacotes da seqüuência seja feito de maneira semelhante para todos os pacotes do fluxo (seja na escolha entre um caminho curto e instável ou um caminho longo e confiável, na alocação de buffers menores ou maiores ou na adoção de determinado nível de segurança).

Os usuários também poderão negociar fatores de QoS e garantir que, para um determinado fluxo, uma certa capacidade de transmissão seja assegurada [Sta96].

O campo priority permite estabelecer 8 valores de prioridade (de 0 a 7) para transmissões comuns e 8 valores (de 8 a 15) para transmissões de tempo-real, o que permite que os roteadores

32 flow label - rótulo do fluxo, numa tradução mais literal. Refere-se a um valor que será colocado no campo e diferenciará diferentes fluxos passando por um mesmo roteador.

${ }^{33}$ QoS - Quality of Service - Qualidade de Serviço 
decidam se determinados pacotes podem ou não ter seu tráfego reduzido durante a ocorrência de um congestionamento.

\subsection{Endereçamento no novo IP}

\subsubsection{0 poder de 128 bits}

Sem dúvida, a característica mais evidente do IPv6 é a sua enorme capacidade de endereçamento. Os endereços de 128 bits são 4 vezes maiores que os do IPv4 e ocupam cerca de 75\% do cabeçalho de um pacote IPv6.

Com 128 bits $\left(2^{128}\right)$ é possível representar números da ordem de $3.4 * 10^{38}$, ou seja, 340.282.366.920.938.463.463.374.607.431.768.211.456 endereços; o suficiente, por exemplo, para suprir vários bilhões de endereços $\mathbb{P}$ por metro quadrado da superfície da Terra.

À primeira vista, a escolha de 128 bits parece ser uma decisão exagerada e talvez realmente seja, mas a previsão de muitos anos futuros de evolução nem sempre pode ser feita com precisão.

Segundo estimativas de crescimento populacional fornecidas pela $\mathrm{ONU}^{34}$ [Sag98], em 2020 o planeta deverá ter cerca de 10 bilhões de habitantes, cada um deles servido por um grande número de computadores, provavelmente em sua grande maioria conectados à Internet. A idéia de cada ser humano servido por centenas de computadores também pode parecer exagerada, mas não pode ser considerada absurda quando se imagina a possibilidade de que equipamentos domésticos, automóveis e objetos comuns sejam controlados por computador (o que já acontece atualmente) e que todos estejam conectados à Internet. 100 computadores por habitante representariam 1 trilhão de computadores em 2020, mas a experiência mostrou que se deveria continuar buscando margens mais seguras. Por isso o IPv6 foi projetado para ser capaz de conectar quatrilhões de computadores $\left(10^{15}\right)$ no próximo milênio [Sta96].

\footnotetext{
${ }^{34}$ ONU - Organização das Nações Unidas
} 
Voltando à taxa $\mathrm{H}$, proposta por Hiutema [Hiu94] e discutida anteriormente na seção 2.6.3, observa-se que, para uma taxa $\mathrm{H}$ igual a $0.22,68$ bits seriam necessários para garantir a conexão de 1 quatrilhão de computadores (62 bits para uma taxa de 0.26 ou 64 bits para uma taxa de 0.23). Houve muita discussão entre a adoção de 64 ou 128 bits, mas prevaleceu a escolha que garantirá, mesmo no pior dos casos, uma alocação confiável e espaço extra para armazenar muitos outros níveis de hierarquia além dos níveis de rede, sub-rede e host do IPv4 [Hiu96].

\subsubsection{Uma nova representação numérica}

Representar os 128 bits do IPv6 da mesma maneira que endereços IPv4 são representados atualmente geraria endereços bastante grandes, como por exemplo 255.05.0.12.0.0.0.0.0.0.0.0.0.0.172.100. Por isso, os enderę̧ $\mathrm{Pv} 6$ são representados através de uma notação hexadecimal, onde grupos de 16 bits são separados por sinais de dois pontos (:). Desta forma, o endereço anterior poderia ser escrito como FF05:000C:0000:0000:0000:0000:0000:AC64. No IPv4, já se eliminavam os zeros à esquerda de cada campo, e esta simplificação continua valendo no IPv6; o endereço anterior, portanto, poderia ser escrito da forma FF05:C:0:0:0:0:0:AC64.

Como um grande número de zeros será freqüente, pelo menos nos primeiros anos de operação com o IPv6, uma outra simplificação foi introduzida. A idéia é que, quando duas metades de um endereço forem separadas por grandes grupos de zeros, o endereço poderá também ser escrito como composto de duas partes separadas por um sinal de dois pontos duplo(::). Com esta simplificação, o endereço anterior poderia ser escrito na forma FF05:C::AC64. A expansão também é simples, visto que todos os endereços IPv6 possuem um tamanho fixo de 128 bits: a primeira metade que antecede o sinal de dois pontos duplo é preenchida no começo do endereço e depois, zeros são adicionados até que a segunda metade alcance a 'parede' direita do endereço. Uma outra notação interessante é a que permite escrever endereços IPv4 de uma maneira similar à que é utilizada atualmente. Como endereços IPv4 no IPv6 são compostos de 96 bits zero seguidos de 32 bits do endereço IPv4, no IPv6 eles podem ser escritos da forma ::IPv4. Por exemplo, o endereço IPv4 154.107.53.13 pode ser escrito como :: 154.107.53.13. 


\subsubsection{Uma nova concepção da arquitetura de endereços}

No Pv4, como visto anteriormente na seção 2.4.1, cada endereço Pv4 identifica uma interface, e não um equipamento; no Pv6 essa noção foi ainda mais explorada fazendo com que cada interface possa ser referenciada por vários endereços, permitindo novas formas de endereçamento que proporcionarão um roteamento mais eficiente.

A experiência com o IPv4 também mostrou que as aplicações da Intemet atual requerem muito mais do que endereços unicast e um fraco esquema de endereçamento multicast implementado pelos endereços classe D do Pv4. O IPv6, entretanto, implementa claramente três tipos de endereço:

- Unicast - é um novo nome para um endereço que identifica uma única interface, também conhecido como endereço ponto-a-ponto;

- Multicast - referencia grupos de interfaces. Na maioria das vezes grupos de interfaces representam grupos de equipamentos, mas um equipamento pode conter várias interfaces e cada interface no Pv6 pode ser acessada por meio de endereços diferentes;

- Anycast - endereços anycast são semelhantes aos multicast, ou seja, referenciam grupos de interfaces, mas com uma diferença: um pacote enviado para um endereço anycast será direcionado para a interface mais próxima do transmissor.

\subsubsection{Endereços unicast - tipos diferenciados para cada tipo de usuário}

Uma análise dos usuários da Internet mostrou que, basicamente, existem três tipos de usuários:

- Usuários que pertencem à rede de uma organização que já está conectada à Internet Cada host já possui o seu próprio $\mathbb{P}$, único globalmente, e utiliza esse endereço para comunicação interna e extema. Este é o caso, por exemplo, de algumas estações de trabalho no ICMC;

- Usuários que pertencem à rede de uma organização que não está conectada à Internet (normalmente a Intranet de uma organização)

No momento que esta organização for conectada à Intemet, vários endereços $\mathbb{P}$ deverão ser fomecidos para que cada host dentro dessa organização seja único também na Intemet. 
- Usuários individuais (teoricamente móveis), conectados por links de telefone ou rádio

Deveriam utilizar um endereço que lhes fornecesse mobilidade de modo que eles não fossem obrigados a alterá-lo cada vez que alterassem sua posição no espaço.

As três classes de endereços unicast do IPv4 não conseguem modelar, de uma forma razoável, as diferenças entre esses três tipos de usuários; o que é natural, já que na época da criação do TCP/IP era difícil imaginar que o acesso à Internet pudesse se dar de outra forma senão através de grandes mainframes pertencentes à redes de grandes organizações.

O IPv6, entretanto, possui três tipos de endereços unicast projetados, justamente, para suportar essas diferenças e ainda vários outros tipos de endereços como endereços multicast, anycast e dezenas de outros reservados para uso futuro.

\subsubsection{Endereços unicast}

No IPv6, os três tipos básicos de endereços unicast são:

- Endereços unicast baseados em um Provedor de acesso (Provider-based unicast address): Quando uma organização se conecta através de um provedor de acesso (ISP - Internet Service Provider), o provedor atribui a seus membros um endereço IP que eles devem utilizar para se conectar à Intemet. $\mathrm{O}$ mecanismo básico para atribuição desses endereços é muito semelhante ao mecanismo atual, derivado do CIDR, que já se encontra em funcionamento. A Figura 3.4 exibe o formato deste tipo de endereço [Bou96].

\begin{tabular}{|c|c|c|c|c|c|}
\hline 3 bits & $\mathrm{n}$ bits & m bits & o bits & $p$ bits & $128-(3+n+m+0+p)$ bit \\
\hline 010 & $\begin{array}{l}\text { IDPO } \\
\text { ORGAO DE } \\
\text { REGISTRO }\end{array}$ & $\begin{array}{l}\text { ID DO } \\
\text { PROVEDOR }\end{array}$ & $\begin{array}{c}\text { ID DO } \\
\text { SUBSCRIBER }\end{array}$ & $\begin{array}{l}\text { ID DA } \\
\text { SUBREDE }\end{array}$ & $\begin{array}{l}\text { ID DA } \\
\text { INTERFACE }\end{array}$ \\
\hline
\end{tabular}

Figura 3.4 - O formato de um endereço IPv6 unicast baseado em Provedor de acesso.

- Endereços de uso local baseados em um Site (Site-local-use addresses) Podem ser associados a uma Intranet e quando, mais tarde, a organização decidir se juntar à Internet, todos os endereços locais do site passam a ser endereços globais com a realização 
de um procedimento administrativo relativamente simples. A Figura 3.5 exibe o formato deste tipo de endereço [Bou96].

\begin{tabular}{|c|c|c|c|}
\multicolumn{2}{c}{10 bits } & n bits & \multicolumn{2}{c|}{ p bits } & 128-(10+n+p) bits \\
\hline 1111111011 & $000 \ldots 0$ & SUDBRA & ID DA \\
& & INTERFACE \\
\hline
\end{tabular}

Figura 3.5 - O formato de um endereço IPv6 unicast de uso local baseado em um Site.

- Endereços de uso local baseados em um Link (Link-local-use addresses) Serão usados por indivíduos que utilizam um link simples para se conectar à Internet. Por exemplo usuários com computadores portáteis acessando a rede por meio de linhas telefônicas (voz ou ISDN ${ }^{35}$ ), rádio, etc. A Figura 3.6 exibe o formato deste tipo de endereço [Bou96].

\begin{tabular}{|c|c|c|}
\multicolumn{2}{c|}{10 bits } & 118-n bits \\
\hline 1111111010 & $000 \ldots . .0$ & $\begin{array}{c}\text { ID DA } \\
\text { INTERFACE }\end{array}$ \\
\hline
\end{tabular}

Figura 3.6 - O formato de um endereço IPv6 unicast de uso local baseado em um link

\subsubsection{Endereços multicast}

A Figura 3.7 exibe o formato de um endereço IPv6 multicast, que permite endereçar, de uma s6 vez, diversas interfaces pertencentes a um mesmo grupo.

\begin{tabular}{|c|c|c|c|}
\hline \multicolumn{3}{|c}{4 bits } & \multicolumn{2}{c}{4 bits } & 112 bits \\
\hline 11111111 & FLAGS & ESCOPO & iD DO \\
& & GRUPO \\
\hline
\end{tabular}

Figura 3.7 - O formato de um endereço multicast no IPv6.

${ }^{35}$ ISDN (Integrated Services Digital Network)- Rede Digital de Serviços Integrados: padrão que prevê a transmissão de dados e voz no mesmo meio físico e que será, provavelmente, a base da telefonia no futuro; 
O campo flags permite indicar se o endereço é permanente ou temporário e o campo escopo determina o escopo do grupo, isto é, basicamente se ele é local ou global. Na verdade, o campo flags contém três bits reservados para uso futuro e um outro ( $\mathrm{T}$, o primeiro), que determina se o endereço é temporário ou permanente. O campo escopo permite 16 valores de escopo diferentes, dentre eles o valor 5, que indica que um endereço é local, e 14 ('E' em hexadecimal), que indica que um endereço é global.

Servidores NTP, por exemplo, utilizarão endereços multicast para enviar e receber mensagens utilizando um identificador de grupo com valor 43 (em hexadecimal). Para eles, o endereço permanente FF05::43 representa todos os servidores NTP de um mesmo site, enquanto que FF0E::43 endereça todos os servidores NTP da Internet [Sta96].

\subsubsection{Endereços anycast}

Endereços anycast são semelhantes aos endereços multicast só que, em vez de endereçar todas as interfaces do grupo endereçam somente a interface mais próxima do remetente (na verdade, a de menor custo).

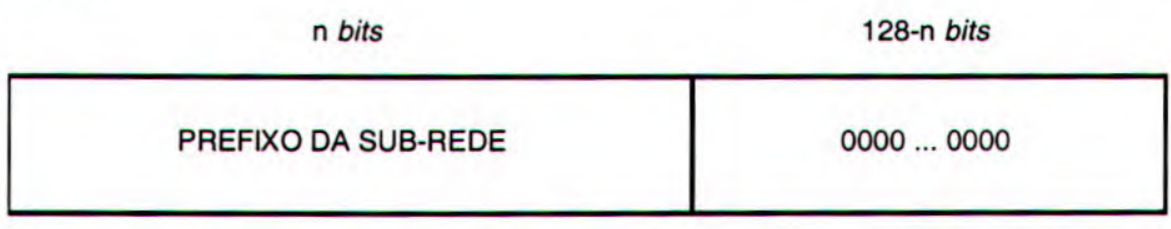

Figura 3.8 - O formato de um endereço anycast no IPv6

Um exemplo da utilização de endereços anycast seria no endereçamento de roteadores intermediários em um caminho. Diversos roteadores intermediários poderiam fazer parte de um grupo anycast e, desta forma, um pacote endereçado ao grupo alcançaria, na verdade, o roteador que proporcionasse o menor custo (por exemplo o menos congestionado ou o mais próximo) [Hiu96]. 


\subsubsection{Uma distribuição voltada para o futuro}

Como dito anteriormente, os 128 bits do IPv6 são suficientes para abrigar os quatrilhões de endereços que devem estar conectados à Internet no próximo século, e ainda suficientes para reservar um grande número de endereços para uso futuro.

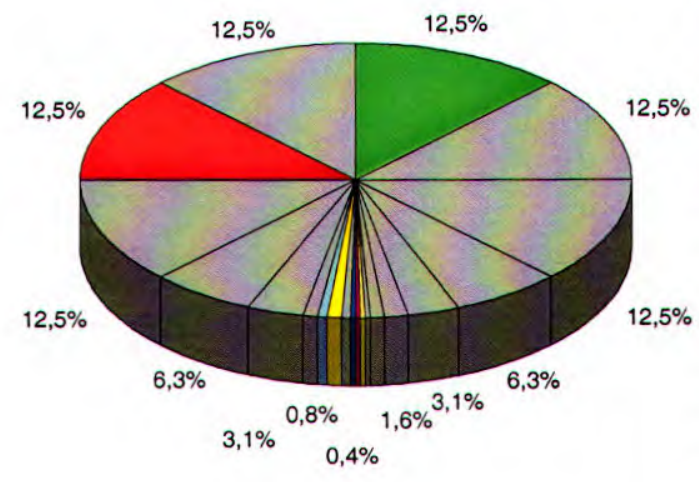

- IPv4 (0000 0000)

$\square$ não definido (0000 0001)

$\square$ OSI NSAP (0000 001)

$\square$ IPX (0000 010)

$\square$ não definido (0000 011)

$\square$ não definido (0000 1)

$\square$ não definido (0001)

$\square$ não definido (001)

baseados em provedor (010)

$\square$ não-definido (011)

baseados em loc.geográfica (100)

$\square$ não-definido (101)

$\square$ não-definido (110)

$\square$ não-definido (1110)

$\square$ não-definido (1111 0)

$\square$ não-definido (1111 10)

$\square$ não-definido (1111 110)

$\square$ não-definido (1111 1110 0)

$\square$ uso local (link) (1111 1110 10)

$\square$ uso local (site) (1111 111011 )

multicast (1111 1111)

Figura 3.9 - A distribuição de endereços IPv6

A Figura 3.9 exibe um gráfico da distribuição de endereços IPv6 onde se pode observar que $70 \%$ dos endereços ainda não foram definidos e estão reservados para uso futuro, o que propiciará uma grande flexibilidade às futuras aplicações do IPv6 e permitirá uma evolução natural do protocolo [Sär96].

\subsection{Autoconfiguração}

Uma das características mais interessantes relacionadas ao endereçamento do IPv6 é a capacidade de autoconfiguração das estações, isto é, de um host obter ou criar automaticamente 
um endereço ao juntar-se à Internet. A autoconfiguração também pode ser utilizada durante a migração de redes IPv4 para IPv6 e elimina a necessidade de reconfiguração manual de cada equipamento.

Existem três maneiras de obter novos endereços IPv6: um método que utiliza informações locais da estação e independe de um servidor que armazene informações de configuração da rede (stateless), um método que utiliza um servidor $\mathrm{DHCP}^{36}$ para obter as informações de configuração (stateful) ou uma utilização conjunta dos dois [MI-98].

\subsubsection{Autoconfiguração stateless}

$\mathrm{Na}$ autoconfiguração stateless, um host gera seu próprio endereço usando informação disponibilizada localmente (por exemplo um identificador derivado da sua placa de rede) e informação publicada pelos roteadores presentes na rede. $O$ host envia uma mensagem conhecida como mensagem de solicitação de vizinhança (Neighbor Solicitation) para o endereço criado e tenta verificar se ele existe. Caso haja conflitos de unicidade, o host parte para um processo de autoconfiguração stateful [MIL98].

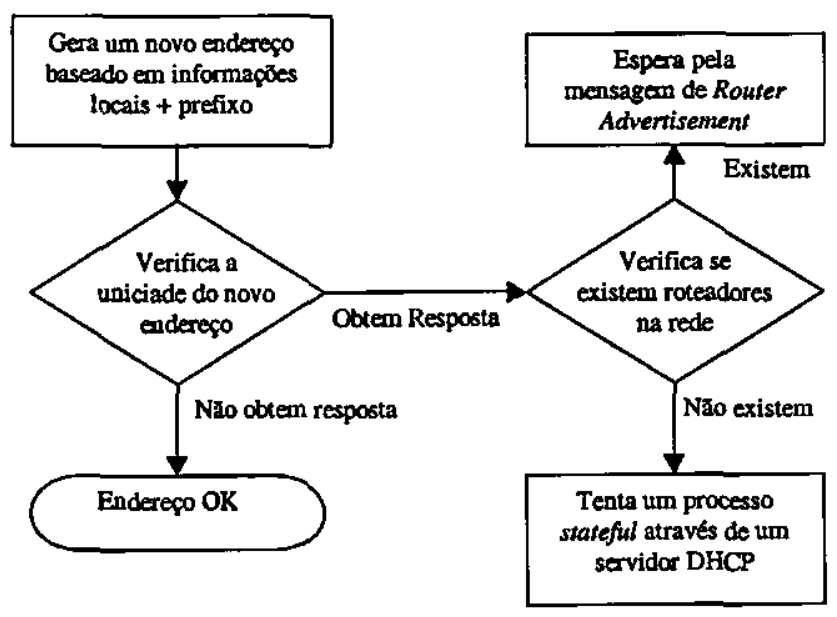

Figura 3.8 - Exemplo de uma sequência de autoconfiguração no IPv6

${ }^{36}$ DHCPv6 - Dynamic Host Configuration Protocol version 6 ou Protocolo de Configuração Dinâmica de hosts versão 6. O DHCPv6 é um protocolo similar ao DHCP existente no IPv4 que permite que um servidor armazene informações de configuração de uma rede e as distribua às estações 
Endereços IPv6 não pertencem mais a uma interface, em vez disso, são cedidos à uma interface por um determinado período de tempo, que pode ou não ser infinito. Endereços cedidos por prazos predeterminados possuem uma data de expiração que indica por quanto tempo eles ainda podem ser utilizados pela interface. Depois de expirado o prazo de validade, o endereço se toma inválido e pode ser, a qualquer momento, atribuído a outro host na Intemet. Para controlar esses prazos, costuma-se definir um endereço como preferred (preferido), indicando que ele pode ser utilizado de maneira irrestrita ou deprecated (desaprovado), indicando que o uso do endereço é desencorajado porque ele pode ser inválido.

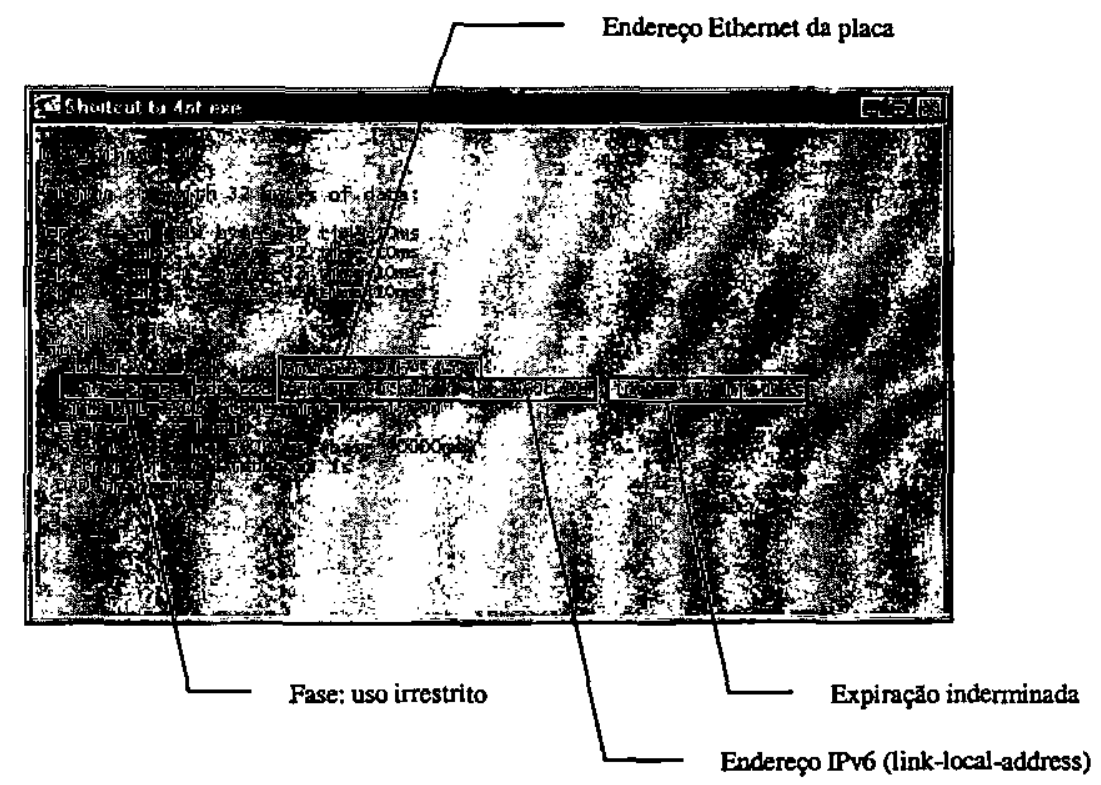

Figura 3.9 - informações sobre um endereço IPv6

\subsubsection{Autoconfiguração stateful}

Em alguns casos, como por exemplo quando existe duplicidade de endereços ou ausência de roteadores na sub-rede, é necessário utilizar um processo de autoconfiguração stateful. O IPv6 prevê a possibilidade de servidores DHCPv6 poderem prover este tipo de informações de configuração para hosts que não conseguirem uma configuração stateless. O DHCPv6 é composto de dois elementos: um protocolo que permite que um host obtenha informações de configuração de um servidor DHCPv6 e de um mecanismo para alocar endereços IPv6 para os hosts. 


\subsection{Roteamento}

Quando o IP surgiu, no final da década de setenta, interligando algumas dezenas de redes, o roteamento não era uma tarefa muito complicada. Nos equipamentos que então ficaram conhecidos como roteadores IP, algumas tabelas armazenavam as rotas que permitiram endereçar um pacote a uma rede extema ou dentro da mesma sub-rede e os endereços dos hosts locais. Com um número razoavelmente pequeno de sub-redes e endereços IP únicos globalmente e que tendiam a permanecer associados aos mesmos equipamentos ao longo do tempo, a complexidade do roteamento era pequena.

Quando no meio da década de noventa a Internet começou a se tornar disponível comercialmente e a ser utilizada em larga escala como um meio de comunicação, entretanto, este cenário começou a mudar. Primeiro porque seria inviável manter o esquema de distribuição totalmente centralizada de endereços e estes começavam, então, a ser distribuídos por Provedores de Acesso ${ }^{37}$.

Essa tendência alterava drasticamente a noção de endereçamento IP. Os endereços passavam a não mais ser indefinidamente de um equipamento. Usuários acessando a Internet por linha telefônica, por exemplo, normalmente passavam a receber um novo IP temporário a cada conexão. E quando uma empresa necessita de um IP fixo, ela pode obtê-lo de um provedor mas será obrigada a trocar de endereço se mudar de provedor.

Finseth [Fin93] observa que não haveria problema em se utilizar endereços variáveis desde que os hosts conseguissem se identificar mutuamente através de um endereço garantidamente único no momento do início da comunicação (proprieđade de identificação) e que durante uma comunicação o endereço destino não mudasse ou a mudança implicasse na também mudança do endereço destino já gravado no pacote (propriedade de localização do destinatário). O problema é que endereços IP não podem ser mais considerados nem bons identificadores nem bons localizadores. Por não serem mais, necessariamente, únicos globalmente, e não serem mantidos por muito tempo associados a urn mesmo host, endereços IP não podern ser considerados bons identificadores.

${ }^{37}$ ISP - Internet Service Provider, do Inglês, Provedor de Acesso à Internet 
Eles também são localizadores ruins. Os endereços já não refletem mais a topologia da rede, isto é, onde na sub-rede o host está localizado, nem a localização da sub-rede em relação às outras redes da Internet [Los99].

Com a quantidade de endereços disponíveis no IPv6, entretanto, não há problemas em conseguir identificadores únicos globalmente. Mesmo em Intranets que, normalmente, utilizam endereços locais ao site, é possível facilmente conseguir um endereço único global quando a sub-rede for posta em contato com um roteador. Essa unicidade facilita, em muito, o roteamento.

\subsection{Desenvolvimento de aplicações para o IPv6}

Do ponto de vista de um programador de aplicações de alto nível, escrever aplicações IPv6 é algo bastante semelhante a escrever aplicações IPv4. Atualmente, a maioria dos sistemas que estão provendo uma camada de rede IPv6 está também disponibilizando uma Interface de Programação com Sockets para o IPv6. A IPv6 sockets $A P I^{38}$ permite que, de uma maneira semelhante ao IPv4, aplicações estabeleçam canais de comunicação TCP ou UDP sobre IPv6.

No Linux, por exemplo, grosso modo, a mudança se deu na adição de uma nova família de protocolos chamada de inet 6 e na atualização das bibliotecas de manipulação de sockets. Em vez de IFNET , o parâmetro IFNET6 será passado como parâmetro para a função Create no momento da criação de um socket. Outras funcionalidades como, por exemplo, manipulação direta do pacote, isto é, o preenchimento direto de campos, também pode ser feita através da sockets API utilizando os chamados RAW sockets [Gil97].

No Windows, a arquitetura do sistema impôs algumas diferenças quando se começou a portar o TCP/IP. Na época, o Windows, ainda nas versões 3.x, funcionava como uma casca ao núcleo monoprocessado do DOS e não permitia nenhum tipo de multiprocessamento. Quando aplicações Unix desejavam utilizar um socket, elas criavam um novo processo (através da chamada fork) e abriam um arquivo com atributos de socket $\mathrm{e}$ utilizavam funções bloqueantes de

${ }^{38}$ API de programação com sockets IPv6 
escrita e leitura sobre eles. Para poder executar outras funções enquanto liam e escreviam nos sockets, elas utilizavam a primitiva fork para criar um novo processo que ficava bloqueado, por exemplo, lendo do socket. No Windows 3.x monotarefa, sem suporte a nada similar ao fork, utilizar sockets que não bloqueassem a aplicação só era possível através da programação por eventos.

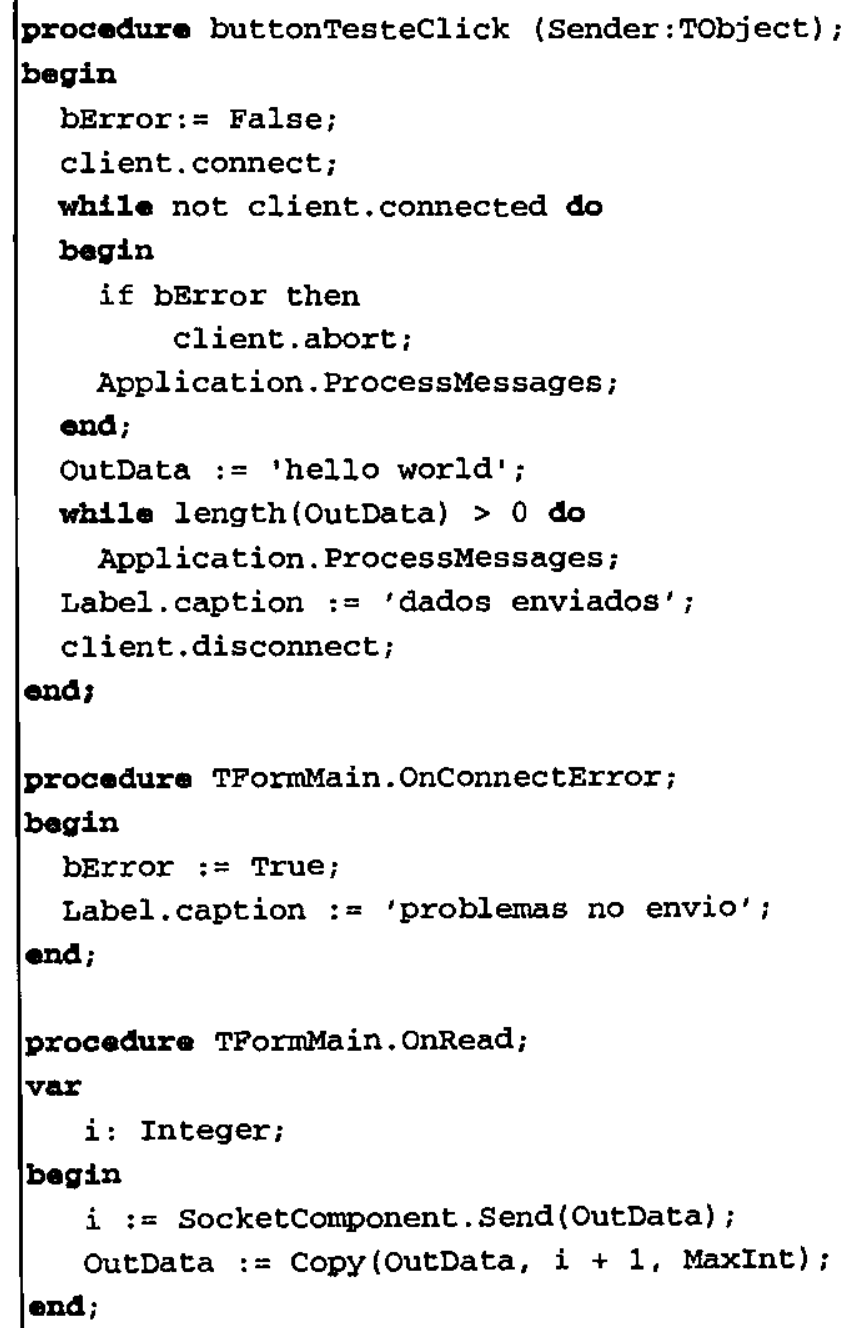

Figura 3.10 - trecho de código em Delphi que manipula sockets através de eventos

A Winsock, a API de programação com sockets para o Windows, foi escrita para operar de forma assíncrona e um evento seria disparado quando um socket servidor recebesse um dado ou quando um socket cliente recebesse a confirmação do envio. Métodos de tratamento de eventos (event handlers) continuariam o trabalho (ver Figura 3.10). 
Com o Win32 e a possibilidade de aplicações criarem múltiplos threads, isto é, diversos contadores de programa que poderiam rodar sobre um mesmo código e sobre mesma área de memória, já era possível bloquear um socket sem bloquear a aplicação.

As aplicações podiam começar a utilizar sockets bloqueantes sem bloquear sua própria execução, agora de uma maneira muito semelhante ao o Unix.

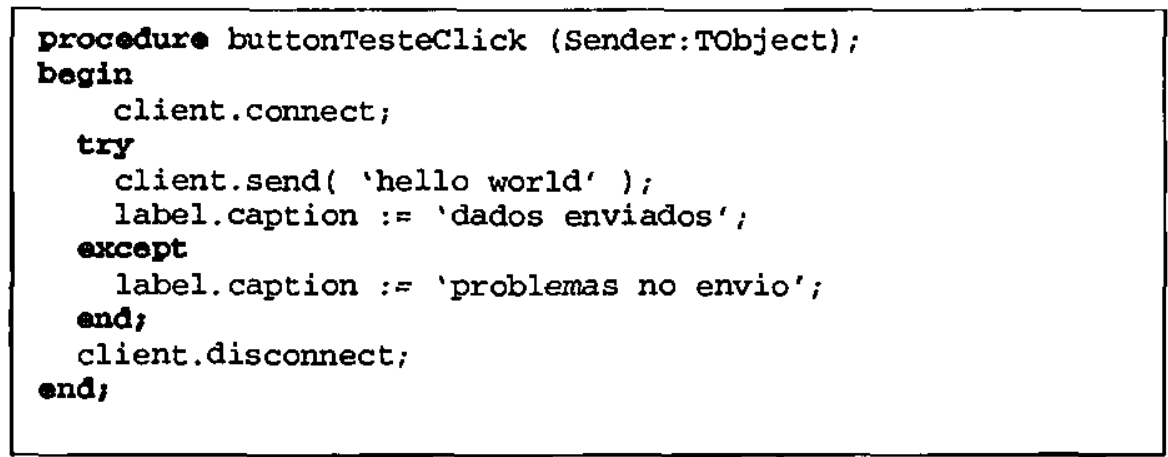

Figura 3.11 - trecho de código em Delphi que exemplifica a programação com sockets bloqueantes

A o trecho de código exibido na Figura 3.11 exemplifica como a mesma funcionalidade conseguida no exemplo anterior (Figura 3.10) através de tratamento de eventos pode ser implementada de uma maneira muito mais legível utilizando threads. Neste caso, quando executamos o método Send, o componente cliente cria um novo thread que fica responsável por enviar os dados, mas não bloqueia a aplicação. Isto acontece porque o thread principal da aplicação, que manipula a fila de eventos do Windows e controla a Interface com o usuário permanece livre.

Outro exemplo é que um "servidor" pode, ao invés de criar uma máquina de estados para tratar os dados que atingem um socket, criar um processo que escuta um socket e cria, para cada cliente que solicitar uma conexão, mais um thread. Além da facilidade de programar de um modo mais legível, sem precisar implementar máquinas de estados nem manipular a fila de mensagens do Windows, esta abordagem permite a execução em múltiplas CPUs e que se controle a prioridade de cada thread. 
A flexibilidade permitida pela programação de múltiplos threads de sockets bloqueantes fez com que adotássemos essa metodologia neste trabalho. Mesmo apesar da grande maioria das aplicações Windows atualmente serem escritas de forma assíncrona. Essa decisão também foi responsável por uma aproximação e posterior ingresso do autor no time de desenvolvimento do Winshoes ${ }^{39}$. O Winshoes é um conjunto de componentes freeware para Delphi que é baseado nesse conceito de programação multi-thread e sockets bloqueantes. O Winshoes é uma arquitetura aberta que vem sendo desenvolvida por um consórcio de programadores organizado pela OpenSource Organization.

\subsection{Considerações finais}

Este capítulo comparou o IPv6 ao IPv4 e discutiu como as novas características do IPv6 deverão ajudar a solucionar os problemas que a Internet ainda enfrenta na sua versão atual. Os próximos capítulos abordarão com mais detalhes outras tecnologias utilizadas neste projeto, como a tecnologia de armazenagem de dados em cartões inteligentes e aspectos de segurança e criptografia. O capítulo seis tratará então do IPSec, um protocolo de segurança embutido no IPv6, que possibilita prover segurança transparente para as aplicações TCP/IPv6.

${ }^{39}$ WDT - Winshoes Development Team, time de desenvolvimento do Winshoes. 
"No século XX parecia ser suficientemente maravilhoso poder armazenar a obra completa de um artista em um único pequeno disco. E agora, em um dispositivo menor que um cartāo, pode-se armazenar não só a obra, mas todo conteúdo do cérebro do artista."

(Frank Poole, personagem de Arthur C. Clark em "3001, a Odisséia Final").

\section{Smart cards}

\subsection{Dados em forma de cartão}

A proliferação dos cartões de PVC começou nos Estados Unidos no início da década de 50 . O baixo custo do PVC possibilitava a produção de cartões robustos e que resistiam muito mais a danos mecânicos e climáticos do que às alternativas em papel ou papelão.

Logo se percebeu que além de identificar pessoas, os cartões podiam ser utilizados como uma forma de pagamento. Uma credencial para permitir compras em nome do cliente.

Para coibir as fraudes, criavam-se novos dispositivos de segurança como impressão do nome do cliente em alto relevo (embossing) e mais tarde o uso de trilhas magnéticas que permitiam armazenar alguns dados relevantes e um código de acesso para utilizar o cartão em máquinas automáticas.

Além da fragilidade da tecnologia de tarja magnética, onde o próprio atrito do cartão com a leitora é responsável pela danificação da tarja após um certo tempo, existe a total ausência de segurança. Qualquer pessoa com acesso a uma leitora pode ler, modificar ou apagar o conteúdo dos dados gravados na tarja. Mesmo que os dados sejam codificados de forma encriptada, sempre é possível, pelo menos, cloná-los produzindo um novo cartão idêntico ao anterior. 
O progresso na microeletrônica no final da década de 70 possibilitou que se integrasse, em um único chip de silício rodeado de PVC, dados e lógica aritmética e foi patenteado por dois alemães em 1968. Entretanto, os cartões só começaram a ser disponibilizados em escala comercial quando foram patenteados na França em 1974 com o nome de cartões inteligentes (smart cards). Nesta época a indústria de componentes eletrônicos já era capaz de fornecer componentes a um preço razoável.

Com chips mais poderosos e melhores algoritmos de criptografia, era possível então armazenar nos cartões, dados encriptados e restringir o acesso à esses dados, de modo a realmente criar um cartão protegido.

\subsection{Arquiteturas diferentes para aplicações diferentes}

Atualmente, existem basicamente dois tipos de cartões inteligentes: com contato e sem contato. Os cartões com contato são caracterizados pela necessidade de contato físico entre o chip presente no cartão e um dispositivo de leitura/escrita, referido normalmente como uma leitora com contato. Os cartões sem contato ou contactless são caracterizados pela comunicação sem contato entre um cartão e uma leitora, já que a troca de dados é feita por ondas de rádio.
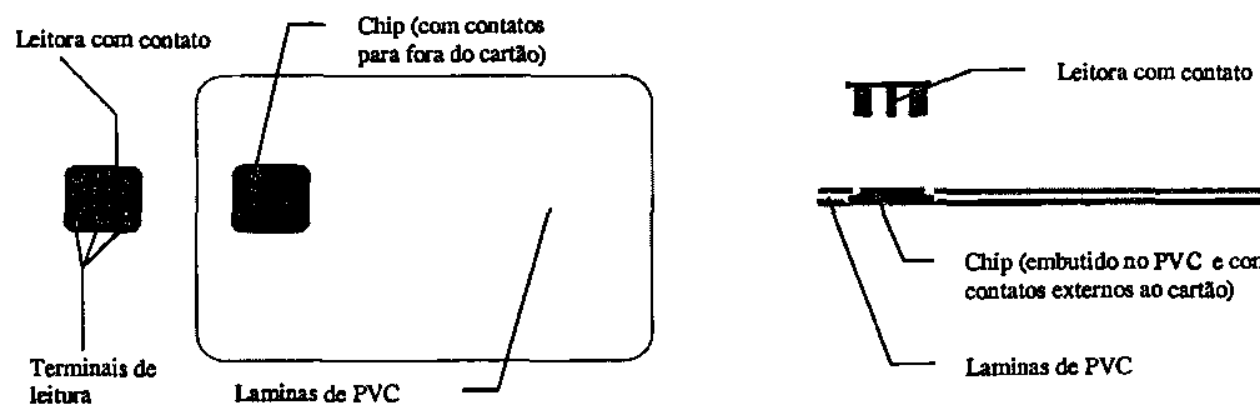

Figura 4.1 - Estrutura de um smartcard com contato

A Figura 4.1 exibe a estrutura de um smartcard com contato. Nela, pode-se observar 0 posicionamento do chip no PVC e como se dá a comunicação com o cartão, isto é, uma leitora encostando seus terminais na superfície de contato do cartão (externa ao chip). 


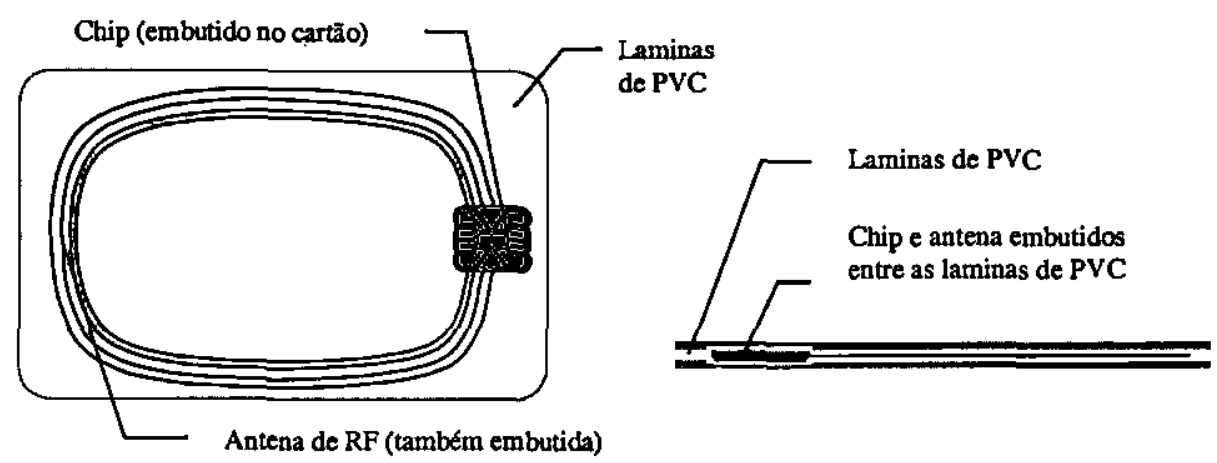

Figura 4.2 - Estrutura de um smartcard contactless

A Figura 4.2 exibe a estrutura de um smartcard sem contato ou contactless. Pode-se observar que não há contato físico entre o chip e a antena e o meio externo. O que acontece, entretanto, é uma comunicação de rádio-frequência entre o chip e uma leitora contactless que também possui uma antena. Além de permitir a troca de dados, as ondas de rádio também provêem energia suficiente para alimentar o chip e armazenar os dados na memória interna.

A tecnologia contactless, apesar de apresentar diversas vantagens em relação à tecnologia com contato como por exemplo maior durabilidade — sem contato físico não há desgaste durante a comunicação com o chip - e maior velocidade de transação, é limitada à quantidade de energia que a antena consegue captar. Por isso, os cartões contactless possuem, em média, memórias internas menores que os cartões com contato e processadores menos poderosos.

Em situações reais, a tecnologia contactless tem sido mais utilizada onde a velocidade de transação e a durabilidade do cartão constituem fatores determinantes para as aplicações. Quando a capacidade de armazenamento e poder de processamento do microprocessador do cartão é mais importante, utiliza-se e a tecnologia com contato.

Existem ainda cartões que conseguem integrar as duas tecnologias: os chamados cartões híbridos e cartões combi. 


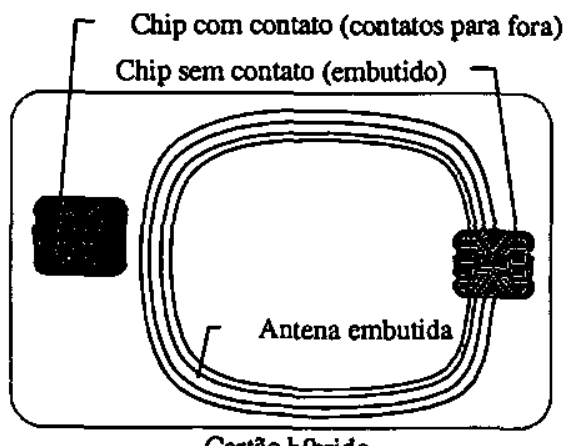

Cartåo hibrido

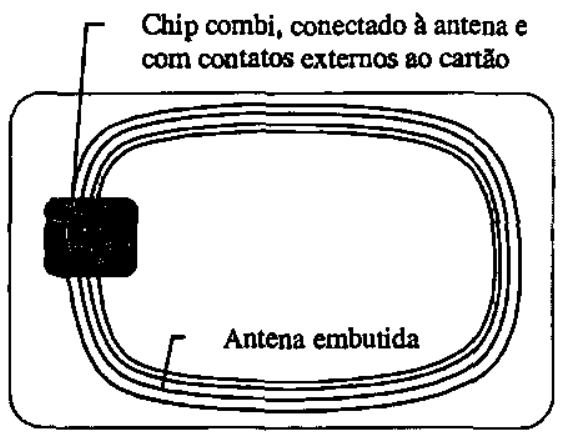

Cartão combi

Figura 4.3 - estrutura de um cartão híbrido e de um cartão combi.

Os cartões híbridos (ver Figura 4.3) abrigam, numa mesma casca de PVC, as duas tecnologias, isto é, possuem os componentes de um cartão com contato e os componentes de um cartão sem contato sobrepostos. Não há interação nenhuma entre eles e o cartão se comporta como dois cartões independentes. Os cartões combi, por sua vez, integram as duas tecnologias através de um único chip que incorpora as funções de um chip com contato e de um chip sem contato. Os cartões combi possibilitam ainda que uma aplicação que tenha acesso somente à parte com contato manipule a memória do chip sem contato.

\subsection{Sistemas Operacionais de cartóes}

Assim como qualquer outro fabricante de hardware, a indústria de cartões tem produzido diferentes cartões e diferentes tecnologias de acesso a cada cartão. Mais fácil do que adotar um padrão único para todos os cartões tem sido escrever aplicações utilizando um Sistema Operacional que permite acessar, em alto nível, as diferentes tecnologias. Quando uma nova tecnologia surge, ela se adapta a API definida pelo sistema provendo apenas as rotinas de baixo nível necessárias. Exemplos de Sistemas Operacionais de Cartões são o CARDOS, MPCOS, MULTOS e o JavaCard.

\subsection{Segurança}

O que difere os Smart Cards de hoje dos cartões de memória produzidos na década de setenta é a preocupação com segurança. Existe um processador que controla e protege o conteúdo da memória de acessos indevidos. Num cartão de memória é possível escrever 
e ler dados sem nenhuma segurança, mas nos Smart Cards apenas o processador se comunica com o mundo externo. Isso permite que se limite $o$ acesso à determinadas áreas e ainda que a informação seja armazenada, de forma encriptada.

\subsection{Considerações finais}

Uma das aplicações dos Smart Cards tem sido armazenar chaves criptográficas em memória, com a vantagem óbvia de poder limitar o acesso à chave armazenada, mesmo para leitura. Este projeto utiliza o MPCOS, um Sistema Operacional para cartões, e cartões inteligentes com contato para armazenar chaves criptográficas de maneira segura [Ran97]. 
"É sábio entender que a maneira de estar a salvo é nunca estar seguro. Todos nós precisamos de uma pitada de insegurança para nos forçar a fazer o melhor que podemos".

(Harold W. Dodds)

\section{Segurança e Criptografia}

Nos últimos anos, a pesquisa e utilização de criptografia no dia-a-dia explodiram. A criptografia deixou de ser uma ciência secreta dominada por organizações militares e se tornou um fato da vida cotidiana. Uma ferramenta essencial na vida de qualquer organização ou indivíduo que deseje proteger seus dados privados, seja do concorrente, da sociedade ou do governo[Sch96].

\subsection{Criptografia simétrica}

Os primeiros sistemas de criptografia misturavam os caracteres do texto original baseados em uma sequiência de números conhecida pelo remetente e pelo destinatário, para produzir um texto ilegível. $O$ destinatário utilizava a mesma função e a sequiência geradora para converter o texto cifrado em um texto novamente legível. Exemplos de algoritmos de criptografia simétrica são o DES (Data Encryption Standard), o IDEA (International Data Encryption Algorithm), e o MD ( Message Digest Cipher).

As técnicas de codificação evoluíram e, embora as análises criptográficas também tenham evoluído, cada vez é mais difícil conseguir decifrar o código que torna o texto, novamente legível. Mas o principal problema persiste desde o início da pesquisa com criptografia: como informar ao destinatário o valor da chave sem correr riscos de que ela seja utilizada para fins indevidos. 


\subsection{Criptografia por chave pública}

Um mecanismo inventado por Diffie e Hellman em 1976 [Dif76] e aperfeiçoado desde então possibilita que exista uma troca de dados encriptados sem que o remetente e o destinatário estabeleçam uma chave privada entre si. Um sistema de criptografia baseado em chaves públicas, como ficou conhecido, utiliza duas chaves. Uma chave, conhecida como chave pública, é visível por todas as pessoas e a outra, uma chave privada, é armazenada confidencialmente.

Para realizar uma comunicação, o remetente codifica os dados que deseja enviar utilizando a chave pública do destinatário e os assina com sua chave privada O destinatário decodifica os dados utilizando a sua chave privada e verifica a autenticidade baseado na chave pública do remetente.

O método é particularmente interessante porque garante que:

- apesar da chave pública do remetente ser visível por todos, apenas ele (com sua chave privada) poderá examinar o conteúdo dos dados;

- a "assinatura" não pode ser forjada porque é uma função dos dados e da chave privada do remetente. Não é possível copiar os modificar os dados sem alterar a assinatura

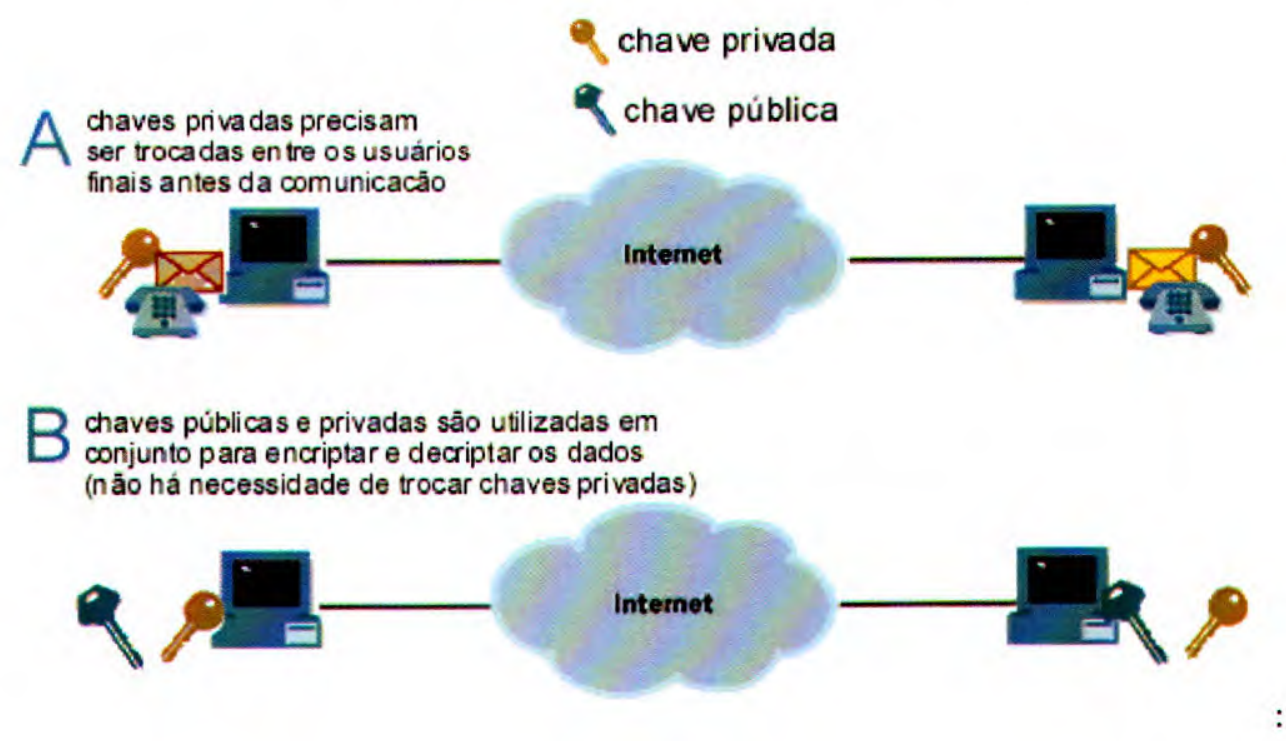

Figura 5.1 - Diferença entre esquemas de criptografia simétrica e com chave pública 
Com a criptografia baseada em chaves privadas (A), o primeiro passo de uma comunicação encriptada é a troca de chaves, o que pode levar à quebra da segurança do sistema. Pior ainda é que as chaves são normalmente trocadas por e-mail ou telefone, o que facilita a quebra da segurança. Com o uso de chaves públicas (B) ainda existe a necessidade de se armazenar chaves privadas, mas não é mais necessário trocá-las entre os dois nós da comunicação.

O esquema de critpografia por chave pública elimina a necessidade de trocar chaves privadas mas introduz a necessidade de verificar o remetente, dado que qualquer um pode ter enviado. Outro problema dos algoritmos de criptografia por chave pública é o custo computacional. Devido a sua complexidade, em média eles são mais lentos que os algoritmos simétricos.

Independentemente do esquema implementado, o gerenciamento de chaves é um tópico importante no sucesso da implantação da criptografia, particularmente quando o número de usuários envolvidos aumenta. Esquemas de troca automática são, então, uma alternativa para reduzir o tempo gasto e os problemas associados à gerência de chaves.

\subsection{Criptografia RSA}

Um algoritmo de criptografia largamente utilizado em todo o mundo e que está sendo utilizado neste Projeto é o algoritmo RSA [Riv92], desenvolvido por Rivest, Shamir e Adleman em 1979.

O algoritmo RSA é baseado na multiplicação de dois números primos de grande extensão. Como os números são muito grandes, é necessário um enorme esforço computacional para fatorá-los, e então, torna-se extremamente difícil descobrir quais são os dois números tendo apenas o produto deles. $O$ procedimento de encriptação baseado na assinatura RSA deve seguir os seguintes passos:

Primeiramente, deve-se obter dois números $p$ e $q$ primos entre si, ou seja, $\operatorname{mdc}(p, q)=1$, e cada número deve ter extensão de aproximadamente 100 dígitos. Em seguida, os valores $n, e$ e $d$ deverão ser determinados da seguinte maneira: 
- $n$ é o produto $p^{*} q$

- $\quad e$ é um número qualquer tal que $e$ e $(p-1)^{*}(q-1)$ sejam primos entre si;

para que $d$ seja obtido, tem-se que $e^{*} d-1$ deve ser divisível por $(p-1)^{*}(q-1)$, ou seja, $e^{*} d=1$ mod $(p-1)^{*}(q-1)$.

As mensagens que serão encriptadas (e decriptadas) terão a forma de números módulo $n$. Os valores $e$ (expoente público) e $n$ podem ser conhecidos, pois isoladamente não terão importância na determinação da chave privada. Por outro lado, o valor $d$ (expoente privado) e os dois números primos, $p$ e $q$, deverão ser guardados em segredo. Depois disso, $p$ e $q$ poderão ser descartados. A chave pública será o par $(n, e)$ e a chave privada será $(n, d)$.

Seja então X a mensagem a ser encriptada conhecida por "plaintext":

$$
\mathrm{X}=\mathrm{X}^{e} \bmod n, \text { ou seja, } \mathrm{f}(\mathrm{x})=\mathrm{x}^{e} \bmod n
$$

Para que esta mensagem seja decodificada, ter-se-á, então, Y ou “ciphertext":

$$
\mathrm{Y}=\mathrm{Y}^{d} \bmod n, \text { ou seja, } \mathrm{g}(\mathrm{y})=\mathrm{y}^{d} \bmod n
$$

Então, se $y=f(x)$ e se deseja encontrar $x$, faz-se $g(y)=g(f(x))=x$. Se apenas uma pessoa conhece o valor de $d$, somente esta pessoa conseguirá decifrar a mensagem mas se alguém puder fatorar $n$ em $p$ e $q$, então poderá conseguir obter a chave privada $d$ e terá acesso à mensagem enviada. Como os valores de $p$ e $q$ são números com muitos dígitos, dificilmente será possível obtê-los conhecendo somente o produto $n$.

Uma limitação do método RSA é que não se pode encriptar mensagens que são maiores que $n$. Entretanto, pode-se "quebrar" a mensagem em blocos de $k$ bits onde $k$ é o maior inteiro tal que $2^{k}<n$ e então encriptar os fragmentos [Riv79]. 


\subsection{Considerações finais}

Este capítulo abordou conceitos básicos de criptografia que permitem descrever a utilização do RSAi e do IDEA no SDT.

A velocidade e a facilidade de implementação, fazem do IDEA um excelente algoritmo de criptografia simétrica. Entretanto, como todos os outros algoritmos de criptografia simétrica, o IDEA tem um ponto franco, a troca segura de chaves entre o remetente e o destinatário.

O que muitos sistemas fazem, é utilizar o RSA para trocar um par de chaves e então utilizar as chaves obtidas em algoritmos simétricos mais eficientes. O SDT utiliza chaves de 2048 bits, presentes nos smart cards do remetente e do destinatário, e o algoritmo RSAi para trocar um par de chaves 128 bits (conhecida como chave de seção) que serão utilizadas no IDEA.

Essa abordagem permite que além de segura, a aplicação também seja eficiente.

O próximo capítulo irá descrever o IPSec, um protocolo de segurança embutido no IPv6, e como ele está sendo utilizado para reforçar ainda mais a segurança do SDT. 
"A arte da guerra nos ensina a não confiar na probabilidade de que o inimigo não venha, $e$ sim na nossa prontidão em recebêlo; nāo na chance de que ele não nos ataque, e sim no fato de que tornamos nossa posição inatingtvel"

(Sun Tzu )

\section{IPSec, segurança no Protocolo Internet}

\subsection{A mudança do cenário da Internet}

A Internet era, originalmente, uma rede baseada na confiança. $O$ desenvolvimento do IPv4 foi baseado na idéia de que o remetente de um pacote seria sempre confiável, que pacotes não seriam alterados durante o roteamento e que ninguém examinaria o conteúdo de um pacote durante a transmissão.

Enquanto a Internet se restringia aos meios científicos e acadêmicos, os problemas de segurança tinham pouca importância e eram facilmente contornados pelos códigos de ética de uso da rede. Encriptar o conteúdo dos pacotes e se preocupar com a confiabilidade da origem seria um excesso de cautela e apenas diminuiria a velocidade da rede [Lar99].

\subsection{Protocolos para garantir segurança do tráfego Internet}

Com a utilização da Internet em escala comercial, os problemas de segurança se intensificaram e mecanismos que garantissem a integridade das transações eletrônicas que passavam a trafegar pela rede passaram a ser não somente desejáveis mas essenciais.

Desde então, diversos protocolos que encriptavam o conteúdo dos pacotes e depois permitiam decifrá-los foram desenvolvidos para assegurar o tráfego seguro na rede. Dentre eles, pode-se citar o SHTTP (Secure Hypertext Transfer Protocol ou Protocolo de Transferência de Hipertexto Seguro), o SLL (Secure Sockets Layer ou Camada de Sockets Segura) e o SET (Secure Electronic Transactions ou Protocolo de Transações Eletrônicas Seguras) [Gar96]. 
Por se situarem nos níveis de sessão e aplicação do TCP/IP, esses protocolos precisam ser implementados em cada aplicação que deseje realizar uma comunicação segura. Por muito tempo, isso foi suficiente apesar de complicar o desenvolvimento e dificultar a interoperabilidade das aplicações, mas hoje se deseja que apenas as transações entre uma aplicação cliente e uma aplicação servidora sejam seguras, mas que seja possível garantir a segurança e a integridade dos dados em geral, de maneira transparente [Che99].

O IPSec ( IP Security ou Segurança do Protocolo Internet ) é uma da das plataformas padronizadas pela IETF (Internet Engineering Task Force, ou Força de Trabalho de Engenharia da Internet) com base nessa experiência com o SHHTP, SSL e SET. O IPSec é um conjunto de protocolos que provê serviços de autenticação, integridade, controle de acesso, confidencialidade e compressão dos dados na camada de rede do TCP/IP [Sta99] [Mer98].

\subsection{A diferença entre o IPSec e os demais protocolos de segurança}

A principal diferença entre o IPSec e os demais protocolos de segurança que têm sido utilizados em conjunto com o TCP/IP é que o IPSec é implementado na camada de rede e não nas camadas superiores como é o caso do SSL, SHHTP e SET. Isso permite que o IPSec ofereça, de forma transparente, segurança para todas as camadas superiores, e consequentemente, para todas as aplicações que se utilizem dessas camadas. Uma desvantagem de encriptar todo o tráfego que transita pela camada de rede, entretanto, é que evidentemente há uma degradação do desempenho da rede. Por isso, o IPSec possui mecanismos de gerenciamento (políticas) dos serviços que oferece que podem ser executados por gerentes da rede ou por aplicações de alto nível [Ss198] [Sil99].

Diferentemente de alguns protocolos de segurança que foram desenvolvidos para suprir as necessidades de uma companhia ou Instituição específica, o IPSec está sendo desenvolvido por um consórcio de diferentes fabricantes e desenvolvedores, e possui uma arquitetura aberta, o que está facilitando ainda mais a sua adoção. Mais ainda, o IPSec permite a utilização de algoritmos de encriptação e criptografia fornecidos por terceiros, o que aumenta ainda mais a sua flexibilidade [Tha98]. 


\subsection{Implementações do IPSec}

Em termos de desenvolvimento, o conjunto de protocolos IPSec pode ser implementado de três formas diferentes. A primeira é implementar o IPSec diretamente sobre o stack do IP, aplicável tanto em hosts como em gateways. O pré-requisito para isso é o acesso ao código fonte do protocolo IP. A segunda forma de implementação, conhecida como Bump-in-the-stack ${ }^{10}$ (BITS) é usualmente utilizada em hosts, onde o IPSec é implementado sob o protocolo IP, entre este e o driver de rede local. Nesse caso, o acesso ao código fonte IP não é necessário. Bump-in-thewire $^{41}$ (BITW) é a terceira forma de implementação IPSec, na qual é utilizada uma placa processadora de criptografia tanto em hosts como em gateways [Si199] [Sah98].

\subsection{Associações de Segurança}

Um dos conceitos fundamentais do IPSec é o conceito de Associação de Segurança (SASecurity Association). Uma SA é uma "conexão" que viabiliza o tráfego seguro, garantida pela utilização de autenticação, encriptação do conteúdo do pacote ou ambos.

Uma associação de segurança é identificada unicamente por três parâmetros: um índice para parâmetros de segurança, o SPI (Security Parameter Index), o endereço do destinatário e o identificador do protocolo (autenticação ou encriptação). O SPI é um número definido durante a negociação que estabelece uma SA e serve para identificar a associação. O endereço IP de destino pode ser unicast, broadcast ou ainda multicast.

Uma SA pode ser estabelecida em dois modos: modo transporte ou em modo túnel.

No Modo Transporte, a associação é estabelecida entre dois hosts. No IPv4, o cabeçalho do protocolo de segurança é inserido entre o cabeçalho IP e os cabeçalhos dos protocolos de mais alto nível, como TCP ou UDP. No IPv6, o cabeçalho do protocolo de segurança é inserido após o cabeçalho básico IPv6 e os cabeçalhos de extensão, e antes dos protocolos de mais alto nível [Mau98].

\footnotetext{
${ }^{40}$ Bump-in-the-stack, lombada na pilha

${ }^{41}$ Bump-in-the-wire, lombada no fio
} 
Quando se utiliza encriptação, uma SA em modo transporte provê serviços de segurança para os protocolos de mais alto nível mas não inclui o cabeçalho IP ou os cabeçalhos de extensão que precedem o conteúdo do pacote. Na verdade, o que se faz é utilizar a encriptação e então utilizar um cabeçalho de autenticação englobando todo o pacote, inclusive o payload encriptado. Essa abordagem é particularmente interessante porque permite que o destinatário verifique a procedência do pacote antes de desencriptar o seu conteúdo.

No Modo Túnel, a SA garante o tráfego de dados dentro de um túnel IP. Neste caso, o chamado cabeçalho IP externo especifica o destino no contexto do IPSec e o cabeçalho IP interno especifica o destino real do pacote IP. Os cabeçalhos dos protocolos de segurança são inseridos depois do cabeçalho IP externo e antes do cabeçalho IP interno.

\subsection{Funcionamento do IPSec}

O termo IPSec engloba os subprotocolos utilizados para enviar dados autenticados e encriptados sobre redes TCP/IP. São eles:

- $\mathrm{AH}$ (Authentication Header) ou Cabeçalho de Autenticação, que provê autenticação e previne ataques do tipo replay;

- ESP (Encapsulating Security Payload) ou Carga de Segurança Encapsulada que provê confidencialidade.

- ISAKMP (IP Security Association Key Management Protocol) ou Protocolo de Gerenciamento de Associação de Segurança do IP, que gerencia a troca de chaves entre remetentes e destinatários [Mau98].

\section{Cabeçalho de autenticação}

A autenticação é feita através de um cabeçalho de autenticação (AH - Authentication Header) e permite garantir se um pacote realmente é proveniente do remetente atual, além de detectar a existência de pacotes duplicados (anti-replay). Mas, como visto no capítulo 5, a autenticação apenas confirma a origem do pacote. Para proteger o conteúdo, é necessário encriptar o pacote mediante a utilização do ESP. 


\begin{tabular}{|c|c|c|}
\hline $\begin{array}{l}\text { Próximo } \\
\text { cabeçalho }\end{array}$ & $\begin{array}{l}\text { Tamanho da } \\
\text { área de dados }\end{array}$ & Reservado \\
\hline \multicolumn{3}{|c|}{ SPI - Indice de Paråmetros de Segurança } \\
\hline \multicolumn{3}{|c|}{ Número de Sequência } \\
\hline \multicolumn{3}{|c|}{ Dados de autenticaçăo } \\
\hline
\end{tabular}

Figura 6.1 formato de um cabeçalho de autenticação (AH) de um pacote IPv6

Como exibido na Figura 6.1, o AH (Authentication Header) ou Cabeçalho de Autenticação, contém parâmetros de segurança (SPI - Security Parameters Index), um número de sequiência (para prevenir anti-replay) e dados de autenticação.

Os dados da autenticação são computados como uma função dos dados do pacote e dos dados de autenticação de chaves, que fazem parte da associação de segurança (SA). $O$ destinatário utiliza o SPI contido no pacote para determinar que algoritmo e que chaves utilizar para verificar a autenticidade dos dados [Ken98b].

Para autenticar usuários, o AH utiliza o algoritmo MD5 (Message Digest 5) desenvolvido pela RSA [Mad98] ou o SHA-1 (Secure Hash Algorithm 1) desenvolvido pelo govemo dos Estados Unidos [Mad98a]. O MD5 é considerado mais rápido, enquanto que o SHA-1 é tido como sendo mais seguro.

\section{Carga Segura Encapsulada}

O ESP, Encapsulation Security Payload ou Carga Segura Encapsulada, permite encriptar o conteúdo do pacote utilizando DES ou outros algoritmos de criptografia. A encriptação garantirá que somente os destinatários autorizados poderão ter acesso ao conteúdo do pacote.

O uso do ESP previne ataques do tipo:

- Replay, através da utilização do campo Número de Sequiência, de maneira análoga ao AH;

- Particionamento de pacotes encriptados, que é o que acontece quando o atacante obtém partes de pacotes cifrados e consegue montar um pacote que pode ser aceito por um dos membros da conexão. 
- Sniffer, ou seja, quando o atacante obtém os pacotes que trafegam na rede. A utilização da criptografia previne este tipo de ataque porque torna ilegível o conteúdo do pacote.

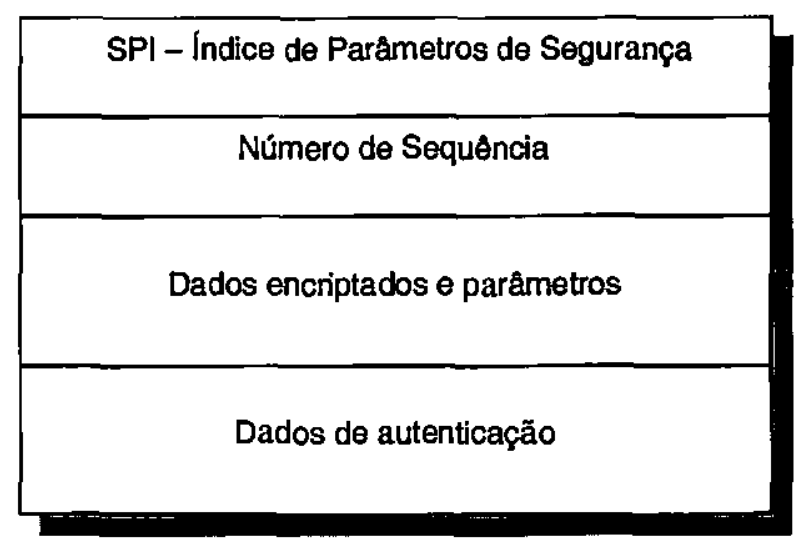

Figura 6.2 formato de um cabeçalho de encriptação (ESP) de um pacote IPv6

Como exibido na Figura 6.2, o ESP consiste em um cabeçalho de controle (SPI e Número de Sequiência), uma área de dados.

O SPI, em conjunto com o endereço fonte, identifica unicamente uma SA para um determinado pacote. O Número de Sequiência permite detectar ataques que duplicação de pacotes duplicados (anti-replay). A área de dados contêm os dados encriptados e parâmetros utilizados pelo algoritmo de criptografia definido pela SA. Os Dados de Autenticaça contêm o ICV (Integrity Check Value) para este pacote, calculado seguindo o algoritmo de autenticação usado, definido pela SA [Ken98].

Para os casos em que se exige apenas a autenticação, ou ainda, onde a confidencialidade não deve ser usada, é recomendada a utilização do AH. No entanto, a situação ideal é a utilização de autenticação e confidencialidade, ou seja, a utilização do AH e ESP em conjunto. Mais especificamente, é recomendado o uso do ESP "dentro" do AH, permitindo-se que o destinatário verifique a autenticidade do pacote antes de decifrá-lo, ou ainda, verifique autenticidade enquanto decodifica o pacote em paralelo [Ken98b].

As especificações IPSec também suportam negociação de compressão IP definidas pela RFC [Sha98]. 


\section{Gerenciamento de chaves}

Como os serviços de segurança IPSec compartilham chaves privadas, as especificações IPSec definem um conjunto separado de mecanismos para o gerenciamento de chaves com suporte para distribuição automática ou manual das chaves.

- Internet Security Association and Key Management Protocol (ISAKMP) [Mau98];

- The Internet Key Exchange (IKE) [Har98];

- The OAKLEY Key Determination Protocol [Orm98].

\subsection{Utilização do IPSec}

O IPSec pode ser utilizado num gateway ou num host, com os requisitos de segurança especificados por um banco de dados de política de segurança (SPD - Security Policy Database) mantido pelo usuário ou pelo administrador da rede.

O IPSec pode ser utilizado para proteger uma ou mais conexões entre um par de hosts, entre dois gateways de segurança ou entre um host e um gateway.

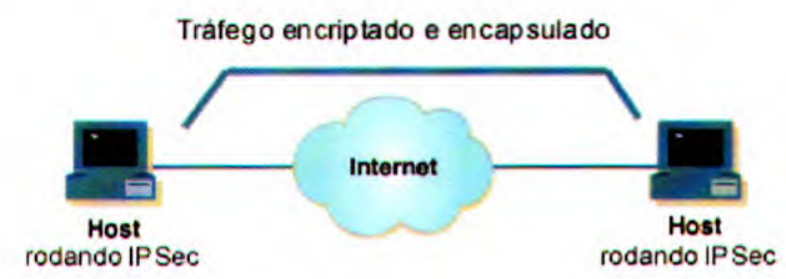

Figura 6.3 exemplo da utilização do IPSec para conexão segura entre dois hosts

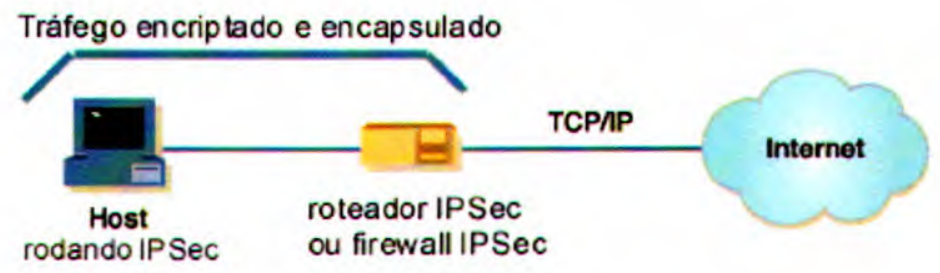

Figura 6.4 - exemplo da utilização do IPSec para conectar dois um host à um gateway 


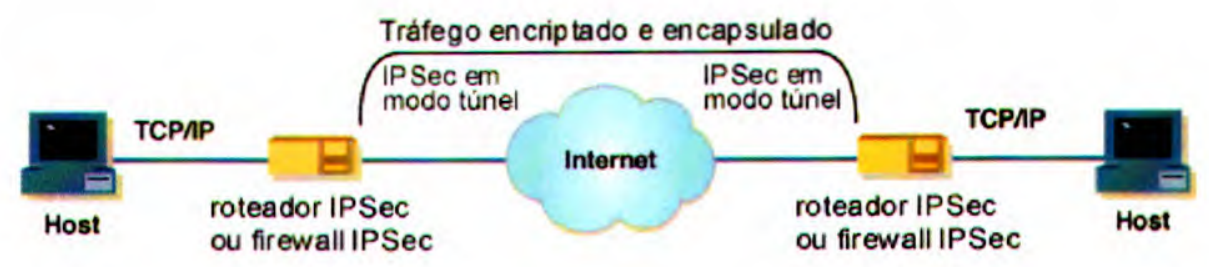

Figura 6.5 -exemplo da utilização do IPSec para conectar dois gateways de forma segura

A figura exibe a utilização de um túnel IPSec para conectar dois roteadores numa arquitetura conhecida como Rede Privada Virtual (VPN-Virtual Private Network).

\subsection{Redes Privadas Virtuais}

Uma VPN permite utilizar uma rede pública como a Internet em vez de linhas privativas para implementar redes corporativas. Com roteadores rodando IPSec, por exemplo, pode-se estabelecer um túnel de comunicação criptografada entre os pontos autorizados e tranferir, de modo seguro, dados entre as redes. Com a mesma tecnologia é possível disponibilizar conexões por linha telefônica (dial-up) para usuários móveis ou remotos [Mos99].

Outro serviço oferecido pelas VPNs é a de criação de Extranets, isto é, redes externas que interligam corporações através da Internet. Esse serviço tem a grande vantagem de reduzir custos operacionais e com telecomunicações em redes corporativas, pois elimina a necessidade de links dedicados de longa distância que podem ser substituídos pela Internet [Tat98].

As redes locais podem, através de links dedicados ou discados, conectar-se a algum provedor de acesso local e interligar-se à rede corporativa. Essa solução é bastante interessante do ponto de vista econômico, principalmente quando as conexões são feitas à partir de links de longa distância. Outro fator importante é que, com a conexão rede-Internet-rede parcialmente a cargo dos provedores de acesso, o custo de manutenção da rede corporativa como um todo cai sensivelmente [Ker98]. 


\subsection{Considerações finais}

Como o IPSec permite que se adicione autenticação e encriptação de forma transparente, isto $e$, segurança disponível a todas as camadas superiores sem que as aplicações precisem ser modificadas, ele constitui uma alternativa interessante na implementação de Redes Privadas Virtuais (VPNs) e na adição de segurança para aplicações que se utilizem do protocolo IP.

O próximo capítulo discute como este Projeto utilizando o IPSec embutido no IPv6 para reforçar a segurança de uma transmissão de dados. 
"Programming is a form of art. that fights back"

.-"A programação é uma forma de arte que contra-ataca"

(Chad Hower, criador do Winshoes)

\section{Modificando uma aplicação para utilizar o}

\section{IPv6}

\subsection{Visão geral do SDT}

Em meados de 1998, quando o autor investigava a utilização do IPv6 em diferentes sistemas, surgiu a possibilidade de pesquisar a utilização do IPSec (embutido no IPv6) como um reforço adicional de uma tecnologia de transmissão segura de dados que estava sendo desenvolvida na S\&V Consultoria e Tecnologia.

Uma aplicação conhecida como SDT ${ }^{42}$, utilizada por bancos para enviar dados confidenciais para um bureau de emissão de cartões de crédito VISA Platinum, permitia encriptar dados através de chaves presentes em cartões inteligentes ${ }^{43}$ e enviar esses dados através de uma conexão x.25..

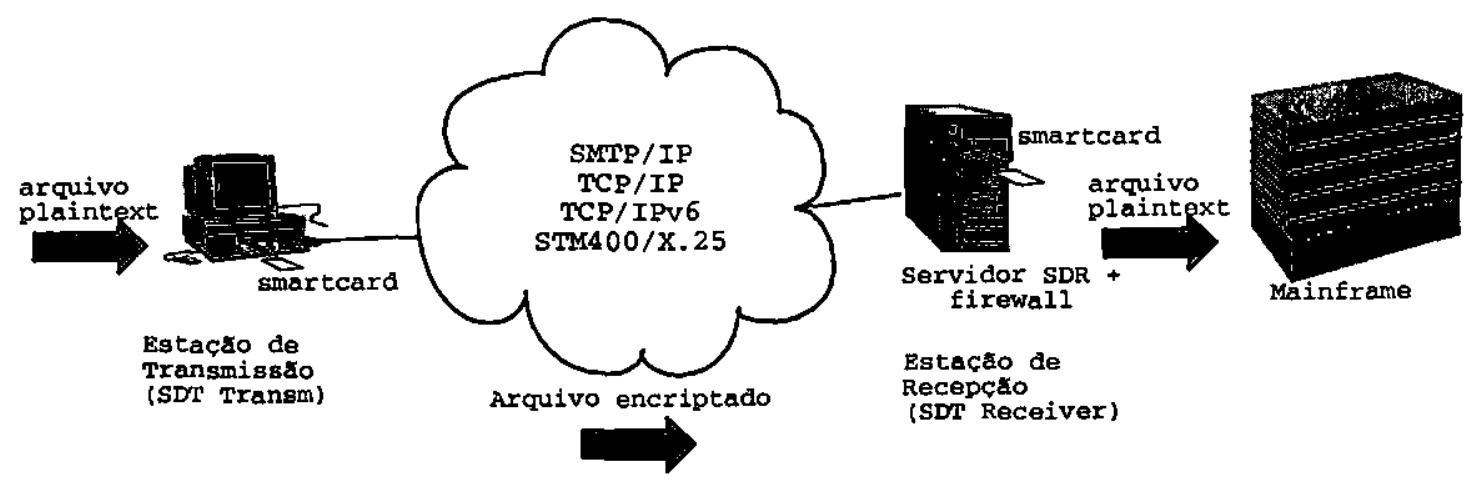

Figura 7.1 Esquema de uma comunicação utilizando o SDT

${ }^{42}$ SDT - Secure Data Transfer 
A exibe uma comunicação utilizando o SDT. A chave pública do destinatário é utilizada para encriptar os dados e a chave privada do remetente, armazenada no cartão presente na Estação de Transmissão, utilizada para assinar a mensagem .

Modificou-se, então, o SDT para suportar também conexões TCP/IP (versão 4) além de X.25 e começou-se a investigar a possibilidade de utilizar o IPv6 além do IPv4 na comunicação.

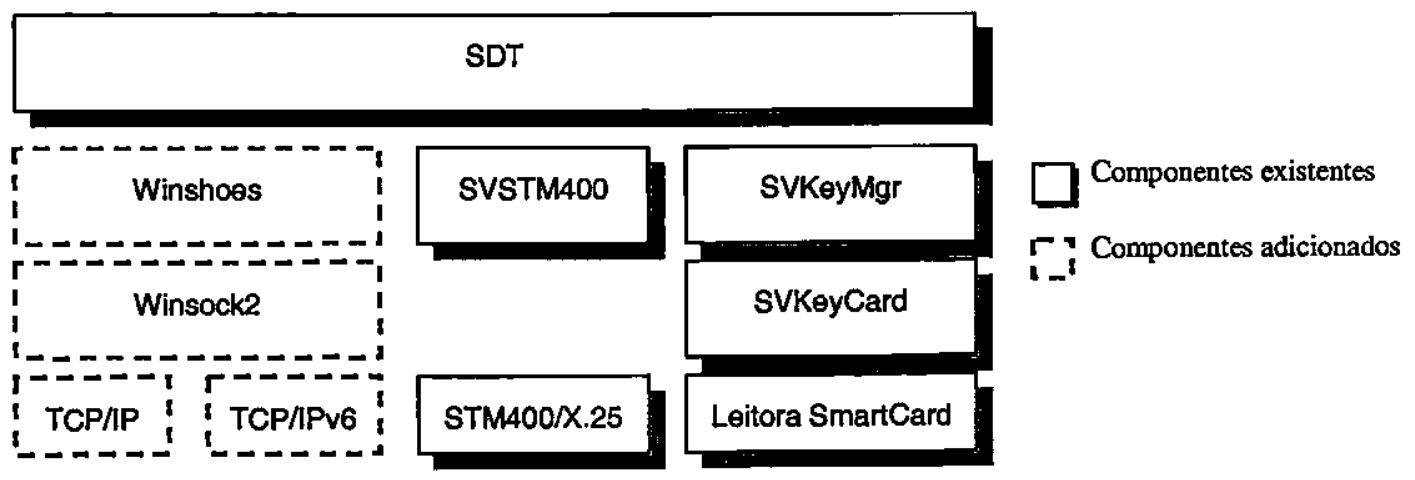

Figura 7.2 Estrutura do SDT

A Figura Figura 7.2 exibe a estrutura básica da aplicação SDT referente à comunicação com a leitora de cartões inteligentes com contato e com o STM400/X.25. Essa aplicação, desenvolvida em Delphi $4^{44}$, passava então a utilizar também sockets no Windows NT para enviar dados através de canais TCP/IP.

43 smartcards com contato MPCOS

${ }^{44}$ Delphi4@ - Uma linguagem de programação orientada à objetos para ambiente Windows 


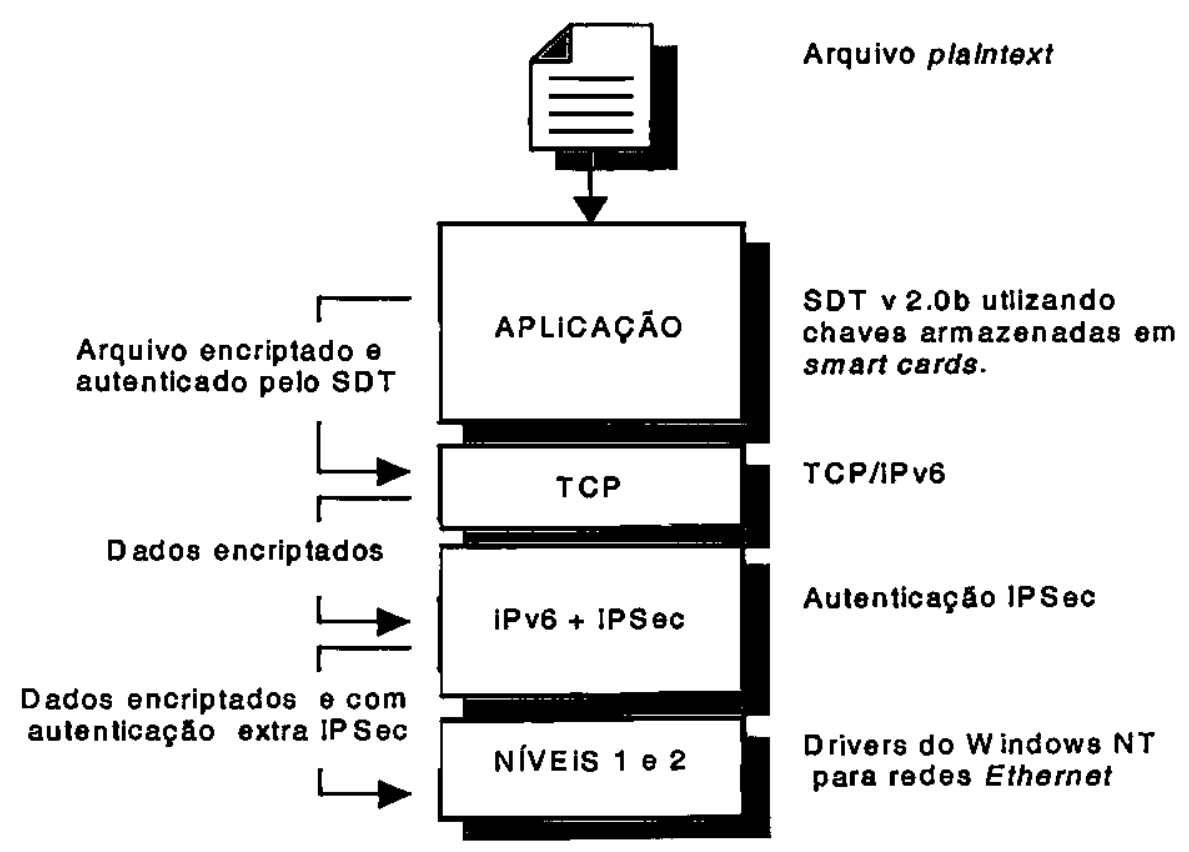

Figura 7.3 - Esquema em camadas da aplicação SDT rodando sore uma rede IPv6 segura

A Figura 7.3 exibe um esquema da estrutura em camadas do conjunto SDT+IPSec. Note-se o fluxo de dados já encriptados na camada de transporte e a camada de rede adicionando um controle extra de autenticação IPSec.

O próximo passo deste Projeto foi instalar uma Intranet IPv6 para validar a possibilidade de programar sockets IPv6 no Windows NT e então utilizar o novo protocolo para transmitir os dados com o SDT. 


\subsection{Instalação de uma Intranet IPv6}

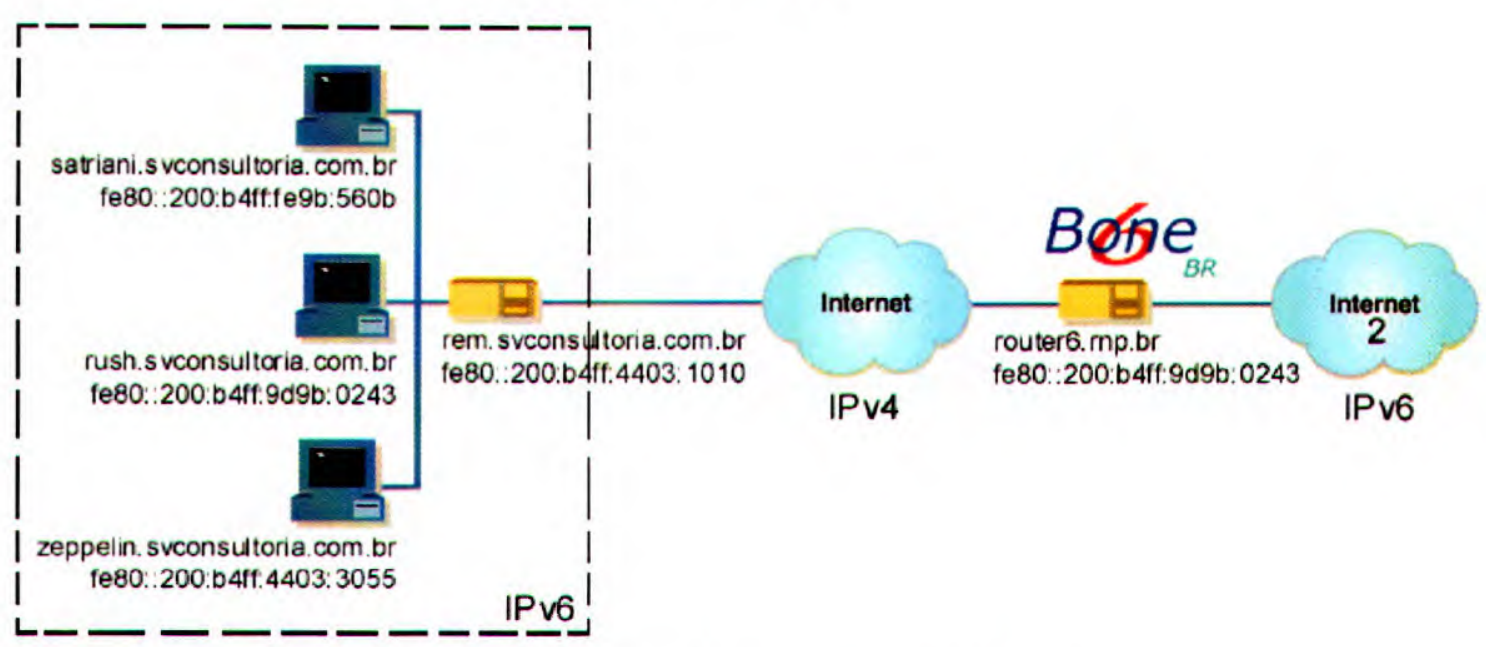

Figura 7.4 - Esquema da Intranet IPv6 instalada na S\&V

Para instalar a Intranet IPv6 instalou-se o suporte ao IPv6 em algumas estações de trabalho da S\&V. Nas máquinas Windows NT, instalou-se o MSR IPv6, um stack IPv6 disponibilizado pela Microsoft Research e nas máquinas Linux, um conjunto de ferramentas denominado inet6app. Ambas as implementações possibilitam estabelecer uma camada de rede IPv6 sobre um meio físico composto de redes Ethernet ou FDDI. As bibliotecas também possibilitam uma integração com a Interface de programação com sockets disponibilizada pelo Sistema e aplicações simples como ping, telnet e ftp para o IPv6 [Car97] [Dra98].

Depois de instalar o suporte ao IPv6 testar a Intranet com os endereços locais (link-local address discutidos anteriormente na seção 3.3.4) obtidos por configuração stateless, configuramos o servidor Internet da empresa (uma máquina Linux rodando kernel 2.2.5) como um túnel entre a $\mathrm{S} \& \mathrm{~V}$ e um servidor IPv6 do $6 \mathrm{BoneBr}^{45}$, o Backbone brasileiro da Internet2.

\footnotetext{
${ }^{45}$ um servidor da RNP - Rede Nacional de Pesquisa
} 


\subsection{Utilização de sockets IPv6 no Windows NT}

\subsubsection{Protocolos de rede no Windows NT}

Os protocolos de rede no Windows NT são, na verdade, gerenciadores de dispositivos (device drivers) carregados dinamicamente de uma maneira muito semelhante aos outros gerenciadores de dispositivo do sistema. Um protocolo no NT tem dois componentes básicos: um driver de baixo nível, que roda com prioridade de Sistema (no caso do IPv6, o tcpip6.sys), e um módulo de alto nível, que permite o acesso ao dispositivo (no caso do IPv6 a wship6.dll).

Diferentemente da arquitetura de sockets utilizada no Unix, onde as operações sobre sockets são chamadas diretas ao núcleo do sistema, a arquitetura winsock é dividida em diversos níveis e componentes.

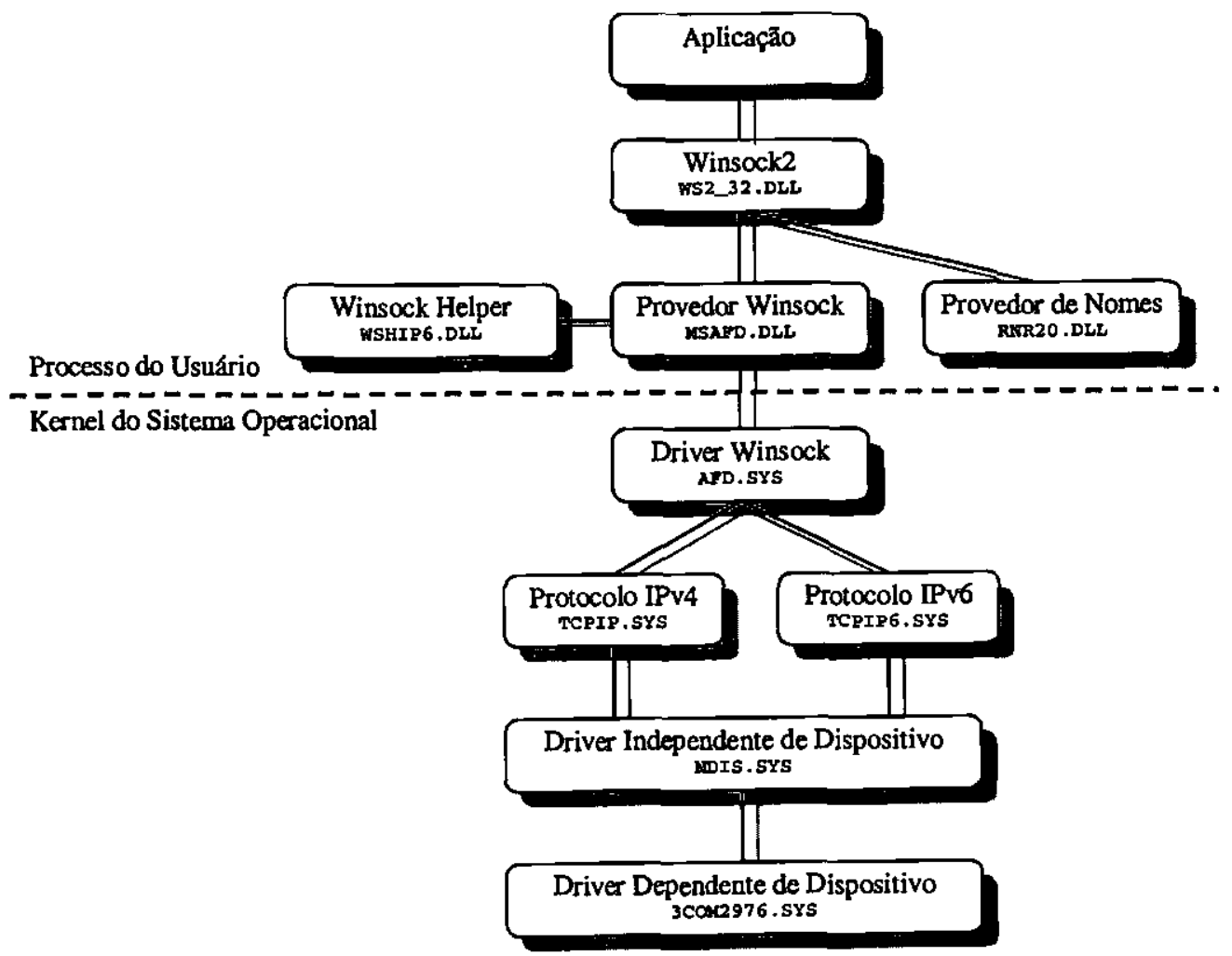

Figura 7.5 -A arquitetura Winsock no Windows NT

Como exibido na Figura 7.5, a Winsock2 (ws2_32. al1) redireciona as chamadas da aplicação para o Provedor de Winsock (WSP - Winsock Provider) ou Provedor de Nomes (NSP - Namespace Provider). Um provedor de sockets pode permitir a adição de uma nova 
família de endereços (AF_INET no IPv4, AF_INET6 no IPv6, AF_IPX no IPX/SPX, etc.) ou implementar de uma maneira diferente o acesso de uma família de protocolos à interface de baixo nível. Os provedores de nomes NSP (Namespace Providers) suportam conversões entre nomes e endereços como DNS e WINS.

A biblioteca msafd.dll (gerenciador de baixo nível da Winsock) permite suportar diferentes protocolos pela utilização de bibliotecas auxiliares (helper $D L L s$ ). No caso do IPv6 isto é feito através da wship6.dll.

A Interface $\mathrm{TDI}^{46}$ ou Interface Independente de Dispositivo de Transporte permite chamar funções assíncronas do kernel do Sistema que atuam diretamente no driver do dispositivo. Um gerenciador de protocolo, no caso o tcpip6.sys exporta uma interface TDI utilizando chamadas do nível NDIS ${ }^{47}$. O protocolo chama o NDIS para enviar um pacote e o NDIS informa 0 protocolo (normalmente através de um call-back), que o pacote foi recebido. Em vez de ser implementado por cada fabricante de hardware, o NDIS é parte comum do sistema (ndis.sys) e os fabricantes de hardware provêem um driver relativamente simples que implementa a funcionalidade específica do seu produto.

\subsubsection{O stack IPv6 desenvolvido pela Microsoft Research e pela USC/ISI East}

Este projeto utiliza um stack IPv6 para Windows NT desenvolvido em conjunto pela Microsoft Research, um centro de pesquisa da Microsoft, e a Universidade USC/ISI East, nos Estados Unidos. O stack IPv6 da MSR, como ficou conhecido, é disponível gratuitamente e com o código fonte incluído e suporta:

- cabeçalhos adicionais de destino hop-to-hop ;

- cabeçalho de fragmentação;

- cabeçalho de roteamento ;

${ }^{46}$ TDI - Transport-Device Independent

47 NDIS - Network Device Independent Specification, Especificação Independente de Dispositivo de Rede 
- descobrimento de vizinhos (Neighbour Discovery);

- autoconfiguração de endereços (Stateless Address Autoconfiguration) ;

- ICMPv6 ;

- IGMPv6;

- níveis físicos Ethernet e FDDI ;

- tuneis automáticos e manuais;

- IPv6 sobre IPv4 ;

- UDP/IPv6 e TCP/IPv6 ;

- transmissão de pacotes através de sockets RAW ;

- autenticação IPSec ;

Infelizmente, até o momento da redação deste documento, nenhuma das implementações de IPv6 para Windows NT analisadas [Har96] [Inr98] permitia utilizar encriptação IPSec (cabeçalhos ESP) e sim apenas autenticação através dos cabeçalhos de autenticação (AH) discutidos anteriormente na seção 6.2. Apesar disto, a utilização do IPSec já era interessante porque adicionava características extras de autenticação e diferenciaria o produto que estava sendo desenvolvido. Mais ainda, como a utilização do IPSec com ESP, em nível de aplicação, será praticamente igual à utilização do IPSec atual, quando a nova versão do stack disponiblizar encriptação ESP, o SDT já estará preparado.

\subsubsection{Modificando o winshoes para suportar IPv6}

Depois de estudar a Interface de Programação com sockets (Winsock 2, ou Winsock versão 2.2) para o Windows NT e de constatar a possibilidade de criar sockets IPv6 sobre ela, o autor passou a se dedicar no desenvolvimento de bibliotecas de alto nível que conseguissem encapsular a Winsock2 e o suporte ao IPv6.

Em linguagens de programação baseadas em ambientes de desenvolvimento visuais, existe o conceito de componentes visuais, isto é, objetos que podem ser executados mesmo em tempo de desenvolvimento, que permitem encapsular diversas funções em uma interface intuitiva ao programador. Através de um editor de propriedades, pode-se modificar o valor de propriedades do objeto, e ativar métodos privados do componente que farão todo o trabalho de baixo nível. 
Através de um editor integrado de programação também é possível editar o código de tratamento dos eventos que devem ser gerados pelo componente em determinada situação.

Um pacote de componentes freeware conhecido como winshoes [How99], com código fonte disponível na Intemet, atendia a todos os requisitos básicos deste Projeto, como possuir um núcleo multi-thread e encapsular o funcionamento da winsock sem bloquear todo o acesso a seus recursos. Mais ainda, por se tratar de um pacote aberto, o Winshoes conta com a contribuição de diversos programadores em todo o mundo e deve continuar evoluindo bastante.

O primeiro passo para permitir a utilização do IPv6 no Winshoes, foi estender o módulo Winsock para suportar as novas estruturas de endereçamento IPv6 (ver Figura 7.6) e portar todas as funções padrão da winsock para trabalhar com os novos endereços e novas opões de sockets IPv6.

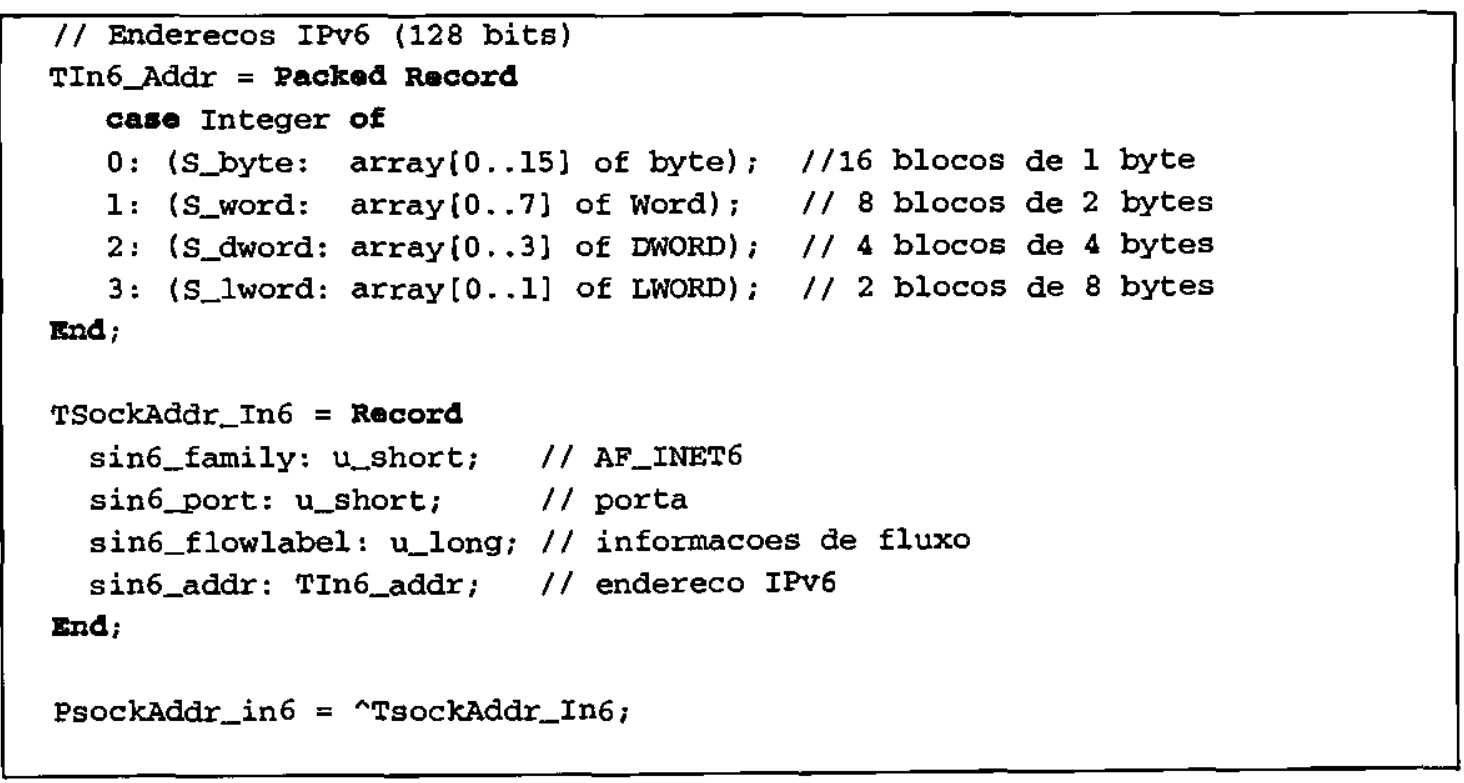

Figura 7.6 - trecho de código da unit Winsock2 . pas exibindo as novas estruturas de endereço IPv6

Através da utilização de overload de operadores, isto é, a declaração de várias funções com o mesmo nome que recebem parâmetros diferentes, manteve-se os nomes originais das funç̋̃es da Winsock2 e o Winshoes compatível com as aplicações IPv4. 
Posteriormente, adicionou-se uma nova propriedade à classe TWinshoe, que deriva as principais classes de manipulação de sockets no Winshoes como o TwinshoeSocket (que maniupla sockets TCP) e o TWinshoeUDP (que manipula sockets UDP). A Figura 7.7 exibe a hierarquia de classes no winshoes e os principais componentes que herdaram novas característica com essa mudança.

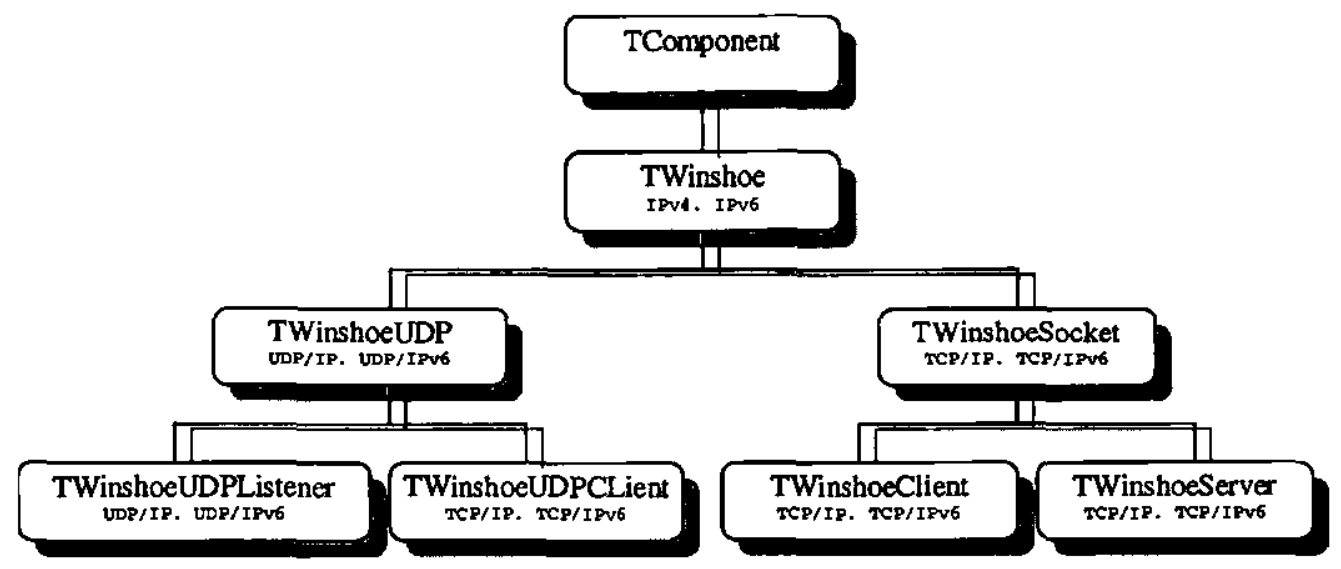

Figura 7.7 -A hierarquia das principais classes no Winshoes

A propriedade Protocol, que representa o protocolo utilizado, permite agora que os usuários escolham que tipo de família de endereçamento desejam utilizar. Com base nessa propriedade, $o$ Winshoes pode iniciar a Winsock de maneira diferente e utilizar estruturas de endereçamento diferentes na chamada das funções da API.

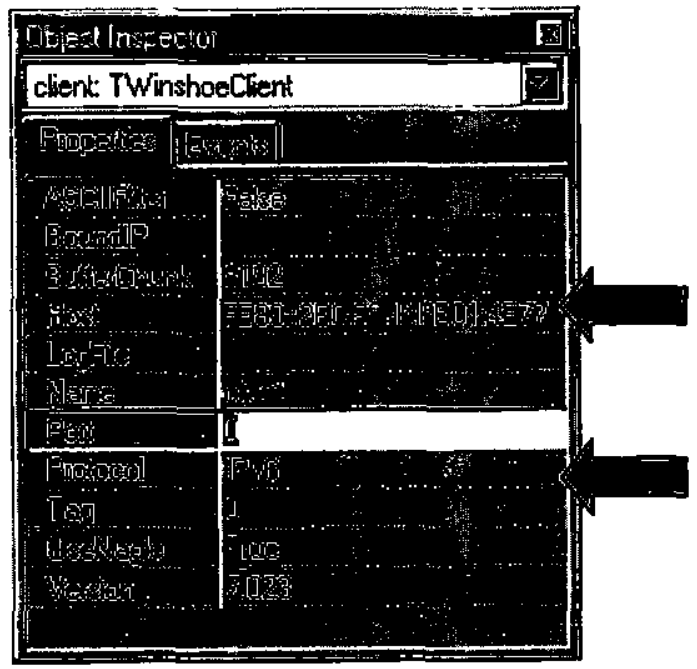

Endereço do host. Note que agora pode-se utilizar endereços IPv4 ou IPv6

Propriedade que permite definir o protocolo à ser utilizado pelos sockets (IPv4 ou IPv6)

Figura 7.8 - Exemplo do editor de propriedades de objeto do Delphi. 
A Figura 7.8 exibe as propriedades de um componente derivado de TWinshoe. As setas indicam a nova propriedade protocol e a possibilidade de utilizar dos novos endereços IPv6 na propriedade Host.

Um desafio durante essa implementação foi permitir que o Winshoes suportasse o IPv6 e ao mesmo tempo pudesse continuar a ser utilizado em ambientes desprovidos de suporte à Winsock2, como é o caso de algumas instalações do Windows 95 .

A solução encontrada foi alterar a unit Winshoes para referenciar dinamicamente a Winsock1 ou Winsock2 dependendo das necessidades do usuário e das características do equipamento utilizado.

Para realizar essa mudança, uma primeira abordagem foi tentar modificar, linha por linha, a unit Winsock. Devido ao enorme esforço de programação que isso representaria, em uma segunda análise, utilizamos ferramentas de análise sintática (lex/yacc portadas para Delphi) para montar um parser simplificado e modificar a unit Winsock para, em tempo de execução, incluir no código a decisão de referenciar a versão 32 bits ou 16 bits da Winsock1 (wsock32.dl1 ou winsock.dl1) ou da Winsock2 (ws2_32.dll ou Winsock2.dl1).

A iniciação da biblioteca Winsock (através da função WSAStartUp), que antes se dava no momento da iniciação do Winshoes, também precisou ser alterada. A inciação da Winsock passou a ser realizada depois da criação dos componentes porque agora era preciso avaliar o valor da propriedade "protocol" para decidir qual versão da Winsock carregar.

\subsection{Configurando o IPSec para autenticar o tráfego IPv6.}

Segundo o RFC2401 [Ken98], as implementações de IPSec no IPv6 devem disponibilizar aplicações ou ferramentas para configurar as opções de segurança. No caso do MSR IPv6, o stack utilizado nesse projeto, existe uma aplicação denominada IPSecGUI (Interface Gráfica de Usuário para o IPSec - IPSec Graphical User Interface) que permite editar o banco de dados de Associações de Segurança e escolher os algoritmos e chaves à serem utilizados. 
O MSR IPSecGUI, permite que se especifique se o equipamento atuará como um host ou um gateway (campo Device Type), se o modo será transporte ou túnel (campo IPSec Mode), se o protocolo proverá autenticação ou encriptação do payload (campo IPSec Protocol), o tipo de algoritmo utilizado (Authentication Algorithm) e os arquivos de chaves que alimentarão o algoritmo (campos Keyfile).

A Figura 7.9 exemplifica a utilização do IPSecGUI para configurar o IPSec neste Projeto

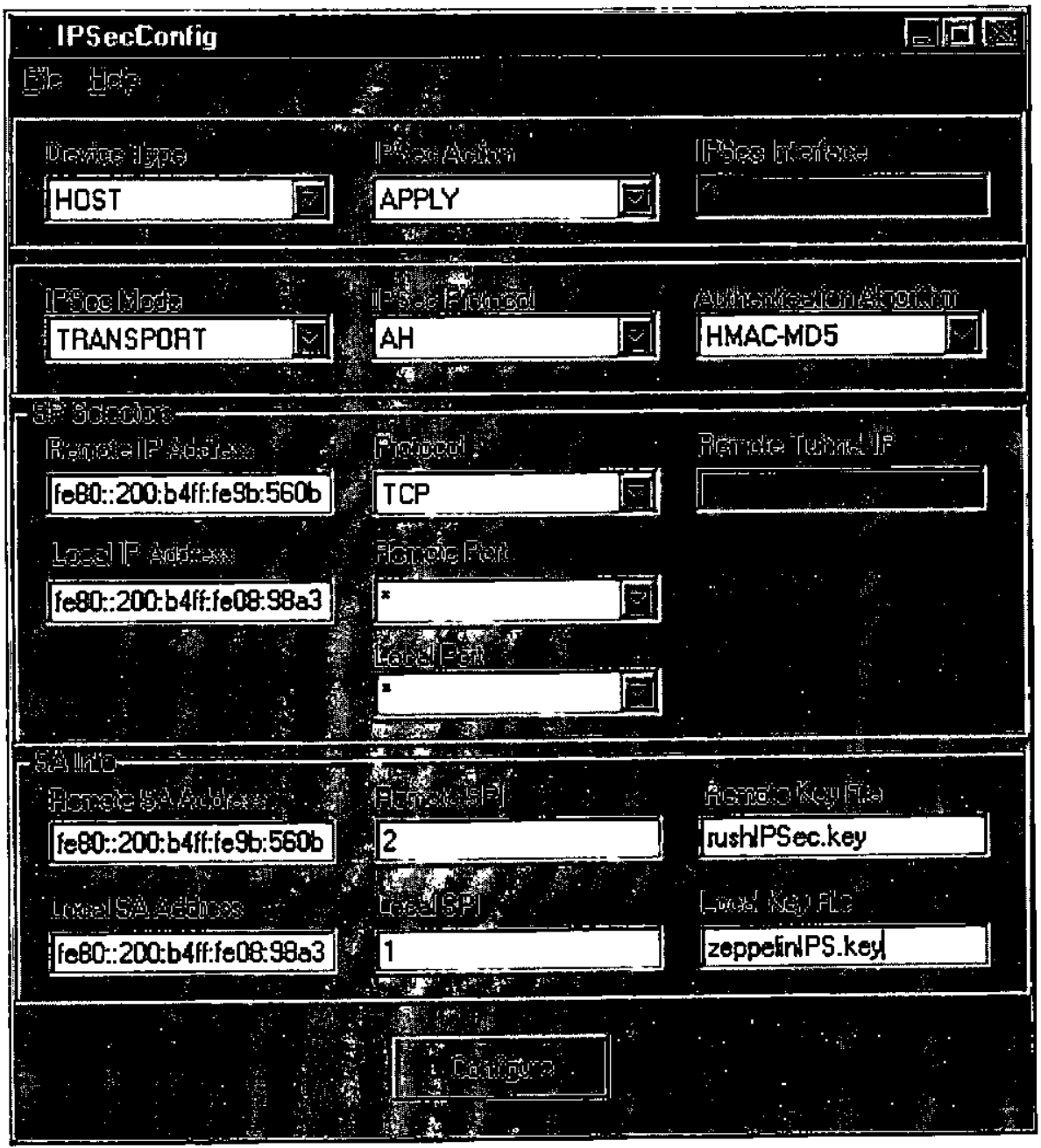

Figura 7.9 - exemplo da utilização da aplicação IPSecGUI para configurar o IPSec 


\subsection{Considerações finais}

Este capítulo discutiu com mais detalhes o esforço necessário para utilizar o IPv6 no SDT e os passos necessários a essa implementação. O próximo capítulo apresenta alguns resultados e conclusões. 
"A alegria está na luta, na tentativa, no sofrimento envolvido.

Não na vitória propriamente dita."

(Mahatma Gandhi)

\section{Conclusões e expectativas}

Este documento descreveu a utilização do IPv6 em uma Aplicação de Transmissão Segura de Dados. Abordou os pontos fracos da versão atual do Protocolo Internet e a necessidade de uma nova versão, que suporte as novas características, agora essenciais, para o sucesso da Internet no futuro. Discutiu as principais características da tecnologia de cartões inteligentes, neste Projeto utilizada para armazenar chaves criptográficas em uma mídia segura e portátil, e aspectos de criptografia e segurança de redes que possibilitarão, mais facilmente, implementar segurança no IP.

\subsection{Objetivos Alcançados}

Apesar de utilizar apenas autenticação IPSec e não o objetivo inicial de utilizar autenticação em conjunto com encriptação de conteúdo (seção 6.7, Utilização do IPSec), o autor acredita que o objetivo primário deste Projeto de Pesquisa foi alcançado. Produziu-se uma versão completamente funcional do SDT, que transmite dados através de sockets IPv6 autenticados pelo IPSec, e ainda contribui-se com o desenvolvimento de uma API aberta que pode ser utilizada por muitas empresas e pesquisadores no futuro (seção 7.3.3, Modificando o Winshoes para suportar IPv6).

Além disso, atingiram-se os objetivos desejados em relação à desempenho e extensibilidade deste Projeto. 


\subsection{Desempenho}

Desde o início, esperava-se uma pequena degradação de desempenho em decorrência da utilização do IPv6 devido ao tamanho dos novos cabeçalhos e à utilização de autenticação IPSec.

A Tabela 8-1 exibe o resultado de testes de desempenho realizados na S\&V Consultoria e Tecnologia em julho de 1999. Os testes se basearam em equipamentos Pentium 300Mhz com 64Mb de RAM, rodando Windows NT Workstation 4.0 (Service Pack 4) e conectados à uma rede Ethernet de $10 \mathrm{Mb} / \mathrm{s}$. Ambos os softwares testados utilizaram buffers de $128 \mathrm{~Kb}$ nos sockets.

A Tabela 8-1 compara esses resultados com os resultados obtidos pelos desenvolvedores do stack MSR IPv6.

\begin{tabular}{|l|l|l|}
\hline IPv4 & \multicolumn{1}{|c|}{} & \\
\hline IPv6 & $1020 \mathrm{~Kb} / \mathrm{s}$ & $1058 \mathrm{~Kb} / \mathrm{s}$ \\
\hline IPv6 c/ IPSec & $730 \mathrm{~Kb} / \mathrm{s}$ & $1032 \mathrm{~Kb} / \mathrm{s}$ \\
\hline
\end{tabular}

Tabela 8-1 -Comparação entre os valores de throughput obtidos com a utilização de sockets IPv6 pela aplicação SDT e pela a aplicação ttcp ${ }^{51}$ no Windows NT

Comparando os dados obtidos neste trabalho, exibidos na coluna "throughput WinshoesIPv6", com os resultados publicados por Richard Draves e Allison Mankin [Dra98a], exibidos na coluna "throughput ttcp", que realizaram testes semelhantes em situações de overhead mínimo, percebe-se que o desempenho do conjunto Winsock2+Winshoes é bastante satisfatório. 0 overhead causado pela utilização dessas ferramentas de alto nível causou uma degradação adicional de desempenho de apenas 3,5\% em relação ao throughput reportado por Draves e Mankin com a aplicação $t t c p^{48}$. A degradação de desempenho relativo entre o IPv6 e o IPv4 também se manteve na faixa dos $2,5 \%$.

${ }^{48}$ ttcp - aplicação padrão que permite enviar dados através de sockets TCP ou UDP 


\subsection{Evolução do SDT}

Esse trabalho foi responsável pelo início do desenvolvimento de um novo produto para Redes Privadas Virtuais (VPNs) que utilizará a infra-estrutura básica do SDT aliada à flexibilidade do IPSec para disponibilizar um caminho seguro para dados em geral.

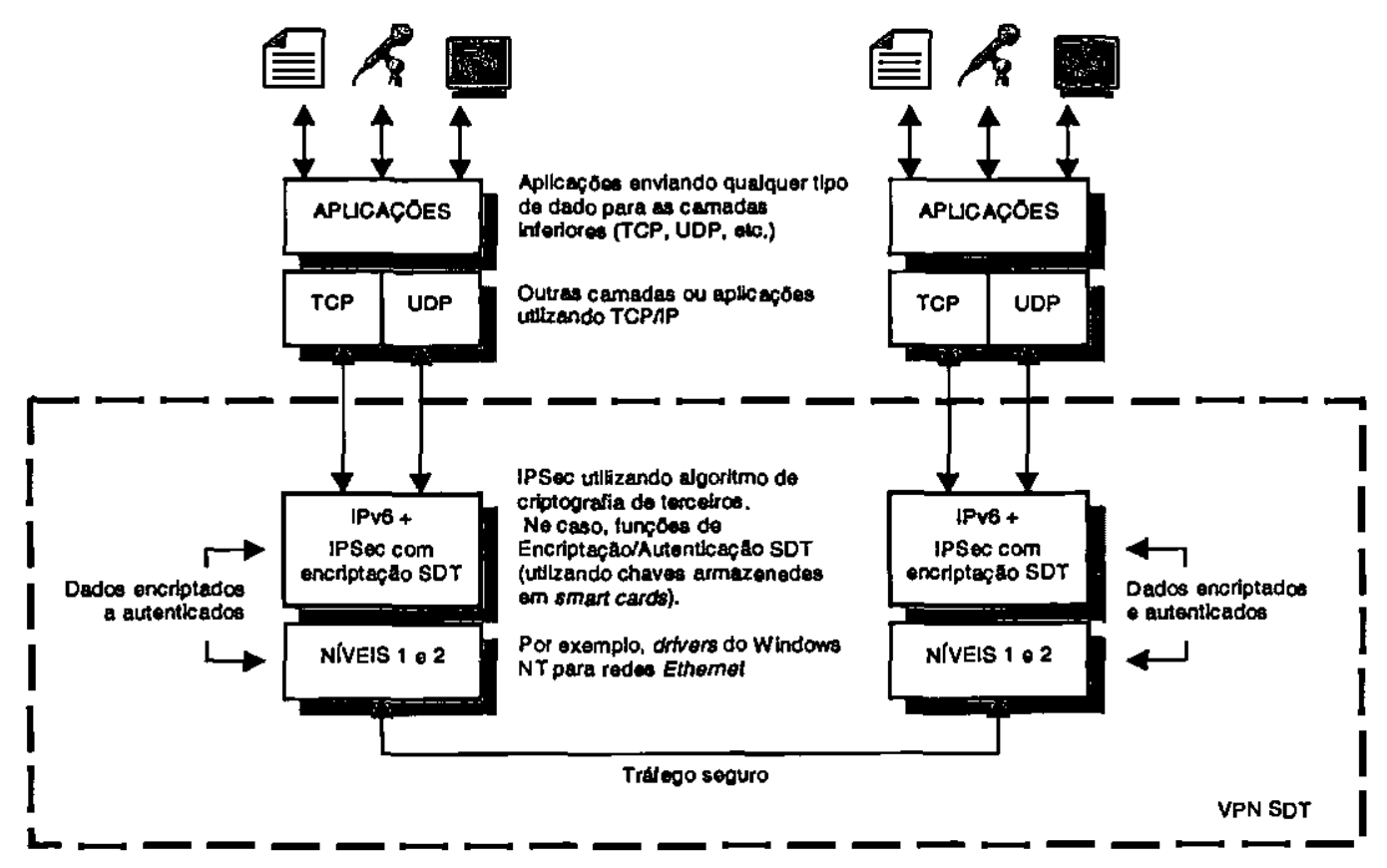

Figura 8.1 - Esquema da utilização do IPSec e do SDT para criar uma Rede Privada Virtual

Como mostra a Figura 8.1, pode-se configurar um equipamento para atuar como um roteador IPSec operando com um algoritmo de encriptação de terceiros, no caso, o conjunto SDT.

A diferença entre esse modelo e o SDT puro (compare a Figura 7.3 com a Figura 8.1) é que por estar integrado ao IPSec, esta configuração pode prover segurança SDT para todos os dados que atinjam o "roteador SDT" e não apenas em nível de aplicação, como é o caso do SDT. 


\subsection{Antevendo o futuro da Internet}

O autor acredita que não existe nada melhor para antever os próximos passos do desenvolvimento de uma nova tecnologia do que participar ativamente deste desenvolvimento. Essa participação tem permitido a todos os envolvidos neste Projeto um contato direto com o estado da arte da tecnologia de redes no mundo. Permite participar na construção do futuro, ao invés de simplesmente esperar por ele 


\section{Referências Bibliográficas}

[Bla99] BLAAFJELL, C. LAN, M. ODWYER, J. YANG, H.J.D., A Comparative Analisys of IPSec and SSL. 1999.

[Bra95] BRADNER, S. MANKIN, A., The Recommendation for the IP Next Generation Protocol, Internet Engineering Task Force. RFC1752. 1995.

[Bra95b] BRADNER, S. MANKIN, A., IPng -Internet Protocol Next Generation. Addison-Wesley Publishing Company, $1^{\mathrm{a}}$ Ed, 307 pg. 1995.

[Car94] CARPENTER, B., IPng White Paper on Transition and Other Considerations, Internet Engineering Task Force. RFC1671. 1994.

[Car97] CARPENTER, J., CROWCROFT, J., REKHTER, Y. IPv4 Address Behaviour Today. Internet Engineering Task Force. RFC 2101. 1997.

[Cla82] CLARK, D.D. Name, addresses, ports, and routes. Internet Engineering Task Force. RFC 0814.1982.

[Cla96] CLARKE, A. C. 3001, The Final Odyssey. Del Rey Publishers. $1^{2}$ Ed. 274 pg. ISBN 0345-42118-3. 1996.

[Che99] CHENG, P. C. GARAY, J. A. HERZBERG, A. KRAWCZYCK, H., A Security Architecture for the Internet Protocol. IBM Technical Paper. http://www.almaden.ibm.com/journal/sj/371/cheng.html. , 1999.

[Com94] COMER,D. STEVENS. D., Internetworking with TCP/IP Volume III Prentice Hall, $3^{2}$ Ed. 1994

[Com95] COMER, D. E., Internetworking with TCP/IP Volume 1. Prentice Hall , $3^{a}$ Ed., 613 pg. ISBN: 0-13-216987-8. 1995.

[Cra96b] CRAWFORD, Matt. Transmission of IPv6 Packets over FDDI Networks. RFC2019. IETF - Internet Engineering Task Force. 1996.

[Cra98b] CRAWFORD, M., NARTEN, T. e THOMAS, S. Transmission of IPv6 Packets over Token Ring Networks. Internet Engineering Task Force. RFC 2470.

[Cra98] CRAWFORD, Matt. Transmission of IPv6 Packets over Ethernet Networks. RFC 2464 Internet Engineering Task Force. RFC 2464. 1998.

[Dee89] DEERING, S. Host Extensions for IP Multicasting. Internet Engineering Task Force - RFC 1112. 1989. 
[Dra98] DRAVES, R. P. MANKIN, A. ZILL, B. D., Implementing IPv6 for Windows NT. Procedings of the 2nd USENIX Windows NT Symposium, 1998.

[Dra98] DRAVES, R. P., Microsoft Research IPv6 Implementation. http://www.research.microsoft.com/msripv6 , 1998.

[Fei93] FEIT, S. TCP/IP, Architecture, protocols and implementation $1^{\mathrm{a}}$ Ed. McGraw-Hill.1993.

[Fei96] FEIT, S. TCP/IP, IPv6, Architecture, protocols and implementation. $2^{*}$ Ed. McGraw-Hill. 1996.

[Fin93] FINSETH, C. The Uniqueness of Unique Identifiers. Internet Engineering Task Force RFC 1439. 1993.

[Fiu98] FIUCZYNSKI, M. E. LAM, V. K. BERSHAD, B. N., The design and Implementation of an IPv6/IPv4 Network Address and Protocol. Procedings of the 1998 USENIX Technical Conference, 1998.

[Ful93] FULLER, V, LI, T., YU, VARADHAN, K. Classless Inter-Domain Routing (CIDR): an Address Assignment and Aggregation Strategy. Internet Engineering Task Force, RFC1519. 1993.

[Gar96] GARFINKEL, S. SPAFFORD, G., Practical Unix \& Internet Security. O'Reilly , 2* Ed., 971 pg. ISBN: 1-56502-148-8. 1996.

[Gil97] GILLIGAN,R. THOMSON, S. BOUND, J. STEVENS, W. Basic Socket Interface Extenslons for IPv6. Internet Engineering Task Force, RFC2133. 1997.

[Ham99] HAMZEH, K., VERTHEIN, W., TAARUD, J., LITTLW, W., ZORN, G. RFC 2637 Point-to-Point Tunneling Protocol. Internet Engineering Task Force, RFC 2637. 1999

[Har96] HARRINGTON, D. T. BOUND, J. P. McCANN, J. J. THOMAS, M., Internet Protocol Version 6 and the Digital UNIX Implementation Experience. Digital Technical Journal, Vol. 8, no.3. http://www.digital.com/DTJN01HM.HTM. 1996.

[Har98] HARKINS, D., CARREL, D. The Internet Key Exchange (IKE). Internet Engineering Task Force. RFC 2409. 1998.

[Has96] HASKIN, D. e ALLEN, D. IP Version 6 over PPP. Internet Engineering Task Force. RFC 2033. 1996.

[Hin96] HINDEN, R. e DEERING, S, Internet Protocol Version 6 (IPv6) Specification, Internet Engineering Task Force. RFC1883. 1996.

[Hin96b] HINDEN, R. e DEERING, S., IP Version 6 Addressing Architecture, Internet Engineering Task Force. RFC1884. 1996. 
[Hiu94] HIUTEMA, C. The H Ratio for Address Assignment Efficiency, Internet Engineering Task Force. RFC-1715. 1994.

[Hiu96] HIUTEMA, C. IPv6 - The new Internet Protocol.. Prentice Hall, $1^{2}$ Ed., 188 pg. ISBN: 0-13-241936-X. 1996.

[How99] HOWER, C. Z. Winshoes Documentation. http://www.pbe.com/SourceWorks/Winshoes. 1999.

[Inr98] INRIA, Rocquencourt IPv6. ftp://ftp.inria.fr/network/ipv6/. 1998.

[Kah74] KAHN, R. E. e CERF,V.G. A Protocol for Packet Network Interconnections. IEEE Transactions of Communications. 1974.

[Kas94] KASTENHOLZ, F. e PARTRIDGE, C., Technical Criteria for Choosing IP - The Next Generation (IPng), Internet Engineering Task Force, RFC1726. 1994.

[Ken98] KENT, S. ATKINSON, R., IP Encapsulating Security Payload (ESP). Internet Engineering Task Force, RFC 2406. 1998.

[Ken98b] KENT, S. ATKINSON, R., IP Authentication Header (AH). Internet Engineering Task Force, RFC 2402. 1998.

[Ker98] KERSTETTER. J., IPSec VPN Standard Hits Speed Bumps. Revista PcWeek. http://seach.zdnet.com/pcweek/news/0511/11ipsec.html. 1998.

[Lar99] LARSON, D., The Race to Secure Cyberspace. http://www.webdeveloper.com/security/security_race_cyberspace.html. 1999.

[Los99] LOSHIN, P., IPv6 Clearly explained. Morgan Kaufmann Publishers Inc., 1a Ed., 305 pg. ISBN: 0-12-455838-0. 1999.

[Lot92] LOTTOR, M. Domain Name Discovering. Network Working Group RFC 1296. 1992.

[Lot97] LOTTOR, M. Internet Growth - Data and Predictions. http://web.msu.edu/staff/rww/netgrow.html. 1997.

[Lot99] LOTTOR, M. Internet Domain Survey. http://www.isc.com/survey

[Mad98] MADSON, C. GLENN, R. The Use of HMAC-SHA-1-96 within ESP and AH . Internet Engineering Task Force. RFC 2403. 1998

[Mad98b] MADSON, C. GLENN, R. The Use of HMAC-MD5-1-96 within ESP and AH . Internet Engineering Task Force. RFC 2404. 1998 
[Mau98] MAUGHAN, D. SCHRTLER, M. SCHEINER, M. TURNER, J. Internet Security Association and Key Management Protocol (ISAKMP). Internet Engineering Task Force. RFC 2408. 1998.

[Mcc96] McCANN J., MOGUL, S. e DEERING, J., Path MTU Discovery for IP version 6, Internet Engineering Task Force RFC1981. 1996.

[Mer98] MERKOW, M. S. BREITHAUPT, J. WHEELER, K. L., Building SET Applications for SECURE Transactions. Wiley, I Ed., 403 pg. ISBN: 0-471-28305-3. 1998.

[Mil98] MILLER, M. A., Implementing IPv6. Migrating to the Next Generation Internet Protocols. M\&T Books , $1^{2}$ Ed.. 464 pg. ISBN: 1-55851-579-8. 1998.

[Mos99] MOSKOVITZ, R., IPv6 for VPNs: It's Looking Better All The Time. http://www.nwc.com/901/901 colmoskowitz.html. 1999.

[Oli97] OLIVEIRA, D.F.N. Utilizando o IPv6 para melhorar o desempenho de aplicações de Realidade Vlrtual. Dissertação apresentada em exame de qualificação. ICMC-USP. 1997

[Orm98] ORMAN, H. The OAKLEY Key Determination Protocol. Internet Engineering Task Force RFC2412. 1998.

[Par95] PARTRIDGE, C., Using the Flow Label Field in IPv6, Internet Engineering Task Force RFC1809. 1995.

[Pos96] POSTEL, J. HINDEN, R. IPv6 Testing Address Allocation, Internet Engineering Task Force RFC1897. 1996.

[Ran97] RANKL, W. EFFING,W., Smart Card Handbook. Wiley , I" Ed., 440 pg. ISBN: 0-471-96720-3. 1997.

[Rek93] REKHTER, Y. LI, T. An architecture for IP address allocation with CIDR. Internet Engineering Task Force, RFC1518. 1993

[Res99] RESCORLA, R. Diffie-Hellman Key Agreement Method. Internet Engineering Task Force. RFC 2631. 1999.

[Riv79] RIVEST, R.L. SHAMIR, A. e ADLEMAN, L.M. On Digital Signatures and Public Key Cryptosystems. MIT Laboratory for Computer Science, Technical Report. 1979.

[Riv92] RIVEST,R.L., SHAMIR, A. e ADLEMAN, L.M. A method for obtaining Digital Signatures and Public Key Cryptosystems. Comunications of ACM. v.21. 1992.

[Sah98] SAHLIN, B. A Conduits+ and Java Implementation of Internet Protocol Security and Internet Protocol, version 6. Helsinki University of Technology. 1998. http://www.tcm.hut.fi/Tutkimus/IPSEC/chapter2.html 
[Sag98] SAGAN, C Billions and Billions. Random House, $1^{\mathbf{2}}$ Ed, 296 pg. ISBN: 0-345-37918-7. 1998.

[Sär96] SÄRS, C. Address Assignment and Management in the IPv6 Enviironment. http://www.iki.fi/ sars/IPv6/address.html

[Sch96] SCHNEIER, B., Applied Cryptography. Wiley , $2^{2}$ Ed., 675 pg. ISBN: 0-471-12845-7. 1996.

[Sha98] SHACHAM, A., MONSOR, R. PEREIRA, R. THOMAS, M. IP Payload Compression Protocol (IPComp). Internet Engineering Task Force. RFC 2393. 1998.

[Sho78] SHOCH, J. F. Internetworking Naming, Addressing, and Routing. Proceedings of COMPCOM. 1978.

[Sil99] SILVA, A. J. S. CICLINI, R., Aquitetura IP Security. RNP News Generator. Publicação da Rede Nacional de Pesquisa, Vol. 3, no. 4. 1999.

[Sou97] SOUVATZIS, I. Transmisslon of IPv6 packets over ARCNet Networks. Work in progress, IETF - Internet Engineering Task Force. 1997.

[Ss198] Introduction to SSL. Netscape Technical Paper. http://developer.netscape.com/docs/manuals/security/sslin/contents.htm , 1998.

[Sta96] STALlings, W. IPv6: The New Internet Protocol. IEEE Communications Magazine. Julho 1996.

[Sta99] STALlinGS, W., Cryptography and Network Security. Prentice Hall , 2^ Ed., 569 pg. ISBN: 0-13-869017-0. 1999.

[Sym94] SYMINGTON, S., WOOD D. e PULLEN, J., Modelling and Simulation Requirements for IPng, Internet Engineering Task Force. RFC1667. 1994.

[Tan96] TANENBAUM, A. Computer Networks, Prentice Hall, 3ª Ed. 1997.

[Tat98] TATE, P., VPNs: Very Pertinent Networks To You. Revista PcWeek, no. 8. http://www.zdnet.com/pcweek/opinion/0330/30corner.html. 1998.

[Tha98] THAYER, R. DORASWAMY, N. GLENN, R. IP Security Document Roadmap. Internet Engineering Task Force. RFC 2411. 1998. 